Review

\title{
Frontiers of Membrane Desalination Processes for Brackish Water Treatment: A Review
}

\author{
Soraya Honarparvar ${ }^{1}$, Xin Zhang ${ }^{1}$, Tianyu Chen ${ }^{1}$, Ashkan Alborzi ${ }^{2}$, Khurshida Afroz ${ }^{1}$ and Danny Reible ${ }^{1,2, *}$ \\ 1 Department of Chemical Engineering, Texas Tech University, Lubbock, TX 79409, USA; \\ shonar@mit.edu (S.H.); xin1992.zhang@ttu.edu (X.Z.); Tianyu.chen@ttu.edu (T.C.); \\ Khurshida.Afroz@ttu.edu (K.A.) \\ 2 Department of Civil, Environmental and Construction Engineering, Texas Tech University, \\ Lubbock, TX 79409, USA; Ashkan.alborzi@ttu.edu \\ * Correspondence: danny.reible@ttu.edu
}

Citation: Honarparvar, S.; Zhang, X.; Chen, T.; Alborzi, A.; Afroz, K.; Reible, D. Frontiers of Membrane Desalination Processes for Brackish Water Treatment: A Review. Membranes 2021, 11, 246. https:// doi.org/10.3390/membranes11040246

Academic Editor: Loubna Firdaous

Received: 27 February 2021

Accepted: 23 March 2021

Published: 29 March 2021

Publisher's Note: MDPI stays neutral with regard to jurisdictional claims in published maps and institutional affiliations.

Copyright: (c) 2021 by the authors. Licensee MDPI, Basel, Switzerland. This article is an open access article distributed under the terms and conditions of the Creative Commons Attribution (CC BY) license (https:// creativecommons.org/licenses/by/ $4.0 /)$.

\begin{abstract}
Climate change, population growth, and increased industrial activities are exacerbating freshwater scarcity and leading to increased interest in desalination of saline water. Brackish water is an attractive alternative to freshwater due to its low salinity and widespread availability in many water-scarce areas. However, partial or total desalination of brackish water is essential to reach the water quality requirements for a variety of applications. Selection of appropriate technology requires knowledge and understanding of the operational principles, capabilities, and limitations of the available desalination processes. Proper combination of feedwater technology improves the energy efficiency of desalination. In this article, we focus on pressure-driven and electro-driven membrane desalination processes. We review the principles, as well as challenges and recent improvements for reverse osmosis (RO), nanofiltration (NF), electrodialysis (ED), and membrane capacitive deionization (MCDI). RO is the dominant membrane process for large-scale desalination of brackish water with higher salinity, while ED and MCDI are energy-efficient for lower salinity ranges. Selective removal of multivalent components makes NF an excellent option for water softening. Brackish water desalination with membrane processes faces a series of challenges. Membrane fouling and scaling are the common issues associated with these processes, resulting in a reduction in their water recovery and energy efficiency. To overcome such adverse effects, many efforts have been dedicated toward development of pre-treatment steps, surface modification of membranes, use of anti-scalant, and modification of operational conditions. However, the effectiveness of these approaches depends on the fouling propensity of the feed water. In addition to the fouling and scaling, each process may face other challenges depending on their state of development and maturity. This review provides recent advances in the material, architecture, and operation of these processes that can assist in the selection and design of technologies for particular applications. The active research directions to improve the performance of these processes are also identified. The review shows that technologies that are tunable and particularly efficient for partial desalination such as ED and MCDI are increasingly competitive with traditional RO processes. Development of cost-effective ion exchange membranes with high chemical and mechanical stability can further improve the economy of desalination with electro-membrane processes and advance their future applications.
\end{abstract}

Keywords: brackish water desalination; membrane desalination; reverse osmosis; nanofiltration; electrodialysis; membrane capacitive deionization

\section{Introduction}

Freshwater supplies are limited and climate change alters their distribution and availability. Meanwhile, the demand for freshwater is continuously growing, exacerbating the pressure on the limited resources. Population growth increases municipal and agricultural consumption and more intensive industrial activities increase freshwater utilization for purposes such as thermoelectric power generation and the extraction of fossil fuels [1-3]. 
A key solution to respond to such growing demands and avoid further deterioration of freshwater supplies is the exploitation of saline water resources. Brackish water is an attractive alternative to freshwater due to its low salinity and abundance in regions facing water scarcity. In the report prepared by US Geological Survey, brackish ground water in the USA is categorized into four main groups, with salinity and dominant ionic constituents as described in Table 1 [4]. Properties of water in none of these groups are suitable for direct use. To reach the water quality requirements for potable and non-potable applications, the organic and mineral content of brackish water should be partially or totally removed. The standards for potable water quality are stricter to avoid health hazards. However, the concern for industrial applications is more related to the potential damage to the equipment and the reduction in productivity due to inorganic and mineral fouling and scaling. A number of existing components in brackish water, e.g., barium and strontium, have very low solubilities that even in trace concentrations may precipitate, resulting in scale formation $[5,6]$.

Table 1. Characteristics of brackish groundwater in the USA [4].

\begin{tabular}{|c|c|}
\hline Mean Dissolved Solid, [mg/L] & Dominant Constituents \\
\hline 1800 & $\begin{array}{l}\mathrm{NaHCO}_{3}-\mathrm{SO}_{4}{ }^{2-} \text { accounting for } 1 / 3 \text { of } \\
\text { anion concentration }\end{array}$ \\
\hline 2500 & $\begin{array}{c}\mathrm{CaSO}_{4}-\mathrm{Na}^{+}, \mathrm{Mg}^{2+} \text { each accounting for } 1 / 4 \text { of } \\
\text { cation concentration }\end{array}$ \\
\hline 8400 & $\mathrm{NaCl}$ \\
\hline 1400 & $\begin{array}{l}\text { Mixture of cations and anions with low solubility-high } \\
\text { silica content }\end{array}$ \\
\hline
\end{tabular}

Currently, brackish water is the feed source of $21 \%$ of the volume of globally produced desalinated water [7]. Development of energy- and cost-efficient desalination processes helps further expand the use of brackish water. Existing desalination processes are broadly categorized as thermal or membrane techniques [8]. Thermal processes are suitable for seawater desalination and in regions with low fossil fuel prices, such as the Middle East [8]. Membrane processes, however, are preferred for the treatment of low-salinity brackish water $[8,9]$, especially in areas where energy costs are of substantial concern [8,9]. Membrane processes used for brackish water treatment are classified as pressure-driven processes, e.g., reverse osmosis $(\mathrm{RO})$ and nanofiltration $(\mathrm{NF})$, and electro-driven processes, e.g., electrodialysis (ED) and (membrane) capacitive deionization (M)CDI (refers to both CDI and MCDI) [10]. The efficiency of these techniques depends on the salinity and chemistry of the brackish water, size of the plant, and desalination objectives. RO has become the state-of-the-art process for desalination of brackish water at higher salinity in large-scale. However, the energy-efficiency of RO decreases for lower-salinity waters and in small-scale desalination plants [11,12]. NF is capable of selective multivalent ion removal $[13,14]$, encouraging its use for water softening. The selectivity and tunability of ED and (M)CDI provide the opportunity for partial desalination and selective ion removal. These processes are at different stages of development; $\mathrm{RO}, \mathrm{NF}$, and $\mathrm{ED}$ have been commercialized while (M)CDI is mainly explored at lab-scale. The knowledge and understanding of the capabilities of these processes assist the research community and industrial sectors to further expand the horizons of their applications.

The unique criteria and the challenges associated with each technique should be taken into account when selecting the desalination process for specific applications. Fouling and scaling are the main challenges associated with membrane processes, resulting in reductions in the amount of generated freshwater and an increase in energy consumption. Many studies have focused on improvement of the membrane material, as well as module design and operation, to reduce fouling and scaling. Such efforts may not be able to completely eliminate membrane clogging for feed water with a high fouling and scaling propensity, 
mandating the use of pre-treatment steps, acid/anti-scalant dosing, and physical/chemical cleaning. A recent review summarized the methods used to assess the fouling and scaling potentials of various feedwaters [15]. These characterization techniques can indicate the likelihood of fouling and evaluate the effectiveness of the proposed mitigation and removal steps. The processes reviewed herein may also face separate challenges depending on their level of maturity. Development of novel membranes with high chemical and mechanical stability as well as superior performance will remain an active research area. Membrane modifications are especially important for advancing electro-membrane processes due to the significant need for reducing fabrication costs and improving the performance of the current ion exchange membranes (IEMs). Improvement of the physical and chemical properties of the electrodes are also vital for further advancing the applications of (M)CDI and ED-based processes. In this article, we review the principles and challenges associated with RO, NF, ED, and (M)CDI and illustrate the capabilities and limitations of each process. We conduct a review of the recent developments and the active research areas for each technology. This review provides a foundation for identifying appropriate fit-for-purpose treatment approaches to reach cost-effective brackish water desalination.

\section{Reverse Osmosis}

Osmotic pressure gradients between two solutions with different salinity, separated with a semipermeable membrane (that can only pass water), drives water toward the higher salinity. In reverse osmosis ( $\mathrm{RO})$, an external pressure is applied to high-salinity feed water, forcing water to flow from the concentrate to the permeate channel as shown in Figure 1. A permeate stream with low salinity and a concentrate stream enriched with salts are the products. RO remains one of the oldest and most utilized approaches for desalination. The first large-scale brackish water RO (BWRO) plant was designed in 1965 [16]. RO and RObased processes have matured over the past few decades and a summary of their historical developments are provided in the Figure 2. Despite their maturity, the technology has seen efficiency improvements through developments in membranes and process optimization.

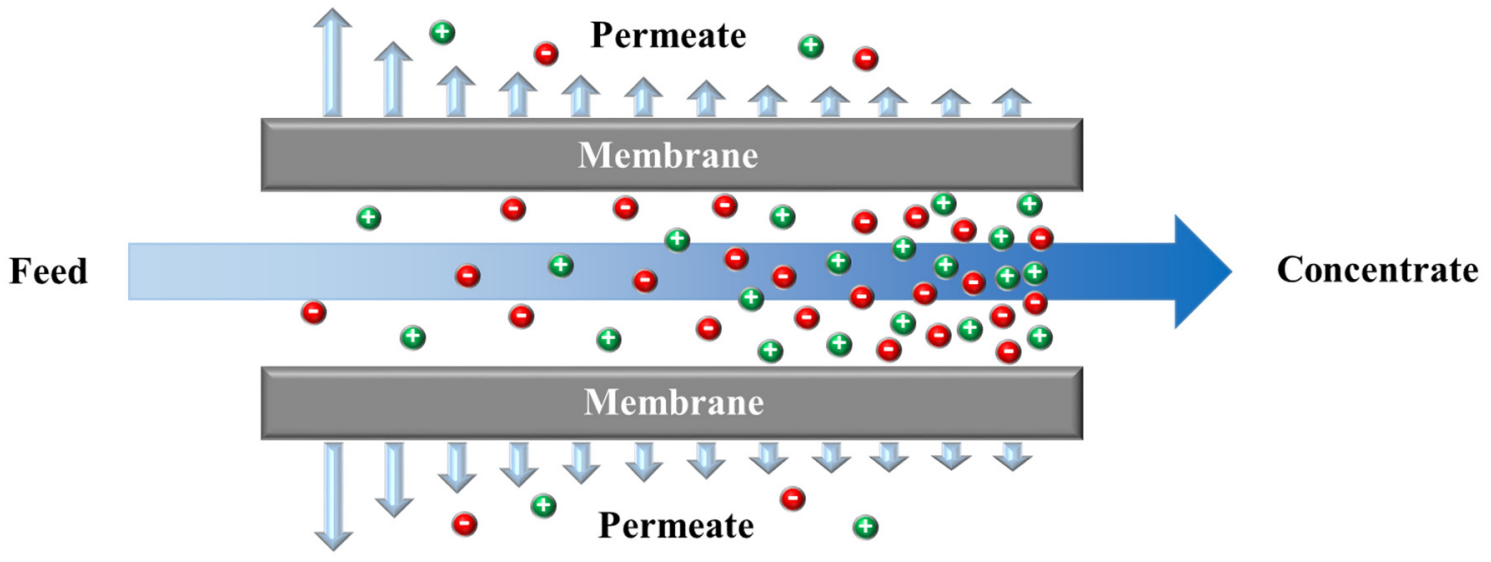

Figure 1. A schematic of a crossflow reverse osmosis (RO) module.

\section{1. $R O$ Membranes}

RO membranes exhibit high water flux and more than $99 \%$ salt rejection under typical operating conditions [31]. Commercial RO membranes are conventionally synthesized from polyamides (PA) and cellulose acetate (CA) polymers [32]. CA membranes exhibit good salt rejection [33] and chlorine resistance [34] relative to PA membranes, but their sensitivity to $\mathrm{pH}$ limits their applications for RO [35]. Thin film composite (TFC) PA membranes contain an ultra-thin cross-linked PA active layer anchored on top of a porous support layer with an interfacial polymerization (IP) reaction. Several authors reviewed the techniques developed for tailoring IP parameters to enrich the properties of PA layers [32,36]. 


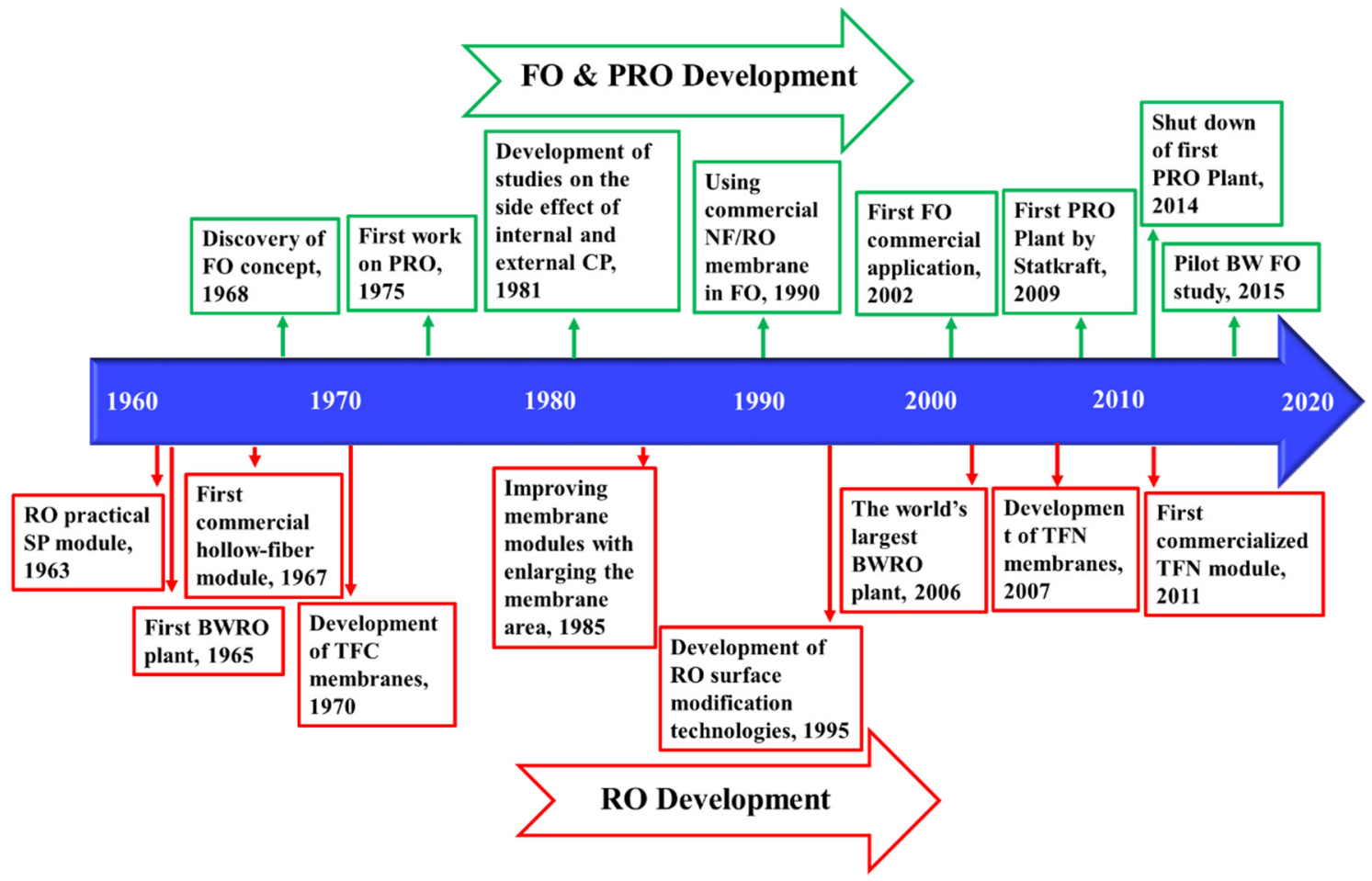

Figure 2. Timeline of the key developments of RO [16-21], forward osmosis (FO), and pressure-retarded osmosis (PRO) [22-30] processes.

\subsection{RO Operational Modes and Network Structure}

$\mathrm{RO}$ is operated in batch, semi-batch or closed-circuit desalination (CCD), and continuous modes. In batch $\mathrm{RO}$ (BRO), the concentrate stream flows back to the feed tank. As salt concentrations increase in the concentrate, elevating the osmotic pressure, the applied pressure must also be increased [37]. BRO can provide operational flexibility for operations at a wide range of water recovery [38]. In a CCD process, $R O$ concentrate is mixed with the raw feed water, and fed to the RO membrane. CCD enables high permeate flux, high water recovery, and low pressure. Recycled concentrate increases the salt concentration of the feed; thus, pressure is raised gradually to maintain a constant permeate flux. Once the target production capacity is achieved, or when the required pressure is too high, excess concentrate is directly flushed without recycling, and a new cycle is launched [39].

Theoretical studies demonstrate low energy consumption for BRO relative to CCD and single-stage continuous RO [40,41]. Swaminathan et al., [42] demonstrated that energy consumption could be reduced by up to $8 \%$ by using a pressurized feed tank in BRO. Moreover, the BRO operation mode allows energy recovery in a single stage without installation of energy recovery devices (ERDs) by feeding pressurized concentrate back into the feed [11]. In CCD, the recirculation of brine results in a decrease in the volume of the concentrate waste [40]. The excess pressure, which is the part of the applied pressure that is above the osmotic pressure of the solution, decreases along the RO module, as opposed to continuous RO that maintains a uniform pressure along the module. In CCD and $\mathrm{BRO}$, excess pressure is time-variant and it continually decreases as the osmotic pressure increases at the outlet. Werber et al., [41] demonstrated that CCD was superior in energy saving compared to continuous $\mathrm{RO}$ without using a booster pump and ERD. Lin et al., [43] indicated that CCD consumed more energy than single-stage RO and less energy than multi-stage RO. However, the theoretical and experimental study conducted by Lee et al., [44] showed that incomplete concentrate flushing would increase the specific energy consumption (SEC) of CCD. Higher salinity accumulation in the system can lead to the need for a higher pressure to balance osmotic pressure. Further experimental analysis of Cohen et al., [45] indicated that the CCD saved more energy than continuous RO only 
under ideal plug flow operation during flushing. They also indicated that CCD had advantages in a wide water recovery range operation by using a single RO system. Such energy consumption analyses determine that batch and semi-batch operations have the potential to improve the energy efficiency of $\mathrm{RO}$ for desalination at small-scale and with lower salinity of the feed water, where ERDs lose their efficiency.

RO modules are arranged in serial and parallel configurations. Typically, multistage arrays with the membrane modules ratio of 2:1 between two subsequent stages are preferred. Overall, multi-stage design exhibits higher water recovery, while singlestage design has a lower capital cost. RO network configuration determines the cost and efficiency of the process [46]. In general, a serial arrangement of $\mathrm{RO}$ modules is preferred due to higher energy efficiency [11]. An inter-stage booster pump is required when a dramatic loss of transmembrane pressure (TMP) is observed, which results in additional energy consumption and capital cost. Recent studies on innovative $\mathrm{RO}$ configurations to optimize SEC are mainly focused on BRO and semi-batch RO (CCD) designs.

\subsection{Energy Recovery Devices in RO}

ERDs are used to decrease SEC in RO, especially when using highly efficient devices such as a pressure exchanger (PX). ERDs harvest waste energy from concentrate and significantly reduce the required power for pumping the feed, and hence reduce net energy consumption. Current commercial ERDs consist of a traditional Pelton turbine or reversible pumps and isobaric processes. Traditional reversible pumps and turbines exhibit efficiency losses during energy conversion [12]. Isobaric processes were developed to avoid energy losses during conversion and directly transfer residual pressure of brine to the feed stream. In these processes, a higher-pressure rejected brine pressurizes the lower-pressure bypass of a feed stream by piston positive displacement or rotary direct mixing [12]. Isobaric processes can perform efficiently in wide ranges of flux, temperature, and pressure, while traditional turbine systems are sensitive to process operations out of their design ranges [47]. The application of ERDs for BWRO is less common due to low energy recovery efficiency and low pressure at the feed side. The efficiency of the energy recovery of the current isobaric processes can reach as high as $97 \%$, which promotes the application of ERDs in BWRO.

\subsection{Main Challenges of $R O$}

Further development of BWRO faces a series of challenges. The volume of globally produced $\mathrm{RO}$ concentrate has exceeded the volume of produced permeate water by $\sim 50 \%$ [7]. Thus, economical and environmentally-friendly management of RO concentrate is a significant challenge. Separation efficiency is impacted by membrane properties and fouling conditions. Hence, current research on BWRO is focused on membrane performance improvement, membrane fouling monitoring and prevention, and minimization of the rejected concentrate.

\subsection{Approaches to Improve Membrane Performance in $R O$}

$\mathrm{RO}$ membrane development is focused on balancing membrane salt rejection and permeate flux. Increasing water flux decreases salt rejection and separation efficiency [48,49]. Chemical and physical modifications of membranes by embedding functional groups are used to enhance water flux, salt rejection, fouling resistance [50], and chlorine tolerance $[51,52]$. RO membrane surface and substrate functionalization are widely used to improve the separation efficiency. Surface functionalization methods include nanoparticle (NP) doping, functional group grafting, and changing surface morphology to improve membrane performance [21,53]. Various materials have been studied for RO including cellulose [54], aquaporin [55], bentonite [56], carbon-based materials (graphene [57,58], carbon nanotubes (CNT) [59], and carbon quantum dot [60]), bromoacetic groups [46], zeolites [61], metal organic frameworks (MOFs) [62], and metal-based NPs (metals [63,64], metal oxides [65], and metal alkoxides [66]). Grafting hydrophilic groups, e.g., polydopamine [67], 
polyethylene glycol groups [68,69], and zwitterion groups [70,71], have been reported to improve membrane antifouling properties. Smooth, hydrophilic, and charged surfaces improve antifouling properties and reinforce chlorine resistance [48,72]. Functionalizing the membrane active layer can improve water permeability without significant effects on $\mathrm{NaCl}$ rejection $[45,47,58]$, while mitigating biofouling [39,42,44], enhancing membrane anti-bacterial properties [46,63,72], and improving chlorine resistance [73,74].

Substrate layers in membranes act as support for the active layers and provide mechanical strength. Modification of the support layer to improve membrane performance has also been studied by several authors. Lind et al., [61] reported that blending zeolites with the support layer boosted the permeating water flux without significantly impacting salt rejection, due to the sieving mechanism of zeolites. He et al., [75] blended the support layer with amphiphilic copolymer groups to enhance both water flux and salt rejection, and increased the porosity and hydrophilicity of the substrate surfaces. Lee et al., [76] incorporated hydrophilic graphene oxide (GO) groups into the support layer to enhance water permeating flux and membrane fouling resistance. Water permeating flux was optimized by controlling the thickness and the number of hydrophilic groups in the substrate. Kim et al., [77] added silver NPs to substrate layer material and increased bactericidal rates. Though functionalization of active and support layers of membranes successfully improves their performance, the large-scale production of such modified membranes is challenging due to the complex fabrication, high production cost, and limited durability. In addition, the stability and potential release of the incorporated functional groups has not been adequately investigated and may be of environmental concern.

\subsection{Approaches to Monitor and Reduce Fouling and Scaling in RO}

Membrane fouling and scaling decrease the effective surface area of the membranes and significantly increase their transport resistance. Fouling is classified as organic, inorganic, colloidal, or biofouling. Organic foulants mostly precipitate on the surface of the membrane, blocking pores or forming a cake layer [78]. Inorganic fouling, known as scaling, forms as a result of salt precipitation. Concentration polarization $(\mathrm{CP})$ increases concentration at the membrane-solution interface on the feed side, increasing salt precipitation and scaling potential. Biofouling takes place due to microorganism attachment and growth on the membrane. Furthermore, the co-existence of organic matter and metals exacerbate particle fouling compared to solutions in which only organic matter or metals are present $[79,80]$. In a solution containing silica and bovine serum albumin (BSA), silica bonded to amino acid groups in BSA and formed a complex that increased fouling [81]. Such synergistic effects necessitate the evaluation of the antifouling performance of membranes for feed water containing a mixture of foulants.

Pre-treatment steps can be used to reduce membrane clogging in the RO unit. Traditional pre-treatment processes include filtration (membrane filtration and media filtration), softening, inhibitor/anti-scalant addition, coagulation/flocculation, fluid mitigation (flow control, backwash, and air floatation), chemical cleaning (acids, alkalis, detergents, complexing agents, etc.), and disinfection (chlorination, ozonation, ultrasound, and ultraviolet (UV) light) [82-84]. Jiang et al., [85] indicated that ultrafiltration (UF)/microfiltration (MF) accounted for $46 \%$ of pre-treatment technologies used for RO desalinations, coagulation/flocculation for $18 \%$, disinfection for $13 \%$, and the addition of scale inhibitor for $5 \%$. Many of the traditional pre-treatment methods may cause secondary contamination as a result of the addition of chemicals. Due to their chemical-free nature, electrocoagulation and membrane-based pre-treatment processes have attracted researchers' attention in recent years.

In electrocoagulation the oxidation reaction at the electrode generates hydrolysis products and hydrogen, leading to the formation of contaminant flocs that are detached from the anodes by the produced hydrogen [86]. Chemical costs for coagulant are avoided in electrocoagulation. However, additional coagulant might be used to facilitate the settling of the particles. Electrocoagulation improves removal efficiency and reduces the amount 
of sludge generated, compared to traditional coagulation [87]. Electrocoagulation also demonstrated excellent efficiency for removal of silica [88], humic acid (HA) [89], cyanobacteria [90], natural organic matters (NOM) [91], and arsenite [92]. High operational costs and the required maintenance of anodes are the major drawbacks of electrocoagulation.

Forward osmosis (FO) is a pressure-driven membrane process that can be used as a pre-treatment step for RO. In FO, the osmotic pressure gradient spontaneously drives water from low-salinity solution to higher salinity draw solutions. Coupled FO-RO processes can improve the osmotic energy savings from RO brines. Zaviska et al., [93] demonstrated low energy consumption and reduced scaling for a FO-RO hybrid system applied to the desalination of brackish water with high scaling propensity without any other pretreatment steps. Chun et al., [29] studied a pilot scale FO-RO hybrid system for brackish water desalination with high fouling tendency and found that fouling mitigation strategies were important to maintain the optimal performance of FO, since traditional physical and chemical cleaning were not sufficient to maintain water flux. Fouling remains an important factor related to the performance of hybrid systems at a large scale [94].

Pre-treatment steps do not eliminate the scale formation due to the precipitation of $\mathrm{CaCO}_{3}, \mathrm{CaSO}_{4}, \mathrm{BaSO}_{4}$, and $\mathrm{Mg}(\mathrm{OH})_{2}$ in RO. Scale inhibitors are used to reduce scale formation in industrial desalination processes due to their easy application and relatively low cost compared to other pre-treatment processes [95]. Conventional anti-scalants consist of polyelectrolyte and non-polymeric materials and can effectively inhibit scale formation [96]. The phosphorus and nitrogen content of these anti-scalants can increase concentrate disposal concerns [97] and negatively impact further concentrate management steps, e.g., crystallization [98]. Moreover, deposition of these anti-scalants may increase biofouling on the membrane surface [99]. Therefore, environmentally-friendly and biodegradable "green" inhibitors that are phosphate-free and nitrogen-free have recently gained more attention. Rabizadeh et al., [100] studied the alternative green inhibitors poly(epoxysuccinic acid) and poly(aspartic acid) to control $\mathrm{BaSO}_{4}$ scaling. Yu et al., [101] reported the green anti-scalant, carboxymethyl cellulose, to prevent $\mathrm{BaSO}_{4}$ scaling. Al-Roomi and Hussain [102] reported organic anhydride-based copolymers to prevent $\mathrm{BaSO}_{4}$ scaling in pipes. Hao et al., [103] synthesized carbon quantum dots as green inhibitors to retard scaling of $\mathrm{CaSO}_{4}$ and $\mathrm{BaSO}_{4}$. Pramanik et al., [104] reported biodegradable non-phosphorus anti-scalant poly(aspartic acid) and its derivatives to control precipitation of $\mathrm{CaCO}_{3}$. Optimization of scale inhibitors helps to reduce chemical costs and minimize chemical discharge to the environment [105]. However, a lack of dosing models and economic feasibility evaluation for these green inhibitors has limited their commercial use for the large-scale RO plants, and further research is needed to address these gaps. "Chemical-free technologies" have been proposed to eliminate the addition of anti-scalants. Dayarathne et al., [106] proposed an inhibitor-free method to control $\mathrm{CaCO}_{3}$ and $\mathrm{CaSO}_{4}$ fouling using micro/nano-sized air bubbles, which minimized CP by increasing mixing and turbulence [107]. Hou et al., [79] used a chemicalfree ultrasonic irradiation method to inhibit biofouling. Neither of these approaches have been attempted at a large scale and, in addition, the mechanical and thermal effects of ultrasonic irradiation on membranes are not known.

In situ monitoring of fouling and scaling in $\mathrm{RO}$ can significantly help to take appropriate physical/chemical cleaning steps. The real-time monitoring of fouling can be achieved through rheometric and acoustic impedance measurements. In rheometric measurements, the rheological properties at membrane surfaces are measured. Rey et al., [108] monitored $\mathrm{CP}$ and membrane fouling using in situ small-angle X-ray scattering, and used in situ micro-particle image velocimetry to measure the rheometric properties at the membrane surface. Meng and Li [109] employed microscopic laser-induced fluorescence to study $\mathrm{CP}$ in the system. Concentration distribution was determined by correlating the fluorescent light intensity and fluorescent dye concentration. Ho et al., [110] applied electrical impedance spectroscopy to measure electrical impedance of the fouling layer formed due to colloidal particles in the feed water. Li et al., [111] used ultrasonic time domain reflectometry to describe the deposition of organic matter leading to fouling. The magnitude 
of the reflected and transmitted ultrasonic waves in these techniques is a function of the acoustic impedance of the media which is related to fouling. The lab-scale monitoring methods have been limited to simple membrane module architecture such as flat-sheet membranes, and the feasibility of these monitoring tools for commercial spiral-wound membrane modules has not been evaluated.

\subsection{Approaches to Manage RO Concentrate}

A major challenge of BWRO is safe management of the concentrate stream. Conventional BWRO is generally operated at water recovery of up to 85\% [112], but depending on feed water quality and operational conditions, the water recovery can be lower. Conventional concentrate management methods include evaporation, surface water discharge, sewer discharge, deep well injection, and crystallization [113]. Concentrate minimization methods were reviewed by Subramani et al., [114] and Giwa et al., [115]. Zero liquid discharge (ZLD) or near-ZLD strategies are designed to minimize concentrate production and maximize water recovery $[116,117]$. In ZLD desalination, concentrate is treated to recover water or remove salt, and there is no liquid waste discharge to the environment. ZLD is traditionally achieved through energy intensive thermal methods, e.g., evaporation and crystallization. Membrane-based methods are also employed to reach ZLD; however, they often suffer from fouling and scale-up challenges [118].

Electro-membrane processes including electrodialysis (ED), electrodialysis reversal (EDR), and electrodialysis metathesis (EDM) are used to increase the overall water recovery and decrease the volume of the concentrate which requires disposal. These processes are described in detail in the subsequent sections. McGovern et al., [119] used a RO-ED hybrid system for brackish water desalination (salinity of approximately $6000 \mathrm{mg} / \mathrm{L}$ for RO concentrate) and achieved more than 98\% water recovery. Loganathan et al., [120] used an EDR system prior to RO to soften feed water with a salinity of 25,000 mg/L, and reached an overall water recovery of $77 \%$. An evaporator-crystallizer was coupled with an EDR-RO system to manage the remaining concentrate stream. Bond et al., [121] demonstrated low SEC and high water recovery for brackish water desalination with a pilotscale RO-EDM. The cost of the hybrid system was estimated to be lower than conventional thermal ZLD treatments. In general, ED-based ZLD technologies are promising for RO concentrate management.

Osmosis driven processes, FO, and pressure-retarded osmosis (PRO), can also be used to dewater $\mathrm{RO}$ concentrate and, in principle, generate power in return. In PRO, the pressurized, highly saline draw solution is used to drive water from a low-salinity feed stream due to the existence of osmotic gradients [122]. In a typical hybrid RO-FO or RO-PRO process, the rejected brine from $\mathrm{RO}$ is used as draw solution for $\mathrm{FO}$ and PRO [123]. Altaee et al., [124] simulated an energy- and cost-efficient (NF)-RO-FO hybrid system for the desalination of water with a salinity of about $2400 \mathrm{mg} / \mathrm{L}$, and reached over $90 \%$ water recovery. However, the upstream NF process provided $75 \%$ of the overall water recovery, while the FO contribution was 15\%. Jamil et al., [125] utilized brine with a salinity of approximately $2000 \mathrm{mg} / \mathrm{L}$ in five stages of FO to reduce the volume of concentrate by approximately 60\%. Lu and Wang [126] used RO brine with a salinity of $12,800 \mathrm{mg} / \mathrm{L}$ as the feed solution for $\mathrm{FO}$ and reported up to $92.5 \%$ water recovery. Lu et al., [127] also coupled FO-RO to treat RO brine and were able to recover $54 \%$ water, and the salinity of the brine was approximately 20,000 mg/L. All of these studies, however, were limited to lab-scale. In addition, the long-term tests indicated significant declines in water flux during the period of operation due to fouling. A scaling control strategy is essential for energy-efficient application of FO for dewatering $\mathrm{RO}$ concentrate. Antifouling FO/PRO membranes are also essential to the performance of hybrid RO-PRO/FO systems. Even though the energy production in FO and PRO partially compensates for the total energy consumption of these systems, the energy efficiency of these processes needs to be improved further [128,129]. Developing self-standing membranes with higher water permeability [130] and better management of fouling are current research directions 
toward improving RO-PRO/FO performance. In addition, the separation performance of FO and PRO is strongly influenced by the salinity of draw solution. To make the hybrid system economical, the draw solution should be available at a relatively low cost with the possibility of cost-effective regeneration. Chemical constituents of the draw solution should exhibit low toxicity and low viscosity [131]. The cost of the draw solution, energy requirements for its regeneration, and the cost of the disposal of the remaining feed stream of $\mathrm{FO} / \mathrm{PRO}$ units are significant factors in comparison with other concentrate management techniques.

Membrane distillation (MD) is another alternative approach for concentrating $\mathrm{RO}$ brine and increasing the overall water recovery. MD is a thermal process in which the temperature difference between two hot and cold streams increases the vapor pressure gradient, driving water vapor through porous hydrophobic membranes. MD has been coupled with RO to minimize the volume of RO brine and increase water recovery [132-134]. However, MD has been mainly studied for managing sea water RO concentrate, with only a couple of studies focusing on BWRO. Martinetti et al., [135] used low temperature MD and FO under similar conditions to recover water from BWRO brines with salinities of 7500 and $17,500 \mathrm{mg} / \mathrm{L}$. The results indicated higher water recovery and a lower fouling tendency for $\mathrm{MD}-\mathrm{RO}$ compared to FO-RO. The high energy requirements are the primary deterrent to wider use of this approach. Modification of the MD membranes through increasing their porosity or developing a thin hydrophilic layer $[136,137]$ can decrease the conductive heat losses in MD. Dudchenko et al., [138] developed a CNT/polymer composite that could be used as a self-heating membrane in MD that significantly improved its energy efficiency.

Overall, integrating membrane processes to further concentrate $\mathrm{RO}$ brine increases the capital cost, overall energy consumption, and operational complexity of the desalination. These approaches can be economical when renewable energy resources are available for powering the desalination processes and also when there is a possibility of salt production and valuable ion recovery. In locations where brine disposal is costly or limited, increasing the water recovery even with higher capital and operational costs becomes inevitable.

\subsection{Overall Status of RO for Brackish Water Desalination}

Overall, $\mathrm{RO}$ is a mature technology suitable for the large-scale treatment of the brackish water with high salinity (above $5000 \mathrm{mg} / \mathrm{L}$ ). The reported water recovery for existing BWRO plants is relatively low, resulting in relatively large concentrate waste streams. The efficiency of ERDs in RO also depends on the salinity and the volume of the water. With lower salinity feed water and in small-scale desalination, ERDs are less efficient, limiting the potential energy recovery $[11,12]$. Increasing the water recovery and feed flow rates may further decrease the efficiency of ERDs [11,12]. Even though RO has dominated the existing desalination processes, alternative approaches may have advantages for the treatment of water with lower salinity ranges, desalination for small communities, and selective ion removal.

\section{Nanofiltration}

In nanofiltration (NF), the pressure gradient across the porous membranes is the driving force for separation. NF is operated at 5 to 40 bars, which falls between the operational pressure of UF and RO [139]. The molecular weight cut off (MWCO) which determines the lowest molecular weight of the solute (in Dalton) that a membrane is able to filter is between 200 and $1000 \mathrm{Da}$, making NF suitable for removing species with a diameter of 0.5 to $2 \mathrm{~nm}$. Hence, NF is capable of rejecting multivalent ions and large organic compounds while passing the majority of monovalent ions [140]. Figure 3 demonstrates the timeline of the key developments of NF from the early commercial application in the 1970s for water softening [141], to the recent development of the hybrid ion exchange-NF desalination process [142]. These developments and research activities are discussed in more detail in the following sections. 


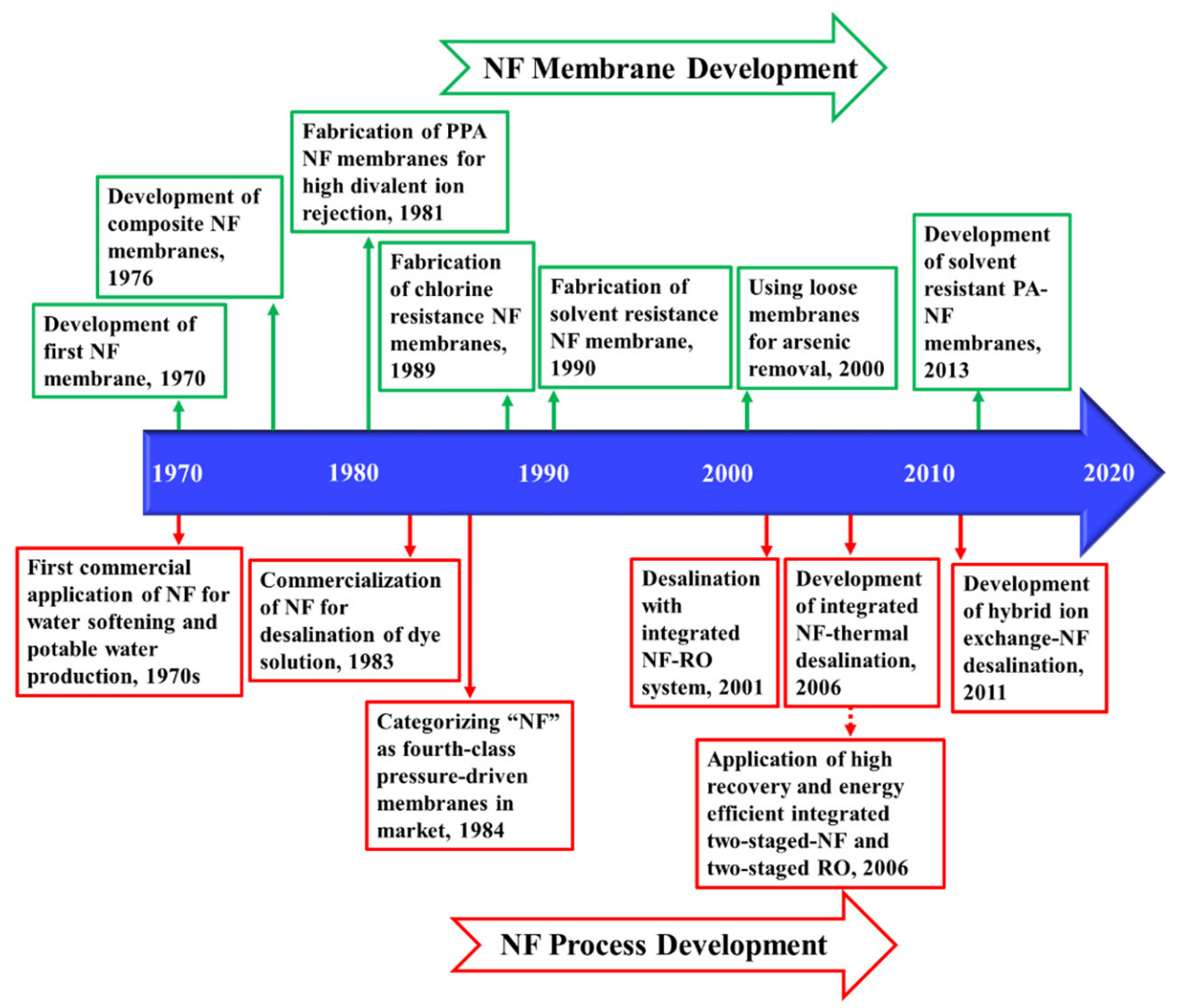

Figure 3. Timeline of the key developments of NF process [142-144] and NF membranes [141,145,146].

\subsection{NF Membranes}

NF membranes are mostly fabricated from PA, polysulfone (PS), polyols, and polyphenols [147]. Recently, inorganic materials such as ceramics, CNTs, and graphene [148,149] have been employed for NF membranes. Although size-related separation is the primary mode of action of NF membranes, Donnan exclusion provides an additional mechanism for hindering co-ion transport through NF membranes with charged surfaces [150]. The approaches employed to improve the properties of NF membranes are summarized in the subsequent sections.

\subsection{NF Operational Modes}

NF is normally operated in tangential flow filtration (TFF) mode, which minimizes $\mathrm{CP}$ in the channel [151]. In TFF mode, feed water flows along the membrane and the permeate stream passes through the membranes. In NF, the membranes are not capable of totally removing all components and particles smaller than $0.5 \mathrm{~nm}$ may pass through the membranes to the permeate side, as presented in Figure 4. Hence, as opposed to RO, NF permeate may require further desalination. NF is operated under either constant TMP or constant flux. Constant TMP is a static mode that can be used to evaluate the permeability of clean membranes and estimate the capacity of the unit. Constant flux is a dynamic mode which changes pressure in response to fouling and is mostly used for water with high fouling potential to assure a fixed permeate flux as the TMP increases [152]. The optimum permeate flux is a sustainable flux beyond which fouling rate significantly increases [152].

\subsection{Main Challenges of NF}

Performance of NF is affected by membrane fouling, selectivity, and lifetime. Herein, we review the current research that has been conducted to improve the efficiency of NF. Many of the strategies employed for RO also apply to NF but here, we focus on work specific to NF membranes. 


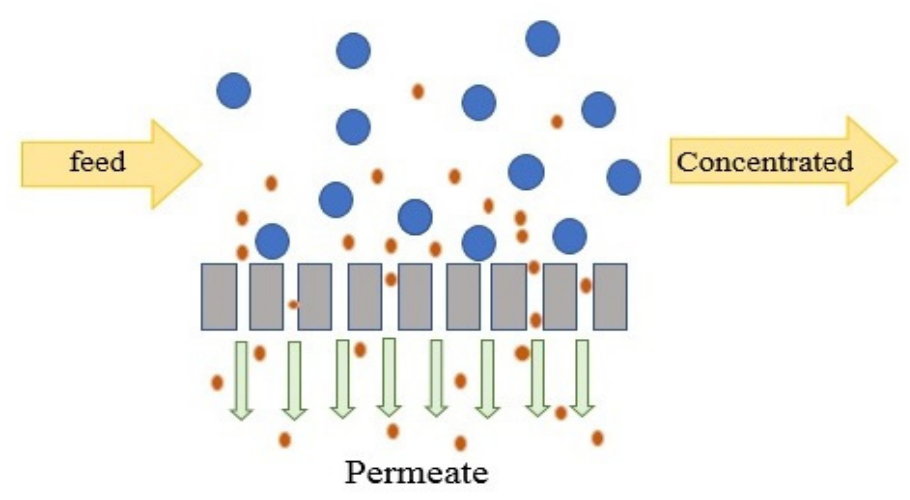

Figure 4. Tangential flow filtration mode.

\subsection{Approaches to Reduce Fouling and Scaling in NF}

Feed water quality and membrane properties such as surface morphology affect fouling and scaling. Membranes with smooth surfaces experience less scaling compared to those with rough surfaces [153]. Combined fouling of NOMs and colloidal particles is greater than their effects separately, although NOMs tend to stabilize the colloidal particles [154]. Similar to RO, physical and chemical cleaning are classical approaches to remove foulants $[155,156]$. Physical cleanings are generally used for loosely-attached foulants and are divided into three major categories, including hydraulic cleaning, e.g., backwashing and forward flushing [157], pneumatic methods such as air sparging [158], and sonication, in which ultrasound irradiation forces foulants to separate from membranes [159]. Chemical cleaning is also possible, using a variety of chemicals including acids, alkalis, adsorbents, and surfactants, as well as enzymes for biochemical cleaning $[160,161]$. The effectiveness of membrane chemical cleaning depends on the foulant types and membrane materials [157]. It was shown that the ultrasonic-assisted chemical cleaning of NF membranes significantly improved water recovery for arsenic-rich brackish water treatment [162]. However, the mechanical vibration accompanied by low-pH acidic solution can damage the mechanical and chemical stability of the membranes in the long-term. Here, we review the strategies developed for mitigation of fouling and scaling in NF. We focus on strategies that are unique to NF; however, many of the pre-treatment approaches employed for RO can be applied for NF to reduce fouling and scaling [163-166].

Self-cleaning and loose membranes can be employed in NF to reduce fouling. Using photocatalytic membranes (PMs), fabricated from the incorporation of photocatalytic materials such as metal-oxides (e.g., $\mathrm{TiO}_{2}$ and $\mathrm{ZnO}$ ) into NF membranes, reduces biofouling due to their superhydrophilicity, high photocatalytic activity, transparency, and electroconductivity. PMs prevent the adherence of contaminants to the surface of membranes using anti-static forces $[167,168]$. The dispersion of these catalyst particles in the membrane matrix is challenging, and the improper incorporation of them leads to the reduced separation performance of the membrane. Using loose NF membranes with an average pore size close to $10 \mathrm{~nm}$ [169] also reduces the fouling potential. The larger pore size of these membranes, however, reduces the ion removal efficiency, adversely affecting the desalination performance. Such NF membranes are used in dye/salt mixture fractionation and arsenic removal, and also in brackish water treatment for fluoride and NOMs removal [145,170,171].

Surface modification of membranes through the regulation of the physical and chemical properties of the surface is another fouling mitigation approach. The surface properties of membranes are modified through adjusting surface charges (to increase the electrostatic repulsion between foulants and membrane), increasing the hydrophilicity (to decrease the hydrophobic interactions of foulants with the membranes), and reducing the roughness (to create smooth surfaces with minimal contact area for attachment of the fouling components). Van der Bruggen [172] reviewed membrane modifications that have been used with polyether sulfone (PES)-NF membranes, including sulfonation, carboxylation, plasma 
treating, grafting, and polymer blending to enhance their antifouling properties. Sulfonation and carboxylation of the membranes improves their hydrophilicity through adding sulfonic and carboxylic groups to the polymer substrate. These chemical reagents react with PES via substitution reactions, improving the hydrophilicity of the membrane [173]. Plasma treatment [174] and grafting, e.g., UV, plasma, and ion beam irradiation, enhance the wettability of the membrane surfaces due to the generation of free radicals on the membrane surface, which attracts water. UV irradiation is a straightforward and cost-effective modification method that can be applied to many membranes to increase resistance against organic fouling and biofouling at lab-scale [175].

The addition of NPs to the membranes to form thin film nanocomposite (TFN) significantly improves their fouling resistance, as well as their permeability and durability $[176,177]$. Antifouling nanocomposite membranes containing metal-based NPs, e.g., $\mathrm{TiO}_{2}, \mathrm{Ag}$, and $\mathrm{SiO}_{2}$, and carbon-based NPs, e.g., CNT and GO, have been developed [178]. $\mathrm{TiO}_{2}$ and $\mathrm{SiO}_{2}$ NPs increase hydroxyl groups and the hydrophilicity of the membrane surface $[179,180]$. Due to disinfection effects, Ag NPs are commonly used for the biofouling control of membranes, reducing bacterial growth by as much as $90 \%$ [181]. Carbon-based nanocomposite membranes have improved anti-fouling, permeability, and desalination capacity [182,183]. Due to the robust pores and hydrophobic interior walls of CNTs, water molecules can easily pass through, leading to high flux and less fouling. Kang et al., [184] demonstrated that embedding sulfonated GO (SGO) into PA-NF membranes improved membrane wettability and fouling resistance. Addition of organic compounds, including polyelectrolytes [185] and coating copolymers, e.g., polyvinyl alcohol (PVA), and poly(oxyethylene) methacrylate (POEM) [186], to the membranes' surface also improved their antifouling properties due to changes in the roughness. Cyclodextrins [187] and zwitterion polymers [188] have also been used to reduce fouling by making the membranes more hydrophilic, as well as increasing water permeability. However, the performance of TFN membranes depends on many parameters, including membrane material, reaction time, fabrication method, dispersing reagents, and concentration of NPs loaded in the membrane matrix. Particle agglomeration is a major challenge in the fabrication of TFN membrane that can lead to surface defects and consequently reduce the salt removal efficiency of the processes. NP modifications, using proper reagents, and optimizing the fabrication conditions might help with the dispersion of NPs in the polymeric solutions. Optimizing the concentration of embedded NPs is a critical factor, since even though loading a high concentration of NPs may increase the permeation flux of NF membranes, it can reduce salt removal efficiency [189].

\subsection{Approaches to Enhance Selectivity of NF}

The selective removal of organic compounds and multivalent ions in NF make the approach applicable to water softening. Pore size and surface charge of the membranes as well as ion hydration shell can impact compound rejection and membrane selectivity. Ions with weaker hydration shells, e.g., $\mathrm{Na}^{+}$, can detach from their hydration shells and pass through NF membranes under operational pressure, whereas those with stronger hydration shells are rejected, e.g., $\mathrm{Mg}^{2+}$ [190]. NF typically rejects $95 \%$ of divalent ions and $20-80 \%$ of monovalent ions. However, the selectivity of NF can further be improved via the approaches described below.

Embedding NPs into the membrane matrix affects membrane pore size and the associated surface thickness/porosity ratio, hence improving ion rejection and selectivity in the process [179,191]. Zareei et al., [192] demonstrated that by using cobalt ferrite-copper oxide NPs in PES-NF membranes, the $\mathrm{Na}_{2} \mathrm{SO}_{4}$ and $\mathrm{NaCl}$ rejection increased by $33 \%$ and $40 \%$, respectively. Carbon-based NP amendments are becoming increasingly common due to their low toxicity, hydrophilic properties, and their ability to uniformly disperse in the polymer matrix [177]. Using amine- $\left(\mathrm{NH}_{2}\right)$ functionalized CNT to modify TFC-NF membranes improved $\mathrm{NaCl}$ and $\mathrm{Na}_{2} \mathrm{SO}_{4}$ rejection [193]. CNT interlayer incorporation in TFC-NF membranes resulted in high divalent ion removal and more than $85 \%$ selectivity 
toward monovalent ions [194]. Introducing B-cyclodextrin into the NF membrane matrix resulted in a decrease in membrane pore size, leading to higher separation and improved permselectivity performance [195]. More than $85 \%$ of copper and lead removals were achieved by employing polyhedral oligomeric silsesquioxane (POSS) NPs and polyetherimide (PEI) based in the NF membrane [196]. MOFs are emerging NPs with tunable pore size and morphology that can be added to membrane structures to control permeability and enhance selectivity due to the dual transport routes [89,197]. Incorporation of copper benzene-1,3,5-tricarboxylate $\left(\mathrm{Cu}_{3}(\mathrm{TBC})_{2}\right)$ into the TFN-NF membrane improved $\mathrm{NaCl}$ rejection due to Donnan exclusion [198]. However, the concentration of added NPs should be optimized to avoid particle agglomeration that reduces the selectivity of NF membranes [21]. Loading high concentrations of NPs in the polymer layers might lead to an increase in void fraction of the polymer, reducing the cross-linking degree and resulting in poor separation performance. There is an upper limit for the concentration of embedded NPs, above which not only does the salt rejection sharply decrease, but also the mechanical strength of the membrane may significantly drop [179].

Surface modification of membranes using layer-by-layer (LBL) assembly of polyelectrolytes is a recently developed method to improve membrane selectivity [199]. Deposition of polyelectrolytes on the membrane surface affects Donnan exclusion and the pore size of the membrane, resulting in monovalent-selective NF membranes suitable for water softening [200,201]. Cheng et al., [202] demonstrated effective divalent ion removal and high selectivity of polyelectrolyte-assisted NF membranes. Modification of polyamide$\mathrm{NF}$ membranes by electrolyte monomer led to improvements in the rejection of $\mathrm{Na}_{2} \mathrm{SO}_{4}$ and $\mathrm{MgSO}_{4}$, and high selective removal of $\mathrm{SO}_{4}{ }^{2-}$ relative to $\mathrm{Cl}^{-}$[203]. Applying $\mathrm{UV}$ for monomer grafting on the NF membrane is another technique to improve salt rejection in brackish water desalination [204]. However, the exposure time and the concentration of monomers play significant roles in the effectiveness of UV irradiation [204].

Integration with other technologies can also enhance the selectivity and performance of NF. UF-NF integrated systems demonstrated significant improvement in seawater softening [205], textile wastewater treatment [206], and drinking water purification, in terms of salts, organic compounds, and bacteria rejection, to reach the potable water standards [207]. A hybrid NF and ED system (ED-NF) has also been proposed to reach high cation fractionation in the desalination of seawater with high $\mathrm{NaCl}$ concentration [116,208,209]. As discussed earlier, integrating processes, even though enhances water recovery and lower fouling and scaling, increases the capital costs, energy consumption, and the operational complexity.

\subsection{Approaches to Increase Lifetime of NF Membranes}

Membrane life span is affected by method of cleaning as well as the frequency and type of chemical agents employed. Optimization of the physical/chemical cleaning processes through the evaluation of hydrodynamics, $\mathrm{pH}$, concentration of chemical cleaning solution, cleaning type, and sequence, as well as the operational conditions during cleaning, can significantly impact water recovery and salt rejection performance [157]. Chemical cleaning at high temperature is more effective and cost-efficient because of reduced chemical requirements. Chen at al. [157] identified that membrane backwashing was more efficient than forward flushing, especially when fouling occurred inside the membrane pores. Depending on the type of fouling (organic or inorganic), the $\mathrm{pH}$ of the cleaning solution can play a significant role in restoring membrane properties. High $\mathrm{pH}$ alkaline solutions provide superior cleaning for organic fouling, since they increase the electrostatic repulsive forces [210]. Acidic solutions are more efficient for inorganic scaling removal from NF membranes [157]. The effects of cleaning with $\mathrm{NaOH}$ and $\mathrm{HCl}$ on membrane performance, including the selectivity and permeability, have been studied for poly(piperazine-amide) (PPA) and PA membranes [211]. After chemical cleaning, PA membranes demonstrated superior ion rejection performance compared to PP membranes. 
In addition to proper cleaning, membrane material and mechanical strength, as well as operational conditions, play significant roles in defining membrane life span and process energy consumption. The modification of polymeric membranes by addition of aramid nanofiber that integrates easily with polymeric materials during fabrication has been recognized as a suitable approach for improving the lifetime of membranes, due to its high mechanical stability and heat resistance properties [212]. Moreover, coating the surface of the membranes with a polyelectrolyte of opposite charge improved the electrostatic bonds between the membrane polymer and coating layer, enhancing membrane durabilty during $\mathrm{HCl}$ cleaning [185].

Although polymeric membranes are the most common due to their low fabrication costs, ceramic membranes have gained increasing attention in the past two decades due to their high thermal and chemical stabilities, as well as elevated mechanical strength toward back-washing [213]. A variety of materials have been applied to fabricate ceramic membranes, including metal oxides, e.g., alumina, titania, silica, zirconia [140], zeolite, and MOFs [149]. Alumina-based membranes are more suitable for large-scale production due to their long lifetime. Zirconia-based membranes are the proper choice for the replacement of polymeric membranes under high temperature and high salinity conditions [214]. However, ceramic membranes are costly and sustain a larger pore size and less permeability compared to the polymeric membranes. These challenges have limited their use to pre-treatment processes. More research is required to further advance their application for desalination purposes [215].

\subsection{Overall Status of NF for Brackish Water Desalination}

NF has also been commercialized, and produces approximately $3 \%$ of desalinated water globally. The lower operational pressure of NF compared to RO makes it a relatively energy-efficient technique for the total desalination of low-salinity waters, or the partial treatment of high-salinity waters. NF is capable of removing multivalent ions, allowing the selective removal of scale precipitating ions and water softening $[13,14]$. This unique characteristic makes NF a superior option for the desalination of brackish water with low to moderate salinity that is dominated by multivalent ions [216,217]. For brackish groundwater with moderate salinity (TDS below $6000 \mathrm{mg} / \mathrm{L}$ ), NF is an effective approach to produce potable water with reasonable salinity $(800 \mathrm{mg} / \mathrm{L})$ at a higher permeate flux compared to RO [14].

\section{Electrodialysis}

Electrodialysis (ED) is an electro-membrane desalination technique that uses an electric field to separate ions from water. As shown in Figure 5, feed water enters the channels between anion and cation exchange membranes (AEMs and CEMs, respectively), alternately placed between two electrodes [218]. The imposed electric field drives ions toward opposite-signed electrodes. Cations can pass through CEM and are blocked by AEM, and anions transport through AEM and are hindered by CEM. The permselective transport of ions through IEMs results in a decrease in ionic concentrations in the diluate channels, and an increase in the adjacent concentrate compartments. An ED stack is formed by a series of repeating unit cells containing a CEM, an AEM, a diluate channel, and a concentrate channel. A typical industrial ED unit may contain over 100 cells with a membrane area of $1-2 \mathrm{~m}^{2}[218,219]$. ED is traditionally designed as a plate and frame module that has low packing density [220]. A number of studies investigated designing, modeling, and optimizing a spiral wound ED (SWED) module [221,222]. The available membrane area in the spiral wound module is high due to the high packing density, decreasing the required imposed potential. Difficulties in membrane cleaning and replacement and the possibility of mixing the electrode rinse solution and water streams are the main limitations of SWED [221,222]. 


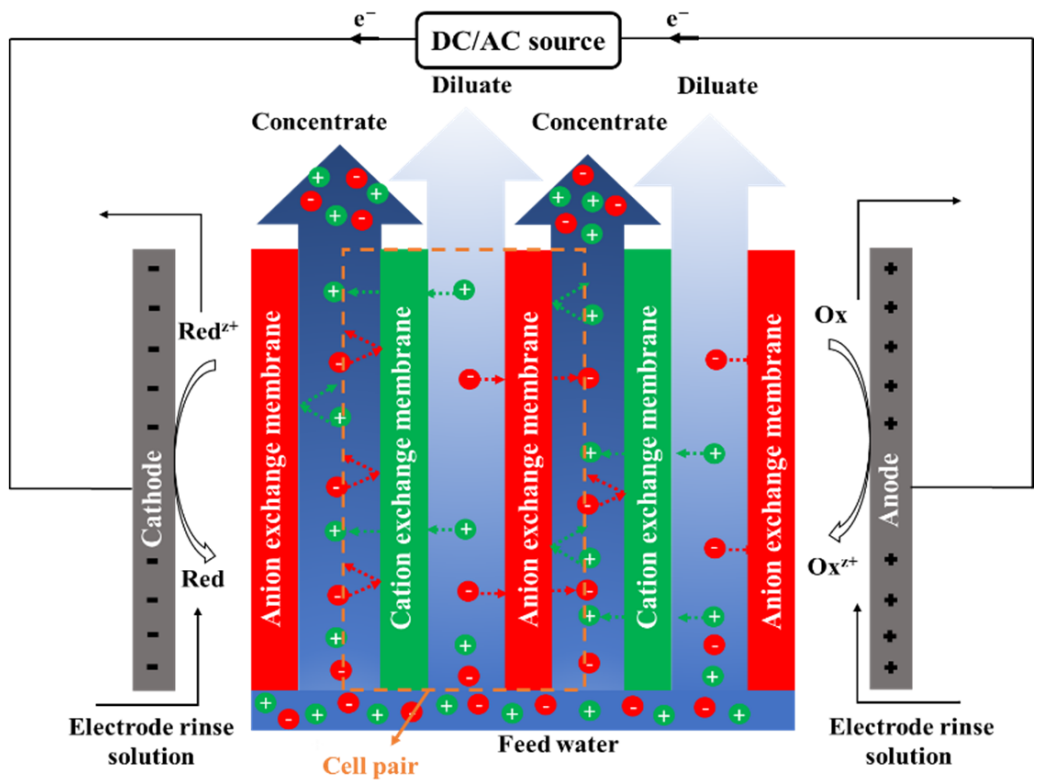

Figure 5. A schematic diagram of an electrodialysis (ED) stack.

Figure 6 demonstrates the timeline of the key developments of ED and ED-based processes, from the early discovery of the concept in 1890 [223], to the first commercial plant in 1954 [224], and recent advances in process development.

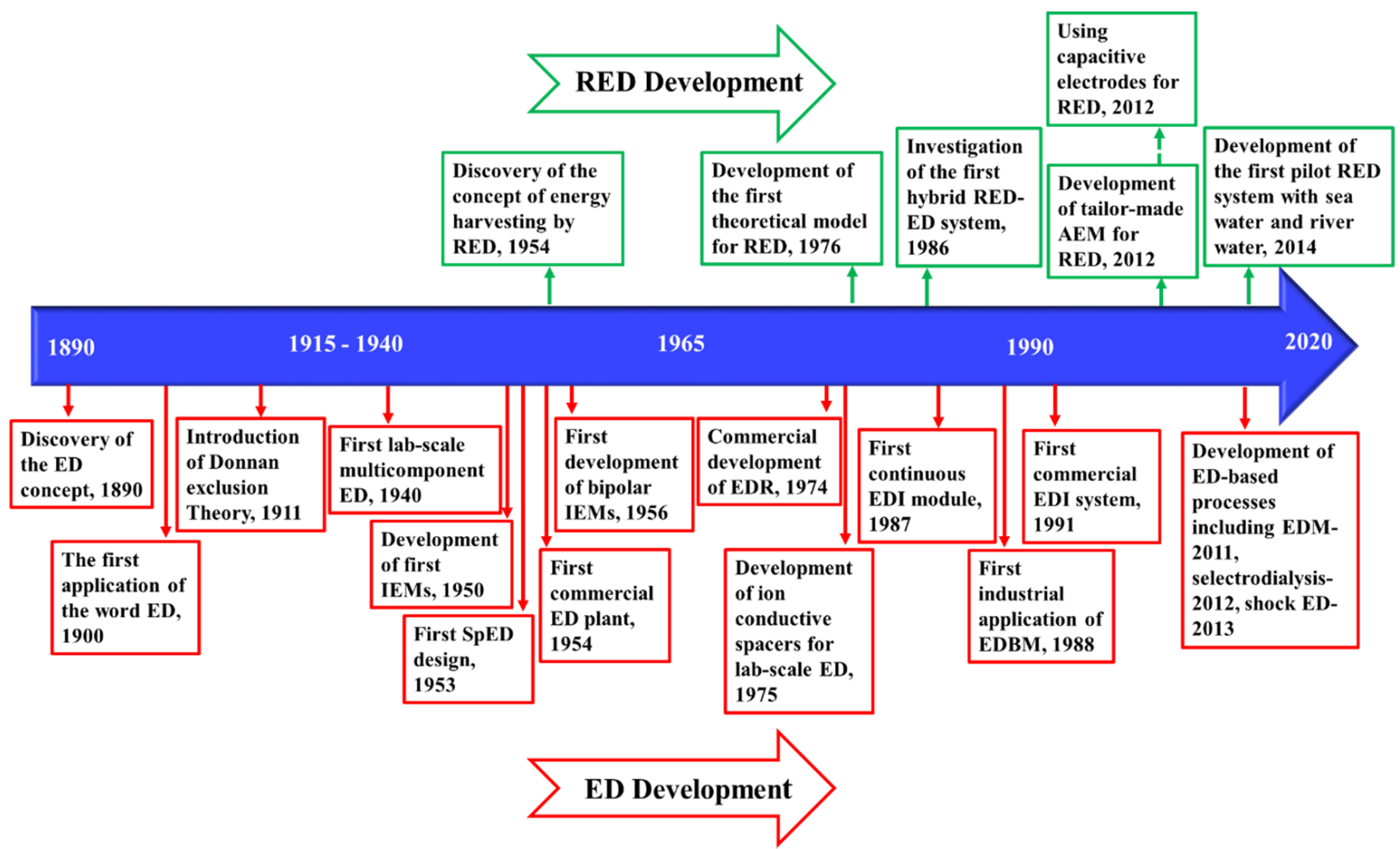

Figure 6. Timeline of the key developments of $\operatorname{ED}[9,121,218,221,223-230]$ and reverse electrodialysis (RED) [231-237].

\subsection{Membranes in ED}

IEMs in ED should possess high permselectivity and conductivity, low resistance, and high mechanical, dimensional, and chemical stability $[215,238,239]$. IEMs are made of polymeric compounds containing fixed-charge functional groups and moveable counterions. CEMs contain negative fixed charges while AEMs sustain positive fixed-charge functional 
groups. When CEM and AEM absorb water, the charged functional groups dissociate, leading to the release of mobile cations and anions, respectively, enabling the counterion transport through the membrane [240]. Bipolar IEMs have a cation exchange layer, an anion exchange layer, and an interfacial layer in their multilayer structure, and are used for water dissociation and acid and base production $[239,240]$.

In the past few decades, numerous polymers and fabrication techniques have been developed for synthesizing and modifying IEMs [240-242]. A number of polymers including polyethylene (PE), polypropylene (PP), PES, polyetherketone (PEK), polybenzimidazole (PBI), polyimide (PI), poly(p-phenelene oxide), polysulfone (PSU), PEI, and polyvinylidene fluoride (PVDF) have been used in the polymeric structure of IEMs. The charged functional groups of CEMs include sulfonic acid, phosphoric acid, and carboxylic acid. For AEMs, quaternary ammonium cations, imidazole cations, and guanidinium, or nitrogen-free functional groups, e.g., phosphonium, sulfonium, and metal cations, are employed as fixed charges [243,244].

Properties of IEMs are governed by their material and fabrication techniques, and the type, concentration, and distribution of fixed-charge groups in the membrane structure $[238,239]$. Ion exchange capacity (IEC) represents the quantity of the fixed charges of IEMs, determining their permselectivity and ohmic resistance. An even distribution of fixed-charge groups in the polymeric structure results in homogenous IEMs, while an uneven distribution of fixed charges forms IEMs with heterogeneous structure [239]. In the absence of water, IEMs have a dense or non-porous structure. Once IEMs absorb water, micro-, meso-, and macro-pores can form in the swollen membranes [245].

Several commercial IEMs are manufactured for ED [246] and ED-related processes [247]. Typical commercial ED membranes have an ion exchange capacity (IEC) of $1-3 \mathrm{meq} / \mathrm{g}$, an electrical resistance of $1-15 \Omega \mathrm{cm}^{2}$, and a transport number of $0.75-0.95$ [248]. Organic and inorganic precipitation, $\mathrm{pH}$ changes, and the chemistry of the feed water impact the lifetime and properties of IEMs, and consequently, the separation efficiency and energy consumption of ED [249]. The development of new fabrication and modification techniques to enhance the chemical and mechanical stability, anti-fouling properties, and permselectivity of the membranes has greatly attracted the attention of the research community [240].

\subsection{Electrodes in $E D$}

In ED and reverse electrodialysis (RED), which is a salinity gradient energy harvesting technology designed based on ED, electron transfer between ionic species and electrodes occurs through electrochemical (Faradaic) reactions taking place in electrode compartments. In ED, the external power supply provides the required energy for non-spontaneous redox reactions in cathode and anode compartments, while in RED, the spontaneous electrochemical reactions at the surface of the electrodes generates electricity from the existing salinity gradient between the diluate and concentrate solutions. The amount of energy dissipation in the electrode compartments depends on the electrode material, electrode design, redox couple, and supporting electrolyte solutions [250]. A number of studies have focused on optimizing and tailoring these parameters for RED and ED systems [234,250-253]. Both reactive, e.g., zinc, and inert, e.g., platinum-coated titanium, materials have been investigated for ED/RED electrodes [232,254]. Depending on the redox couples used in the electrode compartments, various electrochemical reactions can occur with the possibility of the generation of $\mathrm{O}_{2}, \mathrm{H}_{2}, \mathrm{or} \mathrm{Cl}_{2}$ gases [250]. Production of $\mathrm{H}_{2}$, hydrogen cyanide $(\mathrm{HCN}), \mathrm{ClO}_{3}{ }^{-}$, and similar compounds may impose safety, environmental, and health hazards due to their explosive or toxic nature. Moreover, potential losses in electrode compartments with redox reactions that generate gas are relatively high. However, in commercial stacks with a high number of cell pairs, electrode losses are negligible compared to the overall potential drops [250].

Recently, the use of capacitive electrodes has been proposed to avoid Faradaic reactions and the associated energy dissipation and hazardous byproduct generation [236]. Capacitive electrodes contain a current collector and an activated carbon layer, where ions 
are stored in the electric double layer (EDL) and balanced out by electronic charges on the electrodes. Capacitive flow electrodes (FEs), generally composed of micro- or nanoparticles of carbon in an electrolyte solution with a weight percentage below $25 \%$, have also been investigated for RED [255]. The improved performance of RED using FEs offers a possible application of this type of electrode in ED as well.

\subsection{Operational Modes of ED}

ED is operated in continuous, batch, and feed-and-bleed modes [256]. The continuous mode is suitable for a large-scale ED, while the batch mode is appropriate for small- or medium-scale processes [257]. In the feed-and-bleed mode, the desalinated or concentrate streams are partially recycled back to the feed solution to control the salinity of the product water [258]. This operating mode results in a higher water recovery and is applicable to medium- and large-scale processes $[218,258]$. These processes are operated at either constant potential or constant current density [259].

ED is operated at sub-limiting, limiting, and over-limiting current regimes as illustrated in Figure 7 [260]. In sub-limiting regimes, current density increases linearly with imposed potential. Due to the permselectivity of IEMs, CP forms in channels and develops along the cell. Once the concentration of ions at the membrane-solution interface in the diluate channel approaches zero, the current density reaches a limiting value, shown as a plateau in Figure 7. Further increasing the cell potential beyond the limiting value promotes a series of phenomena including gravitational convection, water splitting, co-ion leakage, and electroconvection in the cell, leading to the over-limiting of the current density and a transition to a linear increase in current density with cell potential [261,262]. The enhanced turbulence in the over-limiting current regime may result in mechanical instability. Additionally, a higher degree of water dissociation at higher potentials may lead to drastic $\mathrm{pH}$ changes, increasing salt precipitation and membrane scaling. ED units are typically operated at $80 \%$ of the limiting current density to avoid such consequences and to control the operational energy costs [263].

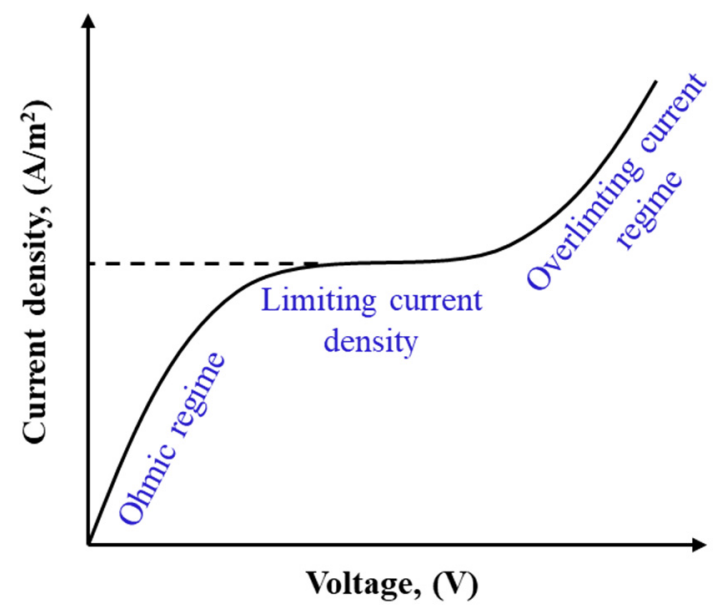

Figure 7. A sketch of the current density-voltage curve in ED.

Operating ED at an over-limiting current regime increases the rate of mass transfer and allows a decrease in the required membrane surface area, reducing the cost associated with IEMs [262,264]. However, economical operation of ED at an over-limiting current regime depends on the membrane properties. To reach the over-limiting current conditions at lower potentials and reduce the energy requirements, the membrane physical and chemical structure should be modified. Electroconvection can be enhanced by increasing the density of membranes' charged groups, as well as the surface heterogeneity and hydrophobicity $[262,265,266]$. Water dissociation ( $\mathrm{pH}$ changes) at over-limiting currents can be controlled by developing membranes that have homogeneous charge distribution [267] and contain fixed charges with lower catalytic activity for the water splitting reaction [268]. 
Although increasing membrane surface heterogeneity enhances the electroconvection, it is normally accompanied by higher water dissociation as well as fouling and scaling formation. Hence, care must be taken in the operation of ED with heterogeneous membranes at over-limiting current regimes for water with a high fouling propensity. Studying the over-limiting current operation of ED for various feed waters $[269,270]$, investigating the effects on transport mechanisms [271,272], and identifying approaches to modify membrane characteristics $[273,274]$ are ongoing research directions.

\subsection{Development of ED-Based Processes}

Since the first commercial ED plant in the 1950s, a number of ED-based processes have been developed, including electrodialysis reversal (EDR) [275], bipolar membrane electrodialysis (EDBM) [276], electro-deionization (EDI) [277], electrodialysis metathesis (EDM) [278], and RED [279]. In EDR, the polarity of the power source is periodically reversed at intervals between a few minutes to a few hours, reversing the ionic flow direction. EDR is a commercialized process with a lower fouling and scaling potential and higher water recovery compared to ED. EDBM takes advantage of bipolar membranes and converts salts into acids and bases. In EDI, the diluate channel is filled with ion exchange resins to improve the conductivity of the solution and avoid the back-diffusion of ions from the concentrate channel. Water dissociation in the diluate channel can result in the self-regeneration of ion exchange resins and aid in the continuous operation of the process. EDI is used for ultra-pure water production. EDM is a novel alteration of ED in which metathesis reactions take place to convert less soluble salts to more soluble species. The repeating unit cell contains four compartments (quad) with two diluate and two concentrate channels. Feed water enters one of the diluate channels and the substituting solution enters the other. Non-precipitating salts are formed in the concentrate compartments. In EDM, high water recovery can be reached, decreasing the volume of the concentrate waste stream and enhancing the ability to produce salts. RED is a technique to harvest salinity gradient energy (blue energy) from the mixing of two streams with different salt content [279]. Blue energy is not affected by seasonal changes, unlike solar and wind, and can serve as a source of renewable energy. The development of these ED-based processes can broaden the applications of the processes for a wider range of feed water quality. However, further research should be conducted on these novel processes to improve the operational conditions, as well as on the membrane and electrode materials to enhance their energy- and cost-effectiveness.

\subsection{Main Challenges in ED}

Desalination efficiency in ED is affected by the performance of IEMs, fouling and scaling, and the electrical resistance of the cell. We summarize the research and development conducted, to overcome such challenges and improve the performance of ED.

\subsection{Approaches to Improve Performance of IEMs in ED}

The economics and energy consumption of ED depend on the cost and selectivity, conductivity, and stability of IEMs [264]. Traditional fabrication techniques used for synthesizing homogeneous IEMs include the direct polymerization of monomers that contain ionizable groups, grafting charged functional groups onto polymeric film, and introducing charged groups to the polymer followed by dissolving it in an organic solvent and casting the solution on a plate. Ran et al., [240] reviewed emerging fabrication techniques used for synthesizing IEMs, including polymer blending, pore filling, pore soaking, in situ polymerization, and electro-spinning. In the polymer blending method, several polymers are mixed to overcome the deficiencies of a single polymer and produce membranes with higher selectivity and conductivity. Pore filling and pore soaking approaches result in IEMs with high permselectivity and low swelling. In situ polymerization reduces the amount of toxic organic solvents used in traditional fabrication approaches. The IEMs synthesized through electro-spinning sustain high porosity and a high specific surface 
area. Although promising, further investigation is required to optimize the mixing ratio in polymer blending, improve the long-term stability of IEMs generated through pore filling, and extend the application of electro-spinning for synthesizing IEMs from various polymers in a larger scale [240].

In addition to investigations of new fabrication techniques for IEMs, numerous researchers have focused on modifying the chemical and physical properties of the existing IEMs. Various NPs, e.g., zeolites, carbon-based, graphene-based, silica, titanium oxide, silver, aluminum oxide, etc. have been used to produce nanocomposite IEMs [248]. The addition of NPs to IEMs enhances membrane properties due to the addition of functional groups of NPs or the dispersion of ionic clusters inside the polymeric structure of the membranes. However, the optimization of the appropriate type and quantities of NPs is essential to avoid shielding the charged functional groups of IEMs and causing mechanical instability [248].

Chemical and physical modifications of membrane surfaces are alternative approaches to improve their permselectivity and antifouling properties [280]. Surface modification techniques such as plasma treatment, adsorption, solution casting, ion implantation, and polymerization adjust surface properties either by coating a layer on top of the surface or by direct improvement of the chemical structure of the surface. These approaches aim to modify surface wettability, smoothness, homogeneity, charge density, anti-bacterial properties, and multivalent ion rejection. For long-term effectiveness of these approaches, the modified surface should be durable and stable.

Many researchers have focused on the development of IEMs with high counterion permselectivity or high specific ion selectivity, e.g., monovalent or nitrate permselective IEMs [281]. Permselectivity of IEMs is impacted by the affinity of ions with membranes and their mobility inside them [282]. A variety of approaches are used to improve permselectivity, including [281] surface modification through developing a highly cross-linked surface layer (to enhance the steric sieving effects), coating a thin oppositely-charged layer on the surface of the membrane (to provide higher electrostatic repulsion for multivalent ions), layer-by-layer film deposition (to provide higher rejection toward multivalent ions due to the increased Donnan exclusion effects and increased hydrophobicity of the surface), and coating a dense and non-charged polymeric layer on the surface of IEMs (to increase size sieving effects). Enhancing IEM properties through advancing fabrication and modification techniques is an ever-growing research direction that can significantly affect desalination performance in ED and related processes.

\subsection{Approaches to Reduce Fouling and Scaling in ED}

$\mathrm{ED}$, similarly to the pressure-driven processes, suffers from membrane fouling and scaling. Fouling occurs due to size exclusion of particles, electrostatic interactions of foulants with charged functional groups of the IEMs, hydrophobic interaction of the organic foulants with uncharged sections of the IEMs, microbial activity, and salt precipitation and deposition $[283,284]$. Mineral scaling is mainly dominant on the CEM (due to the precipitation of salts such as $\mathrm{Ca}(\mathrm{OH})_{2}, \mathrm{Mg}(\mathrm{OH})_{2}$, and $\mathrm{CaCO}_{3}$ ) while organic and colloidal fouling mainly occur on the AEM (due to the negative charges of such organic compounds causing electrostatic adsorption to the positively charged membrane surface) $[285,286]$. Parameters affecting fouling and scaling include size and concentration of foulants; salinity, composition, temperature, and $\mathrm{pH}$ of water; operational mode of the process (ohmic, limiting, or over-limiting current regimes); cell hydrodynamics; and membrane properties including morphology, pore size, and chemistry [284]. Fouling and scaling lead to a decrease in IEM permselectivity and an increase in membrane ohmic resistance $[249,283]$.

Similar to RO and NF, pre-treatment steps such as filtration, pressure-driven filtration [287], activated carbon [288], pellet reactor [289], UV irradiation [290], and phytoremediation [291] have been shown to reduce fouling and scaling issues. However, the addition of the pre-treatment steps increases the capital costs and operational complexity. Chemical and physical cleaning of the IEMs are used to remove fouling and scaling and restore mem- 
brane properties. Cleaning methods are generally the same for pressure-driven processes and ED. However, a number of mechanical removal techniques such as backwashing, air sparging, and forward flushing that are applicable to pressure-driven processes may damage IEMs, due to their non-porous structure and ability to pass ions rather than water $[284,292,293]$. The choice of cleaning agents depends on the structure of the membranes as well as the nature and intensity of fouling [293,294]. Guo et al., [295] identified that $\mathrm{HCl}$ is a superior agent for removal of $\mathrm{CaCO}_{3}, \mathrm{BaCO}_{3}$, or $\mathrm{Mg}(\mathrm{OH})_{2}$ scale, while $\mathrm{NaOH}$ is more efficient in the elimination of organic and oily foulants. It is worth noticing that chemical cleaning with some strong oxidizing or alkaline agents may result in the deterioration of charged functional groups or the polymeric matrix of the IEMs [296,297]. In addition, the chemical cleaning results in the production of an effluent waste stream which needs to be properly managed. The cost of chemical agents further increases the cost of desalination.

Membrane modification is also employed in ED as an anti-fouling approach. Many of the modification techniques used to improve IEM antifouling are similar to those for pressure-driven membrane processes. Physical and chemical alterations of the membrane surface are used to adjust surface charge density, increase the hydrophilicity, and reduce the roughness. Increasing the negative charge density and hydrophilicity of the surface through coating a polyelectrolyte or a thin nanocomposite layer on the surface has enhanced the antifouling properties of the membranes [298-300]. However, these surface coatings may result in an increase in surface roughness, adversely affecting AEM fouling resistance [285]. Hence, the concentration of the coating layer and the fabrication time and conditions should be optimized to minimize fouling. Approaches to control biofouling typically focus on preventing the attachment of microbial communities to the surface of the membrane, or destroying bacterial communities adhered to the surface. Such anti-adhesion and antimicrobial approaches are achieved through modification of the membrane by coating a layer of polyelectrolyte or silver nanomaterials on the surface [301-303].

A unique advantage of ED over RO and NF is the possibility of manipulating the operational conditions to mitigate fouling and scaling. Periodically switching the polarities of the electrodes in EDR reduces fouling and scaling by detaching organic foulants and dissolving deposited minerals [284]. A single-pass EDR with no anti-scalant addition was able to achieve high water recovery for feed water with a $\mathrm{CaSO}_{4}$ saturation level above $190 \%[304,305]$. By using modified thin spacers and high diluate flow rate relative to that of the concentrate stream, Turek and Dydo [304] reached more than $90 \%$ water recovery in an EDR of feed water supersaturated by $\mathrm{CaSO}_{4}$ and $\mathrm{CaCO}_{3}$. Pulsed electric field operation of ED (PEF-ED) is an alternative low-maintenance approach to control fouling and scaling and minimize chemical dosing [306-318]. PEF-ED consists of pulse periods with a constant electric field followed by pausing lapses with no imposed electric field [319]. PEF-ED leads to the restoration of concentrations in the boundary layers during the pause lapses, minimizing CP in the cell $[306,318]$. Hence, PEF operation can reduce water dissociation, fouling and scaling, and energy inefficiency in ED. In current studies pulsing parameters (frequency and duty cycle) are selected randomly and different values are reported for various feed water compositions. To reduce the number of trial steps and maximize the performance of the PEF-ED, a systematic approach should be developed for optimizing the pulsing parameters according to the chemistry of the feed water.

\subsection{Approaches to Decrease the Electrical Resistance in ED}

Decreasing the electrical resistance of an ED cell minimizes energy dissipation and improves ion separation efficiency. Modifications of chemical and physical structures of membranes to reduce electrical resistance and improve the mixing at the surface of the membranes can improve the electrical conductivity of the ED unit. Increasing the concentration of charged functional groups on the membranes decreases their ohmic resistance. However, increasing IEC is normally accompanied by higher water uptake in the membranes and lower dimensional stability [320]. The balance between IEC and water uptake of the IEMs is achieved through cross-linking methods [321-323]. The conductivity 
of the cross-linked membranes is controlled through adjusting the cross-linkers type, crosslinking process, time, and temperature [324].

Corrugated or profiled membrane surfaces are an alternative approach to improve the conductivity of ED. The use of profiled IEMs eliminates the need for a non-conductive spacer in the channel that can reduce membrane area (shadowing) and increase resistance. Pawlowski et al., [325] reviewed the development of profiled IEMs, their application in electro-membrane processes, limitations, advantages, and the preparation techniques. Using profiled IEMs and a high feed water flow rates increases turbulence in the channel, improving cell conductivity and ion transport. Under such conditions, fouling and scaling are minimized which further decreases the electrical resistance of ED. Due to better mixing with profiled membranes, $\mathrm{CP}$ and water dissociation are less significant, resulting in an improvement in current efficiency. Furthermore, since fouling and scaling increases electrical resistance, fouling mitigation approaches also help minimize the ohmic resistance.

In addition to membrane modification, improving the properties of spacers can significantly help reduce the cell resistance. Spacer nets are used inside the channel to keep membranes separated and promote cross-channel mixing, minimizing $\mathrm{CP}$ formed as a result of IEM's semi-permeability. Reducing $\mathrm{CP}$ increases the conductivity in the boundary layers of the diluate channel, enhancing the current efficiency. Geometry, water contact angle, mesh size, and filament size of spacer screens should be adjusted to enhance their performance and reduce the corresponding pressure losses in channels [326-329]. Although polymeric spacer nets increase the conductivity of the boundary layer, they may increase the overall electrical resistance due to their non-conductive nature, shadow effects, and fouling potentials. Ion-conductive spacers were developed to reduce the electrical resistance of the spacers and increase ion transport and current density [330-333]. Despite such advantages, ion-conductive spacers have not been adopted in commercial ED plants, possibly due to their complexity and high production costs as well as the increased fouling potential due to surface charges [218,284]. More recently, Balster et al., [334] proposed the use of gas sparging as an alternative to spacer nets to promote mixing in the spacer-free channel, and were able to increase mass transport with minimal increases in cell resistance. Mechanical stability of the membranes in such spacer-free channels and means of achieving uniform distribution of the air bubbles require further investigation [334].

\subsection{Status of ED for Brackish Water Desalination}

ED and ED-based processes (EDR and EDI) produce about 3\% of the global volume of desalinated water [7]. ED has been found to provide cost-effective desalination of brackish water with a salinity between 1000 and $10,000 \mathrm{mg} / \mathrm{L}$ [264]. At water recovery above $80 \%$, the energy requirement of EDR is lower than continuous RO and semi-batch RO for the same salinity of the feed water [335]. The ability to operate at low-pressure and with less pre-treatment due to the more robust nature of IEMs compared to RO membranes is among the main advantages of ED.

\section{Membrane Capacitive Deionization}

\subsection{Capacitive Deionization}

Conventional capacitive deionization (CDI) uses porous electrodes to extract ionic species from feed water via electro-sorption [336]. Ion adsorption in electrodes occurs due to electrostatic forces between applied electronic charges on electrodes and ionic species in water. During adsorption, there is no charge transfer between electrode and electrolyte, and the mechanism of ion adsorption and storage is analogous to that of a capacitor. The capacitive electrode is often assumed to be composed of both micropores, where ions are stored forming an electric double layer (EDL), and macropores, which provide the transport path from the bulk fluid (Figure 8) [337]. Non-conductive spacers are typically used in channels between electrodes to prevent electrical short circuiting, increase mixing, and reduce formation of $\mathrm{CP}$ at the electrode-solution interface [338]. Mosaic membranes [339], 
ion-exchange resins [340], and granular activated carbons [341] have been applied as spacers in MCDI to reduce cell resistance.

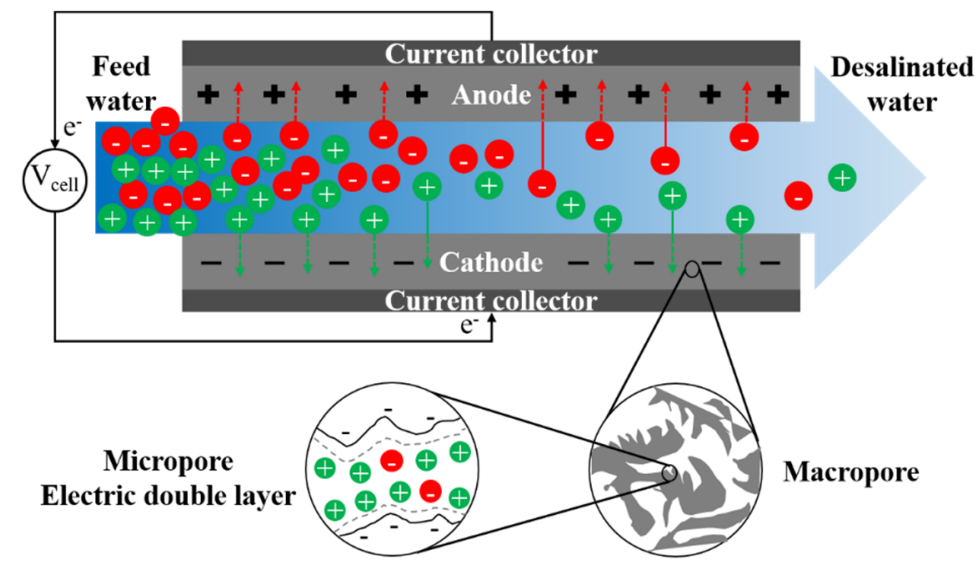

Figure 8. A schematic graph of the desalination process in conventional capacitive deionization (CDI).

During desalination (when electrical potential is applied to the electrodes), ions are attracted toward oppositely charged electrodes and are adsorbed (Figure 8) [342]. During electrode regeneration, the electrodes are short-circuited or their polarity is reversed to repel ions back into the solution, generating a concentrate stream [342]. The electrosorption performance during the desalination cycle depends on applied voltage, flow rate, cell configuration, desalination/regeneration cycle times, as well as the physiochemical properties of the electrode [343].

\subsection{Membrane Capacitive Deionization}

Membrane capacitive deionization (MCDI) is a modification of conventional CDI by incorporating IEMs between the electrode and spacer. A CEM is attached to the cathode and an AEM is attached to the anode. The MCDI cell assembly and ion transport route during the desalination process are described in Figure 9. The role of IEMs is to prevent coions from being flushed out of electrodes during desalination, or penetrating into electrodes during regeneration. Thus, MCDI improves charge efficiency, salt adsorption capacity, desalination rate, and energy efficiency compared to conventional CDI [338,344].

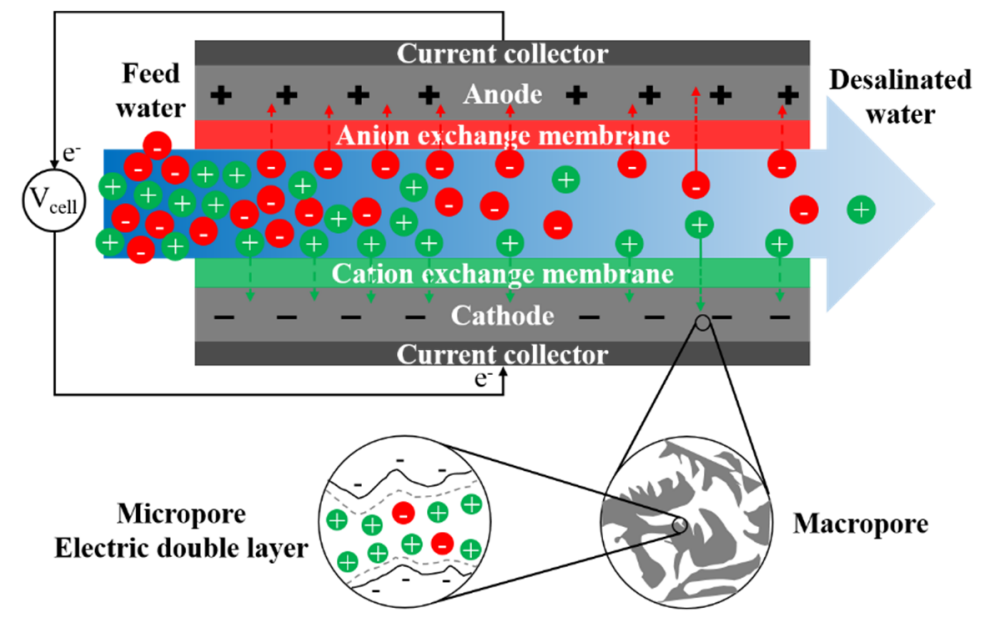

Figure 9. A schematic graph of desalination process in membrane capacitive deionization (MCDI).

The first MCDI cell was developed in 2006 [345], a few decades after the first design of CDI [346]. More recently, electrode and membrane materials and cell structures have been improved in MCDI as summarized in Figure 10 and discussed below. These developments 
remain at bench and pilot scale, but the relatively low energy consumption suggests that scale-up and commercialization may be feasible.

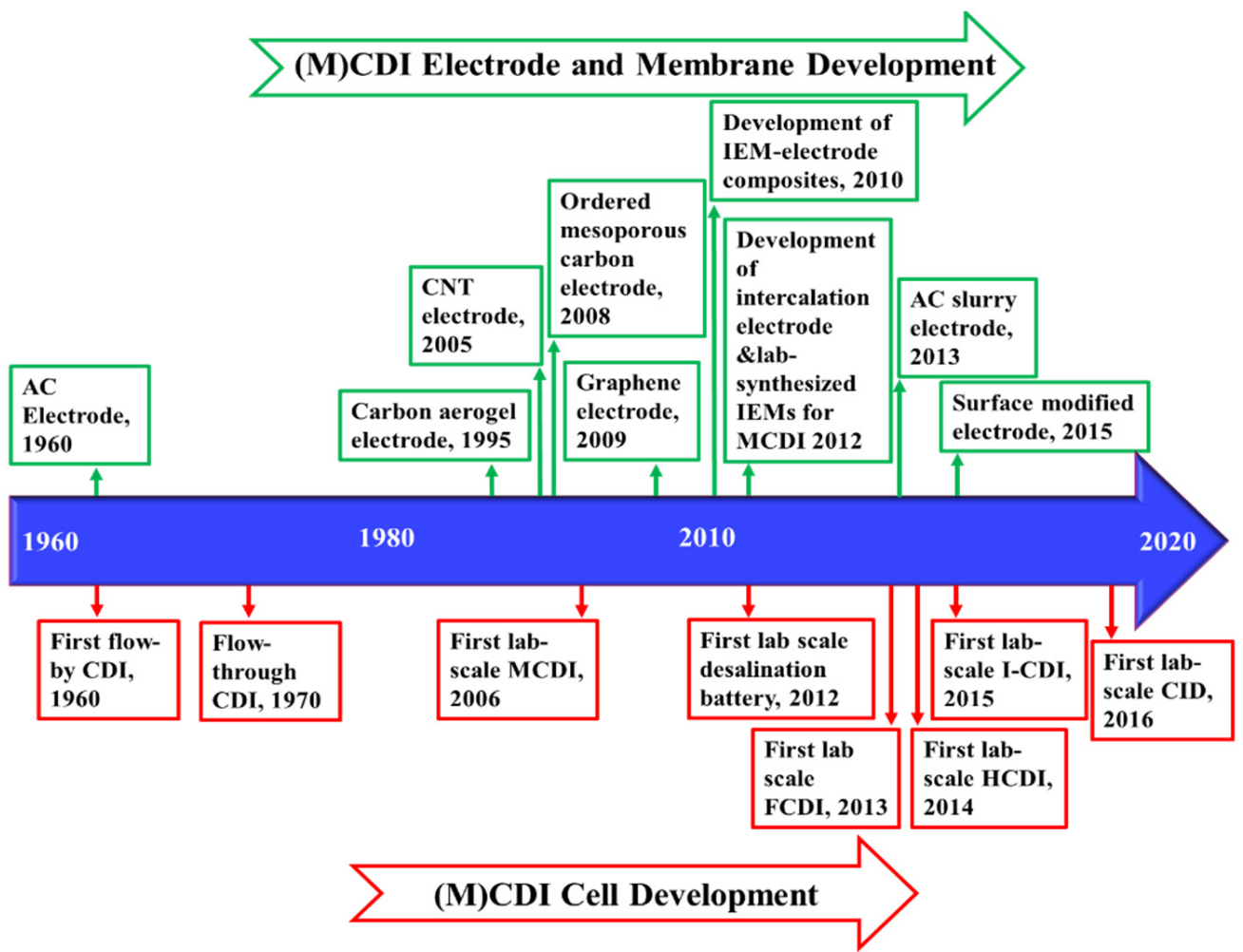

Figure 10. Timeline of the key developments of the cell structure [345-352], membranes, and electrodes of (M)CDI [352-360].

\subsection{Membranes in MCDI}

Commercial IEMs with high permselectivity as well as high chemical and mechanical stabilities are appropriate for MCDI [361]. MCDI does not require self-standing membranes, thus, thinner IEMs and electrode-IEM composites with relatively low electrical resistance and favorable stability have been developed for MCDI. Fabrication techniques including solution casting [362-364] and pore-filling polymerization [240,365-368] are employed to synthesize thinner and more conductive IEMs, specifically for application in MCDI. IEMs synthesized via casting methods possess low resistance [362-364]. Membranes fabricated through pore-filling techniques have shown superior dimensional and chemical stabilities [365-368]. The $\gamma$-irradiation process during pore-filling polymerization was proven to help further strengthen membrane dimensional stability and anti-chemical corrosion resistance. Kim et al., [367] fabricated a CEM through pore-filling with both sulfonic acid groups and weak acid chelating groups and the resulting IEM was stable over a wide range of $\mathrm{pH}$ and was effective for multivalent cation removal. In addition, electrodeIEM composites are produced by immersing or spraying the electrode with functional solutions, in situ polymerization of the electrode, and electrode chemical oxidation with dopant [369]. Electrode-IEM composites possess low contact resistance at the interface of the electrode and ion exchange polymer, as well as enhanced capacitance in some cases [361,370]. Electrode-IEM composites synthesized via IEM blending with carbon slurries possess relatively low material cost [371]. Despite these advances, the stability and longevity of the IEMs in MCDI require further improvements to fully develop the technology [371]. Fouling issues and the appropriate cleaning methods of these electrodeIEM composites should also be explored. 


\section{4. (M)CDI Operational Modes}

(M)CDI (refers to both CDI and MCDI) is operated under constant voltage (CV) or constant current (CC) modes [372-374]. Under CV mode, the effluent concentration decreases rapidly but sorption of ions slows as the electrodes approach capacity. Under $\mathrm{CC}$ mode, the concentration drops to a minimum value and remains constant until the end of the desalination cycle. Saleem et al., [375] operated a CDI cell under the hybrid $\mathrm{CV}-\mathrm{CC}$ mode, achieving a low concentration rapidly under $\mathrm{CV}$ mode first and switching to $\mathrm{CC}$ mode to maintain the concentration. The hybrid CV-CC mode improved ion removal compared to $\mathrm{CC}$ and $\mathrm{CV}$ modes.

CC mode generally consumes less energy compared to CV mode over complete cycles. However, the energy consumption of MCDI in a batch process under various operational modes largely depends on the concentration of feed water, concentration of the product water, and the volume of the product water in a batch mode MCDI [376]. At the same concentration of feed water, energy consumption of both modes increases at higher water production rates and lower product concentration. At the same adsorption objectives and salt removal rate, CV mode exhibits a smaller change in SEC compared to CC mode when doubling the volume of product water or lowering the salt concentration of product water. However, Dykstra et al., [377] identified that under the same desalination objectives, CC mode could recover more energy. Kim et al., [378] demonstrated lowered energy consumption by marginally charging the electrodes $(0.3 \mathrm{~V})$ during regeneration in $\mathrm{CV}$ mode, as a result of a higher charge efficiency. Further study should be conducted on the energy consumption of CC and CV modes at the same cell size, feed water quality, water recovery, salt removal efficiency, and energy recovery mode to make a valid comparison of these operational conditions.

\subsection{Cell Architectures}

A variety of cell architectures have been developed for CDI. In addition to conventional CDI and MCDI, there are flow-through CDI, inverted CDI (I-CDI), flow-electrode CDI (FCDI), and CDI with intercalation electrodes (also known as Faradaic electrodes) which includes hybrid CDI (HCDI), and cation intercalation desalination (CID) and a battery architecture (Figure 11). Here, we provide a summary of various designs of (M)CDI-based processes along with their main merits and drawbacks and most recent research studies that have improved their performance in Table 2. However, a more detailed review was conducted by Tang et al., [379].

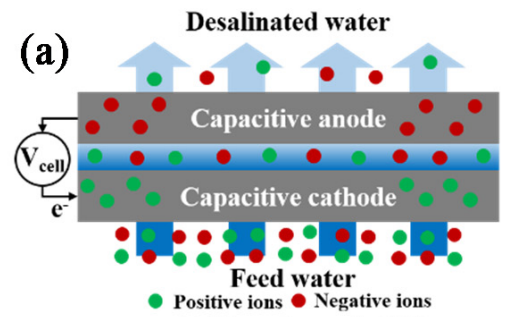

(d) (b)

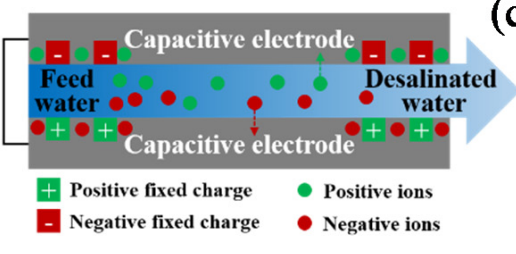

(b) Inverted CDI (c)

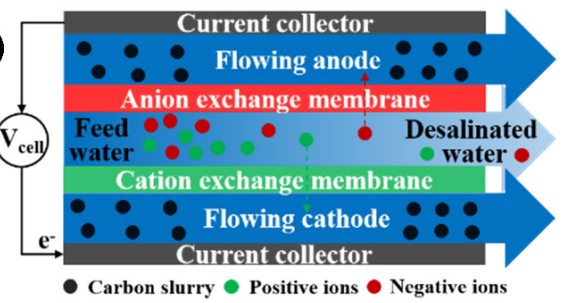

(c) Flow-electrode CDI

(e)

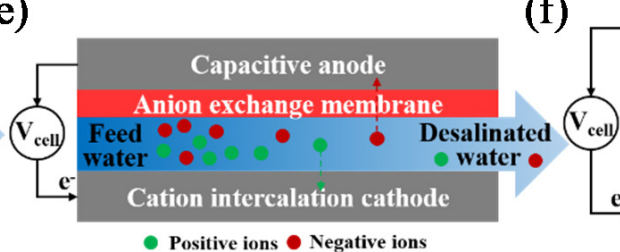

(e) Hybrid CDI

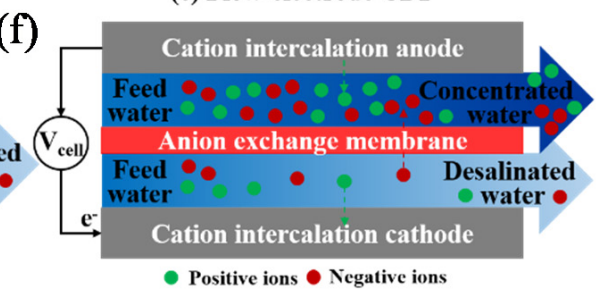

(f) Cation intercalation desalination

Figure 11. Cell architectures: (a) flow-through CDI; (b) I-CDI; (c) FCDI; (d) desalination battery; (e) HCDI; (f) CID. 
Table 2. Comparison of various CDI cell architectures.

\begin{tabular}{|c|c|c|c|c|c|}
\hline MCDI Architecture & Main Changes in the Cell Architecture & $\begin{array}{c}\text { Characteristic Desalination } \\
\text { Mechanisms }\end{array}$ & Merits & Drawbacks & Recent Advances \\
\hline $\begin{array}{l}\text { Flow-through CDI } \\
\text { Figure 11a }\end{array}$ & $\begin{array}{l}\text { Flow direction of feed water is vertical to the } \\
\text { charged electrodes. }\end{array}$ & $\begin{array}{l}\text { Both spacer and electrode } \\
\text { macropores serve as the flow } \\
\text { path. Adsorption occurs only in } \\
\text { electrode micropores. }\end{array}$ & $\begin{array}{l}\text { (1) Enabling a more compact } \\
\text { cell structure with thinner } \\
\text { spacers [379]. } \\
\text { (2) Improving desalination rate } \\
\text { and salt removal capacity [379]. }\end{array}$ & $\begin{array}{l}\text { (1) Major hydraulic pressure } \\
\text { loss [380]. } \\
\text { (2) Performance degradation } \\
\text { from anode oxidation [379]. }\end{array}$ & $\begin{array}{l}\text { (1) The enlarged macropores after laser } \\
\text { perforations significantly decreased } \\
\text { hydraulic pressure loss [380]. } \\
\text { (2) Nitrogen purging of the feed water } \\
\text { helped remove dissolved oxygen [379]. }\end{array}$ \\
\hline $\begin{array}{l}\text { I-CDI } \\
\text { Figure } 11 b\end{array}$ & $\begin{array}{l}\text { Positive charges are coated on the surface of } \\
\text { cathodes and negative charges are added to } \\
\text { the surface of anodes. }\end{array}$ & $\begin{array}{l}\text { Desorption occurs during } \\
\text { electrode charging, while } \\
\text { adsorption occurs during the } \\
\text { regeneration period. }\end{array}$ & $\begin{array}{l}\text { (1) Enhancing electrode } \\
\text { stability [351]. } \\
\text { (2) Extending cell operation } \\
\text { longevity by inhibiting anode } \\
\text { oxidation [351]. }\end{array}$ & $\begin{array}{l}\text { (1) Relatively low salt } \\
\text { removal capacity due to the } \\
\text { small working voltage [379]. }\end{array}$ & $\begin{array}{l}\text { (1) Amine-treated cathode helped } \\
\text { improve salt removal efficiency [353]. } \\
\text { (2) Inverted MCDI (I-MCDI) by } \\
\text { assembling IEMs into I-CDI possessed } \\
\text { higher energy efficiency than MCDI, } \\
\text { especially under low working } \\
\text { voltage [381]. }\end{array}$ \\
\hline $\begin{array}{l}\text { FCDI } \\
\text { Figure 11c }\end{array}$ & $\begin{array}{l}\text { The fixed electrodes are replaced by flowing } \\
\text { electrodes (usually activated carbon slurry). }\end{array}$ & $\begin{array}{l}\text { (1) Adsorption occurs in the } \\
\text { flow-electrode channel. } \\
\text { (2) Both the flow-electrode and } \\
\text { the electrolyte in the } \\
\text { flow-electrode channel serve as } \\
\text { the adsorption sites. }\end{array}$ & $\begin{array}{l}\text { (1) Overcoming the limited } \\
\text { desalination capacity [379]. } \\
\text { (2) Enabling (semi-)continuous } \\
\text { operation [382]. } \\
\text { (3) Allowing the desalination of } \\
\text { moderate to high concentration } \\
\text { brackish water [349]. }\end{array}$ & $\begin{array}{l}\text { (1) Poor conductivity in the } \\
\text { flow-electrode channel [383]. }\end{array}$ & $\begin{array}{l}\text { (1) High flow-electrode content [384], } \\
\text { conductive additives such as carbon } \\
\text { black [385], carbon nanotubes [386], } \\
\text { and plate-type graphite [387], and high } \\
\text { flow rate of flow-electrode in } \\
\text { flow-electrode channel [16] helped } \\
\text { promote cell conductivity. }\end{array}$ \\
\hline MCDI Architecture & Main changes in the cell architecture & $\begin{array}{l}\text { Characteristic desalination } \\
\text { mechanisms }\end{array}$ & Merits & Drawbacks & Recent advances \\
\hline $\begin{array}{l}\text { Desalination battery } \\
\text { Figure } 11 d\end{array}$ & $\begin{array}{l}\text { Capacitive electrodes are replaced by cation } \\
\text { intercalation electrodes (transition metal } \\
\text { compounds [388,389], Prussian Blue } \\
\text { Analogues (PBAs) [390], and redox-active } \\
\text { polymers [73]) and anion intercalation } \\
\text { electrodes ( } \mathrm{Ag} / \mathrm{AgCl}[389], \mathrm{Bi} / \mathrm{BiOCl} \text {, and } \\
\qquad \mathrm{MnO}_{2} \text { [391]). }\end{array}$ & \multirow{3}{*}{$\begin{array}{l}\text { (1) Faradaic adsorption in } \\
\text { addition to capacitive } \\
\text { adsorption occurs. } \\
\text { (2) In CID, one electrode adsorbs } \\
\text { cations via positive Faradaic } \\
\text { reactions, while the other } \\
\text { electrode rejects cations through } \\
\text { negative Faradaic reactions. } \\
\text { Anions penetrate the AEM and } \\
\text { move to the concentrate stream } \\
\text { to meet the enriched cations. }\end{array}$} & \multirow{3}{*}{$\begin{array}{l}\text { (1) Enhancing salt removal } \\
\text { capacity [391]. } \\
\text { (2) Increasing selectivity } \\
\text { towards specific ions [391]. } \\
\text { (3) Possessing competitive } \\
\text { energy consumption [379]. }\end{array}$} & \multirow{3}{*}{$\begin{array}{l}\text { (1) Reduced desalination } \\
\text { performance due to the low } \\
\text { electrical conductivity, } \\
\text { especially of anion } \\
\text { intercalation electrodes [379]. } \\
\text { (2) High capital cost [379]. }\end{array}$} & \multirow{3}{*}{$\begin{array}{l}\text { (1) Conductive additives aided } \\
\text { intercalation electrode in a CID cell } \\
\text { achieved a ten-fold improvement of salt } \\
\text { removal rate compared to conventional } \\
\text { CID [390]. } \\
\text { (2) Long-term cell stability and } \\
\text { remarkable adsorption capacity were } \\
\text { achieved in an intercalation-anode- } \\
\text { assisted I-CDI [392]. }\end{array}$} \\
\hline $\begin{array}{l}\text { HCDI } \\
\text { Figure 11e }\end{array}$ & $\begin{array}{l}\text { Capacitive cathode is replaced by cation } \\
\text { intercalation electrode, while anode is a } \\
\text { capacitive electrode with an AEM. }\end{array}$ & & & & \\
\hline $\begin{array}{l}\text { CID } \\
\text { Figure 11f }\end{array}$ & $\begin{array}{l}\text { Both capacitive electrodes are substituted } \\
\text { with cation intercalation electrodes and an } \\
\text { AEM is employed as a separator to } \\
\text { simultaneously generate desalinated and } \\
\text { concentrated streams. }\end{array}$ & & & & \\
\hline
\end{tabular}


Modifications of the cell structure and electrode materials, as well as the efforts to change configurations of $(\mathrm{M}) \mathrm{CDI}$, are aimed at decreasing energy consumption and increasing the adsorption capacity. These modifications can help make (M)CDI processes more competitive with $\mathrm{RO}$ in the desalination of low-salinity water.

\subsection{Energy Recovery in (M)CDI}

During the regeneration step, ions are repelled from the electrode by reversing the polarity or by the short-circuiting of electrodes. The energy stored in EDL during desalination can be partially recovered during regeneration. Direct energy recovery in $(\mathrm{M}) \mathrm{CDI}$ can be implemented via a buck-boost converter to transfer part of the stored energy which is released during regeneration to an inductor and later discharge it to a capacitor or another (M)CDI cell [393]. The amount of energy recovery in (M)CDI is affected by the operational mode, applied current and voltage, salinity of the feed water, salt removal capacity of the electrodes, and cell hydrodynamics [333,394-397]. The energy recovery ratio (the energy recovered over the energy consumed) of CC mode is higher than that of CV mode under the same discharging mode [394,395]. During regeneration, increasing the applied current or voltage negatively affects the energy recovery due to higher energy dissipation through cell internal resistance and the ohmic resistance of the external load [333,394]. Salt removal capacity has a positive impact on energy recovery since greater salt removal increases reversible electrical energy storage [395]. Higher salinity of the feed water and a thinner channel result in greater energy recovery due to the relatively low resistive energy loss under these conditions [396]. An energy recovery system has also been widely applied in various FCDI layouts. Ma et al., [398] recovered energy with a two-chamber device by applying reversed polarity on an isolated circulating flow-electrode and inserting an AEM to eliminate short-circuiting. Porada et al., [399] incorporated a pair of cylindrical IEMs into FCDI as pathways for the saturated flow-electrodes to continuously harvest energy based on the principles of capacitive mixing to generate energy from the salinity gradient and gas phase $\mathrm{CO}_{2}$ gradient. Energy recovery in FCDI could be promoted by increasing the electrolyte concentration, enhancing the content of the flow-electrode, and adding conductive additives [398,400].

\subsection{Main Challenges of $(M) C D I$}

Although $(\mathrm{M}) \mathrm{CDI}$ has been investigated for a wide range of applications, a series of challenges still exist. Limited electrode capacitance, high electrical resistance of the cell elements, fouling and scaling, and irreversible Faradaic reactions are among the key challenges that should be addressed to further advance the MCDI technology. Current efforts in these areas are discussed below.

\subsection{Approaches to Improve Electrode Performance}

Ion removal efficiency in $(\mathrm{M}) \mathrm{CDI}$ is influenced by electrode surface area, pore geometry, surface charge, and conductivity of the electrode, as well as by the imposed electric field [401]. The adsorption capacity of (M)CDI is mainly controlled by the physiochemical properties of the electrode materials and the applied voltage. Charge efficiency, which is defined as the ratio of ion adsorption at equilibrium to the applied charge [402], depends on the extent of co-ion repulsion and the occurrence of unexpected side reactions, e.g., oxygen reduction [403]. Charge efficiency is one of the key factors for evaluating electrode performance. Each imposed electronic charge is supposed to remove one salt ion from the solution. In reality, the applied charge is used to adsorb counterions as well as to reject co-ions [378]. Lower charge efficiency results in higher energy consumption. Grafting ion-selective functional groups onto electrodes [404,405] can reduce co-ion repulsion and increase charge efficiency. During desalination, IEMs in the MCDI cell prevent co-ions from being repelled out of the electrode, improving the charge efficiency in the process. Intercalation electrodes also help adsorb counterions more efficiently. In many cases, charge efficiency and adsorption performance can be improved in a similar manner. 
As mentioned above, the adsorption capacity of the electrodes and the ion removal efficiency in (M)CDI can be improved by tuning the pore geometry. A high specific electrode surface area is usually preferred to increase ion adsorption; however, it does not necessarily ensure better performance due to the potential for dead-end or poorly interconnected pores [406]. These unfavorable pore geometries hinder the diffusion of ions inside pores and thus reduce electro-sorption. Various parameters, e.g., precursor loading, calcination temperature, heating-cooling rate, and different synthesis routes are being used for tuning pore geometry [407]. The micro/mesopore ratio also plays an important role since micropores $(<2 \mathrm{~nm})$ ensure a large adsorption surface area while mesopores $(2-50 \mathrm{~nm})$ [408] facilitate quicker transport of salts to and from sorption sites [409]. The efficiency of both adsorption and desorption are important to overall performance. Chmiola et al., [410] showed increased volumetric capacitance for pore sizes smaller than the solvated radius (less than $1 \mathrm{~nm}$ ). The optimum pore size range for ion adsorption in EDL in CDI was reported as $0.8-2 \mathrm{~nm}$ [411]. However, this optimum pore size is still under debate. If the thickness of the EDL is similar to the pore width, the double layers formed on the pore walls overlap, which hinders ion adsorption inside the pores. Yang et al., [412] introduced the concept of a cut-off pore width $(0.6 \mathrm{~nm})$, below which there is no effective ion adsorption inside the pore. However, the thickness of EDL depends on the ionic concentration and applied voltage [413]. The overlapping effect is reduced at a higher imposed voltage and salt concentration, ultimately resulting in better adsorption for a small pore size [414]. In addition to pore size optimization, current research is focused on controlling pore structure by using various calcination environments, e.g., ammonia [415], developing hierarchical porous biomass-derived carbon materials [416-418], and using MOF-derived materials [419,420] and biomass-derived materials [416,421,422]. The high surface area and tunable pore size of MOFs can be utilized to prepare electrode materials. Large-scale production and mechanical stability of these MOF-derived materials under long-term cyclic operation should be further studied to advance their application in electrode materials.

Another approach to improve the ion adsorption capacity of electrodes is material doping, which helps rearrange charge distribution and adjust the electronic properties of the electrode. Doping can be done through using precursor materials containing the dopant molecules, adding an external element containing the dopants, or treating the material in an environment that introduces the dopants into it. While nitrogen doping of carbon materials is widely used [423,424], other atoms, e.g., phosphorus [425] and sulfur [426], can also improve conductivity and wettability by the formation of defects on carbon materials. The outermost shell electron configuration of phosphorus is similar to nitrogen, while its larger diameter enables the creation of more deformations in carbon atoms [425]. Larger atoms are capable of better improvement of electrical conductivity by imposing more polarization in the electric field and creating more charge positions [427]. Multiple atomic doping can promote synergistic effects, resulting in better conductivity and hydrophilicity that ultimately results in improved ion adsorption [426,428]. While multiple atomic doping results in improved conductivity, this technique often suffers from an increased dopant leaching effect. Synthesis processes need proper optimization to take advantage of multiple atomic doping. The improper distribution of dopant atom in the electrode material is another limitation which should be minimized.

High hydrophilicity of the electrode materials ensures complete wetting by the aqueous solution, further increasing the electro-sorption of ions and enhancing adsorption capacity. Introducing polar functional groups to the electrode materials significantly reduces the surface contact angle of the electrode, making it more hydrophilic [429]. Cheng et al., [430] recently reviewed various modification strategies including coating, heteroatom doping, and functionalizing the electrode surfaces to improve the specific capacitance, conductivity, and hydrophilicity of the CDI electrode. Several strategies including insertion of multiple wall CNTs [431], acid treatment [46,432], base treatment [433,434], oxygen plasma treatment [435], and heteroatom doping [427] to introduce surface functional groups [406] are reported to improve the hydrophilicity of the electrodes. Grafting sulfonic and amine 
functional groups into the electrode materials was reported to increase hydrophilicity as well as the selective adsorption of ions from saline water [436,437]. Although these strategies improve the hydrophilicity and ion adsorption capacity of electrode materials, their deficiency in non-charged pollutant removal puts limitations on the performance of (M)CDI processes and requires further investigation.

An alternative approach to overcome the finite adsorption capacity of carbon electrodes is utilizing intercalation electrodes with Faradaic reactions to capture ions from saline water [438]. Yu et al., [439] reviewed various types of intercalation electrodes with different deionization cell configurations and discussed material properties for such electrodes. The ion adsorption capacity of intercalation electrodes is much higher than EDL capacitance. In capacitive electrodes, the applied charge is partially used to repel co-ions from the electrode, which results in low charge efficiency. Electrodes involving Faradaic reactions might be asymmetric [440] to provide better oxidation and reduction function to capture cation and anions from saline water [441]. Intercalation electrodes [442,443] increase counter-ion adsorption and thus improve charge efficiency. Suitable crystal structure [444] and proper interlayer spacing [441] facilitate rapid diffusion of ions inside intercalation electrodes. Incorporating organic materials into intercalation electrodes $[73,442]$ helps leverage their properties, e.g., high specific capacity. A tremendous number of research studies are devoted toward the development of EDL-based conventional carbon electrode materials, as well as Faradaic electrodes. Carbon-based electrode-related research is focused on different strategies to improve ion adsorption capacity and charge efficiency, which will provide durable electrodes with appropriate porous structure. The theoretical molecular simulation studies on electro-sorption physics facilitate the research efforts on tailoring electrode material more effectively. Along with the need to develop better materials, proper characterization of the physicochemical properties of electrodes and the evaluation of their ion adsorption performance is essential. Faradaic electrodes show promising performance in regards to improving ion adsorption capacity, but still more research is required on other aspects of the (M)CDI processes, including the cell architecture, operational conditions, and economic analyses to further advance the industrial application.

\subsection{Approaches to Decrease Fouling and Scaling in (M)CDI}

The extent of fouling in CDI and MCDI is different due to the existence of IEMs in the latter. Fouling in CDI mainly occurs on electrodes and results in a reduction in electrode conductivity, electro-sorption capacitance, and cell stability. Organic foulants reduce cell performance by blocking electrode pores, competing with ions for adsorption sites, hindering ion diffusion to the electrodes, and accelerating intercalation electrode dissolution $[445,446]$. The observed scaling issues are less severe than fouling in (M)CDI studies, which may be a result of the relatively low hardness of brackish water used in $(\mathrm{M}) \mathrm{CDI}$. The alternating desalination and regeneration processes also help to reduce the accumulation of scale. Zhang et al., [447] showed that the effects of calcium and magnesium scale on the long-term performance of CDI cells were limited due to the sufficient desorption of these scale-forming ions from electrodes during regeneration. Silica stays neutral during CDI operation and does not contribute to scaling. Ferric ion intensifies electrode scaling due to the formation of iron hydroxide deposits on the surface of the electrode [445,448].

Electrode modification techniques are used to reduce the extent of fouling in $\mathrm{CDI}$. $\mathrm{TiO}_{2-}$ coupled electrode composites possess anti-fouling properties due to their photocatalytic ability, removing HA foulants [449]. Zwitterionic polymer molecules coated onto carbon electrodes mitigated fouling by improving hydrophilicity of the electrode surface and preventing organic foulants from reaching the electrode [450]. A dual-layer electrode constructed from attaching an ultrafiltration membrane onto carbon was able to keep the organic foulants from reaching the electrode and used an electro-catalytic oxidation reaction to remove the foulants from the solution [451]. Electrode modification for reducing fouling issues is an active research area. The observed stability of the modified electrode 
and the effectiveness of antifouling confirm the practicability for future industrialization. Future research should be conducted to evaluate the cost effectiveness and operational challenges of CDI with modified electrodes in large-scale.

To regenerate the fouled electrodes, hydraulic cleaning as well as acid and alkali cleaning are applied to remove foulants and scales from electrodes. An acidic solution (0.1 $\mathrm{M}$ hydrochloric acid) and an alkali solution ( $0.1 \mathrm{M}$ sodium hydroxide) are used to remove accumulated scale and foulants, respectively [448]. Although alkali cleaning could effectively remove most organic foulants, it could alter the electrode surface structure, accelerating Faradaic reactions, and lead to electrode corrosion for electrodes containing PVDF binder [446]. Pre-treatment steps would then still be necessary to lower dissolved organic compound content in feed water to sustain cell performance.

In MCDI, electrode fouling has been found to be less severe than that in CDI due to the presence of IEMs [446]. However, IEMs may still clog, resulting in an overall reduction in cell performance [452]. The period of desalination in MCDI should be kept sufficiently short to avoid penetration of the foulants through IEMs. Even though the scale formation in MCDI is negligible, minerals can increase the formation of organic fouling [452,453]. Surface modification of IEMs has been investigated as an antifouling approach for MCDI [284]. Fouling on IEMs can be removed by the reverse polarity during MCDI regeneration [446]. Mild alkali solution has been used to remove organic foulants from IEMs [284,452]. AEMs accumulate most of such foulants [446] but AEMs do not maintain their integrity in high $\mathrm{pH}$ alkali solutions. As a result, pre-treatment for the removal of dissolved organic compounds is suggested for the sustainable operation of MCDI.

\subsection{Approaches to Minimize the Irreversible Faradaic Reactions}

Redox (Faradaic) reactions may occur inside electrodes with a relatively high working voltage. Three types of Faradaic reactions exist, including anodic oxidation, cathodic reduction, and Faradaic ion adsorption via intercalation electrodes (Figure 12) [454].

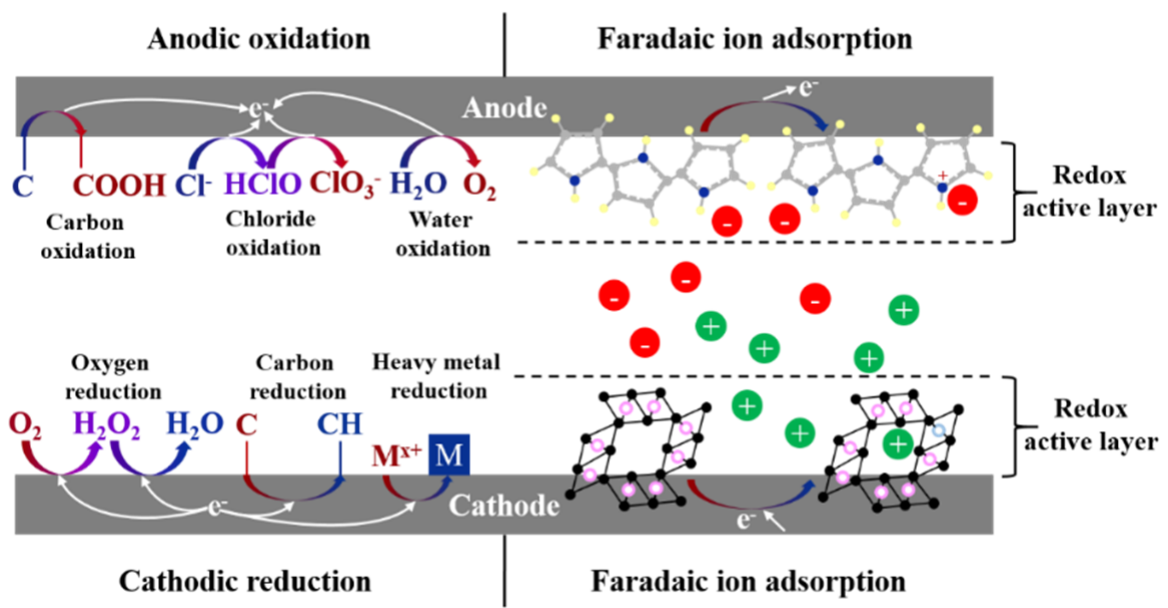

Figure 12. Schematic of Faradaic reactions in CDI, including anodic oxidation, cathodic reduction, and Faradaic ion adsorption via intercalation electrodes.

Anodic reactions mainly include the oxidation of the carbon electrode, which leads to aldehyde and alcohol group formation on the electrode and ultimately conversion to carbon dioxide; oxidation of chloride to chlorine, hypochlorous acid, and chlorate; and the dissociation of water into oxygen, protons, and hydroxy radicals.

Cathodic reactions mainly include the reduction of oxygen to hydrogen peroxide, and ultimately, water; reduction of heavy metals, if present, to a precipitating form; and the reaction of the carbon electrode with water to form carbon-hydrogen bonds on the electrode surface. 
In contrast to the positive effects of reversible Faradaic reactions on intercalation electrodes, the above reactions lead to structure degradation, reduction in long-term stability of the electrode, reduction in energy efficiency, and fluctuations in water quality. Parasitic energy losses (due to irreversible Faradaic reactions) are a significant factor in reducing the efficiency of CDI [455] and should be minimized.

Electrode modification helps suppress irreversible Faradaic reactions. Choi and Choi [456] coated PVDF onto AC powders and bonded them to serve as a CDI electrode. They discovered that elevated PVDF content deactivated the redox functional groups and inhibited Faradaic reactions. A few electrode-polymer composites $[457,458]$ and titaniaassisted carbon composites [409,459] have also shown the capability for inhibiting Faradaic reactions. However, the amount of attached titania on the electrode surface should be controlled within a certain range to not reduce capacitance by blocking electrode pores [460]. Furthermore, stability of those titania-functionalized electrodes should be improved to lower the material cost.

Faradaic reactions can also be reduced by adjusting the CDI operational parameters. The optimal applied voltage to avoid trigging Faradaic reactions was found to be $0.8 \mathrm{~V}$ in studies under CV mode [372]. Controlling the total applied charge during desalination reduced the Faradaic reactions [461]. CC mode decreased the period of cell operation at a relatively high voltage, thus reducing Faradaic reactions [454]. However, the performance of CC mode depends on the imposed current density. Operation at a low applied current could potentially result in a longer desalination period. Hence, the cell voltage rises slowly, leading to a relatively long operation at high voltage and increased parasitic energy losses [462]. Periodic reversal of polarity also mitigated Faradaic reactions at the expense of incomplete electrode regeneration due to the adsorption of co-ions during regeneration in CDI [454]. By inserting IEM to form MCDI, this co-ion penetration can be largely reduced. The applied voltage during regeneration can be kept low to limit the extra energy consumption.

Alternative CDI architectures help mitigate Faradaic reactions. Attaching CEM onto the cathode helps prevent oxygen from reaching the electrode surface, thus mitigating Faradaic reactions [454]. Removing AEM in MCDI could eliminate oxidative degradation associated with AEM [463]. MCDI with thin IEMs containing high fixed charges could be operated under a relatively low voltage which minimizes the Faradaic reactions without sacrificing the salt removal capacity [464]. In FCDI, pH fluctuation in the flow-electrode channel was negligible if the flow-electrode regeneration was conducted outside the cell, inhibiting the Faradaic reactions [454]. In I-CDI, the functional groups formed in Faradaic reactions served as new adsorption sites and contributed to ion storage capability [454]. Flow-through CDI altered the degree of Faradaic reactions positively toward producing hydrogen peroxide, enabling the potential application of the process for water disinfection and contaminant degradation in bio-wastewater treatment [465].

\subsection{Status of (M)CDI for Brackish Water Desalination}

(M)CDI has been mainly studied at lab-scale, with few efforts reporting large-scale applications and pilot studies [466]. The lab studies suggest, however, that CDI is energyefficient for the desalination of low-salinity brackish water (salinity below $3000 \mathrm{mg} / \mathrm{L}$ ) [467] and MCDI even consumes less energy compared to CDI under the same operational conditions [468]. Such results suggest that (M)CDI can be a competitive technology for the desalination of low-salinity brackish water. However, a number of studies demonstrated higher energy consumption for $(\mathrm{M}) \mathrm{CDI}$ compared to ED and RO when treating brackish water under the same desalination conditions $[9,469,470]$. A more recent theoretical investigation showed that MCDI can be efficient using the intermittent flow mode with high water recovery [471]. MCDI was able to outperform $\mathrm{RO}$ when water recovery was set to $95 \%$, although at this high water recovery, problems from fouling and scaling are more likely. 


\section{Brackish Water Desalination: Which Technology to Choose?}

The composition of brackish water varies widely, as do the quality requirements of various applications. The optimal use of brackish water desalination technologies requires definition of both the feed quality and the application quality requirements, and determination of the appropriate niches for each of the technologies. The standards for potable water quality are to some extent location-dependent, with some regions allowing for higher salinities (500-1000 mg/L) and some determining more strict regulations (250 mg/L). Greater flexibility in treatment requirements can be achieved through blending highersalinity waters with low-salinity waters to meet final water quality goals. The water quality required for industrial applications is heavily dependent upon the process and varies even more. Boilers generally require ultra-pure water, while the water used for hydraulic fracturing in oil and gas development can employ exceedingly high levels of non-precipitating salts as long as there are minimal scale-producing constituents. In desalination for irrigation purposes, both the tolerance of the crops to the salinity and maintaining soil quality (avoiding soil salinization) define desalination requirements [472,473]. The quantity of the treated water required and the availability of concentrate disposal appropriate for those quantities also affect technology selection. Desalination technologies that are efficient for producing potable water for large municipalities may not be economical for small communities and non-centralized treatment. In addition, energy availability and cost and energy efficiency are critically important for large facilities but may be minimally important for small systems such as the desalination of only drinking or cooking waters in a distributed system (e.g., individual home treatment systems). All the technologies reviewed have specific strengths and limitations, and there is no single technique that can be counted as the ultimate solution without consideration of the quantity and quality of both the available waters and the required applications. Table 3 provides a comparison of the main advantages and limitations of the reviewed processes. Thus, to develop the most efficient fit-for-purpose treatment, the desalination process should be selected according to the feed water composition and desalination objectives.

$\mathrm{RO}$ is a mature, widely-used technology suitable for the large-scale treatment of brackish water with high salinity (above $5000 \mathrm{mg} / \mathrm{L}$ ) and seawater. In RO, energy is consumed to transport water from the concentrate to the permeate side, while in ED and (M)CDI, ions are removed from the water to achieve desalinated streams. As a result, the energy efficiency of ED and (M)CDI improves for low-salinity feed waters which require less desalination. At low salinity ranges and high water recovery, ED becomes more energyefficient than RO [335]. The efficiency of ERDs in RO decreases under such conditions, further reducing the energy-efficiency of RO. Even though $\mathrm{RO}$ has dominated the existing desalination processes, the abovementioned limitations suggest that ED, (M)CDI, and NF may have advantages for the treatment of water with lower salinity, desalination for small communities, and selective ion removal.

As noted previously, the lower operational pressure of NF compared to RO makes it a relatively energy-efficient technique for the total desalination of low-salinity waters or the partial treatment of high-salinity waters. The ability to selectively remove multivalent ions suggests that NF is a superior option for the desalination of brackish water with low to moderate salinity that is dominated by such ions [216,217]. For brackish groundwater with moderate salinity (TDS below $6000 \mathrm{mg} / \mathrm{L}$ ), NF is an effective techno-economical approach to produce potable water with reasonable salinity $(800 \mathrm{mg} / \mathrm{L})$ at a higher permeate flux compared to RO [14]. NF is commonly used for water and wastewater treatment, heavy metal removal, arsenic removal from contaminated groundwater, hard brackish water softening, dye and salt removal from industrial wastewater, and partial desalination [474]. 
Table 3. Comparison of the desalination processes for brackish water treatment.

\begin{tabular}{|c|c|c|}
\hline Desalination Technique & Advantages & Limitations \\
\hline $\mathrm{RO}$ & 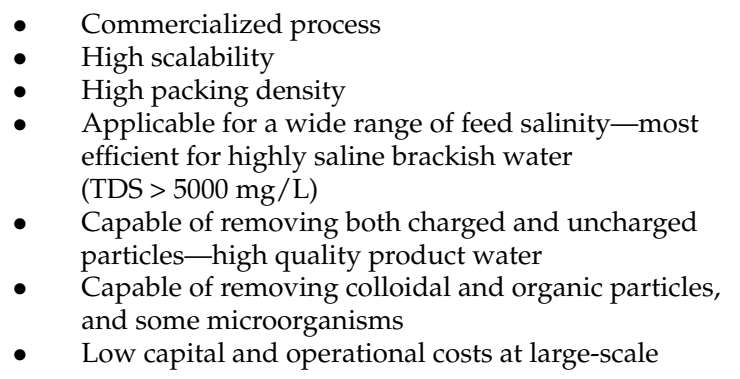 & $\begin{array}{l}\text { - } \quad \text { High-pressure operation } \\
\text { Sensitivity of the membrane to chlorine and } \\
\text { high temperature } \\
\text { - } \quad \text { More required pre-treatment } \\
\text { low-salinity feed water } \\
\text { - Low water recovery at small-scale and } \\
\text { low-salinity feed water }\end{array}$ \\
\hline NF & $\begin{array}{ll}- & \text { Commercialized process } \\
\text { - } & \text { High scalability } \\
\text { - } & \text { High packing density } \\
\text { - } & \text { Low operational pressure relative to RO } \\
\text { - } & \text { Low energy consumption and high permeation } \\
& \text { relative to RO } \\
\text { - } \quad \text { Energy-efficient for treating moderate-salinity } \\
\text { brackish water (TDS }<6000 \mathrm{mg} / \mathrm{L}) \\
\text { - } \quad \text { Capable of selective removal of multivalent } \\
\text { ions-suitable for water softening } \\
\text { - } \quad \text { Cuitable for partial desalination } \\
\text { - } \quad \text { Low capital and operational costs }\end{array}$ & $\begin{array}{l}\text { - High operational pressure relative to ED } \\
\text { and MCDI } \\
\text { - } \quad \text { Unable to fully remove monovalent ions } \\
\text { Low ion removal efficiency for high-salinity } \\
\text { brackish water } \\
\text { - Post-treatment required }\end{array}$ \\
\hline ED & 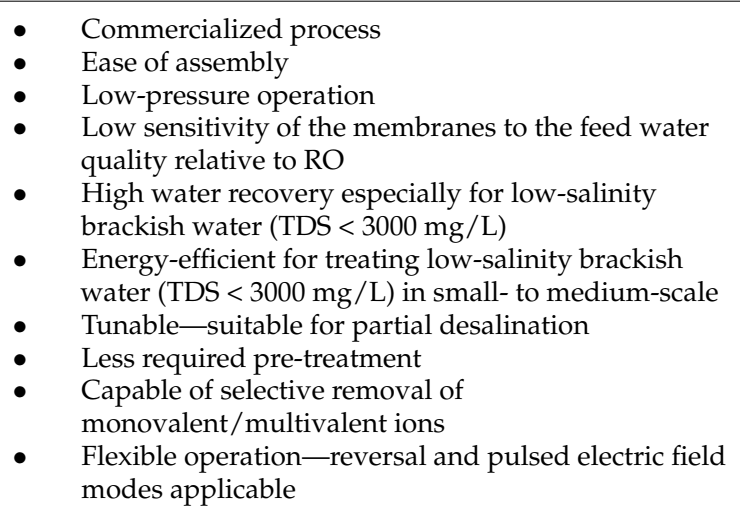 & $\begin{array}{l}\text { - Low packing density } \\
\text { - } \quad \text { High cost of ion exchange membranes } \\
\text { - } \quad \text { Restricted to operation below limiting } \\
\text { conditions-increased water dissociation, energy } \\
\text { inefficiency, and fouling and scaling once the } \\
\text { current exceeds the limiting value } \\
\text { - Unable to remove contaminants other than } \\
\text { charged species-more required post-treatment } \\
\text { - Relatively high capital costs compared to RO }\end{array}$ \\
\hline (M)CDI & 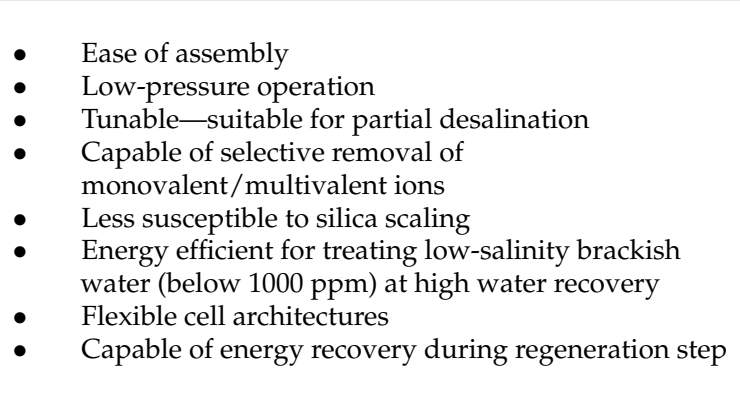 & $\begin{array}{l}\text { - } \quad \text { Mainly explored in the lab-limited } \\
\text { industrial applications } \\
\text { - } \quad \text { Low packing density } \\
\text { - } \quad \text { Poor scalability-most limited to lab-scale and a } \\
\text { few pilot-scale applications } \\
\text { - } \quad \text { Relatively high cost of the IEM } \\
\text { Unable to remove contaminants other than } \\
\text { charged species-more required post-treatment } \\
\text { Energy intensive for desalination of high-salinity } \\
\text { brackish water at high flow rates } \\
\text { - Significant parasitic losses from Faradaic } \\
\text { reactions under relatively high applied voltage }\end{array}$ \\
\hline
\end{tabular}

ED is the leading electro-membrane technique, with cost-effective operation for the desalination of brackish water with salinity between 1000 and 10,000 mg/L [264]. At water recovery above $80 \%$, the energy requirements of $\mathrm{ED}$ is lower than continuous $\mathrm{RO}$ and semi-batch RO [335]. Such high water recovery and low SEC make ED a superior option for the desalination of brackish water with moderate salinity (below $3000 \mathrm{mg} / \mathrm{L}$ ). The low-pressure operation and less required pre-treatment (due to the lower sensitivity of IEMs compared to RO membranes) are among the main advantages of ED over RO. ED is tunable and thus can also be used for partial desalination to reach the required water quality for non-potable water applications. ED can be applied for the selective removal 
of both monovalent and multivalent ions [475]. Modification of IEMs, electrodes, spacers, cell architecture, unit design, and operational conditions not only have enhanced the performance of ED for brackish water desalination [476-479] but have also introduced new applications for ED and ED-based processes. A number of such applications include boiler feed water production [480], recovery of valuable metals such as lithium [481,482], selective removal of contaminants [483-485], RO concentrate management [486], industrial wastewater treatment $[487,488]$, desalination for agricultural uses [489], zero-liquid discharge desalination [121], ion recovery [490], in-home water treatment with higher water recovery compared to RO [491], acid and base generation [492], nutrient recovery [493,494], and organic acid production [495].

(M)CDI performance has been largely assessed in laboratory studies, but they suggest that the technology can be competitive for the desalination of low-salinity brackish water [496,497]. In addition, (M)CDI typically exhibits a lower capital cost compared to $\mathrm{RO}$ [498] and is less susceptible to silica scaling, which can reduce maintenance costs. As noted previously, however, (M)CDI has exhibited higher energy consumption compared to ED and RO when treating brackish water under the same desalination conditions $[9,469,470]$. Recent studies have shown some potential for improved energy performance at very high water recoveries (95\%) [471]. Alternative applications for which (M)CDI may be more efficient include the removal of trace elements from RO permeate compared to second stage RO [499]. In addition, for the desalination of low-salinity feed water (below $1000 \mathrm{ppm}$ ) with high water recovery, the thermodynamic energy efficiency (TEE) of RO is relatively low (11-15\%), and close to that of (M)CDI with capacitive electrodes [500]. The improvement of process design and electrode material and the implementation of ERDs further reduce energy consumption and make (M)CDI more competitive with RO and ED [349,391,467,501]. (M)CDI with intercalation electrodes can reach a TEE as high as $40 \%$ when treating low-salinity water (below $1000 \mathrm{mg} / \mathrm{L}$ ) [500]. Various cell architectures can be advanced, e.g., FCDI with two pairs of stacked IEMs [502], aiming at cell scaling up to improve desalination capacity and productivity.

Similar to ED, (M)CDI is tunable and selective and thus can be employed for partial desalination. Lab studies indicate that $(\mathrm{M}) \mathrm{CDI}$ can be used for ultra-pure water production [496], selective removal of scale-forming ions (such as calcium and magnesium ions) for water softening [503], heavy metal removal [496,497], selective removal of nutrients (phosphate and nitrate) [496], water treatment for irrigation [504], water disinfection [497], and the removal of organic compounds through a combination of capacitive and Faradaic adsorption [497] or photocatalytic reactions [505]. FCDI has extensive applications, including water softening [506], ammonia recovery [385,507], nutrient species (phosphate and nitrate) recovery [508,509], heavy metal recovery (copper [510]), lithium extraction [511], divalent and monovalent ion separation [512], and uranium-polluted groundwater treatment [513]. In addition, (M)CDI and ED can be superior alternatives to RO for home-scale potable water desalination, due to the reduced importance of energy efficiency for small production volumes and potentially decreased maintenance costs.

The direct comparison of desalination processes is challenging due to their different levels of readiness and maturity. RO, ED, and NF have been commercialized while (M)CDI is mostly in the research and development stage. With the growing attention of the research community toward the development of novel membranes, electrodes, and operational conditions, it is expected that the application of ED, NF, and (M)CDI will become increasingly competitive for brackish water desalination.

\section{Conclusions}

A variety of technologies are available to provide freshwater from inland brackish waters. The most appropriate technologies are those that can take advantage of the relatively low salinity of brackish waters and can generate water at high recovery rates to minimize concentrate production. Due to generally low energy requirements, membrane desalination processes have been extensively explored for brackish water treatment. Over 
the past few decades, optimization of the process design and operation, development of novel membranes and electrodes, and the implementation of ERDs have reduced the cost of desalination and made these technologies more feasible. However, membrane performance, fouling and scaling, and concentrate management remain challenges that limit brackish water desalination. In this article, we reviewed the key challenges associated with the membrane processes used for brackish water treatment, and recent research and development efforts to improve those technologies.

Due to the diverse characteristics of brackish water and differences in purification goals, a fit-for-purpose treatment approach considering both the volume and quality of the feed and the requirements of the product water should be considered in selecting the appropriate desalination technique. Technologies that can adapt efficiently to specific purposes and can be tuned to achieve partial desalination for those purposes, such as ED and (M)CDI, have inherent advantages in such applications over the less flexible $\mathrm{RO}$ processes, but all processes can be adapted and operated in a manner to achieve appropriate levels of desalination for any desired purpose. The discussion provided insight into the advantages and limitations of these processes that can assist in making appropriate technology choices for any particular desalination application.

Author Contributions: Conceptualization, S.H. and D.R.; investigation, S.H., X.Z., T.C., K.A., A.A.; writing-original draft preparation, S.H., X.Z., T.C., K.A., A.A.; writing—review and editing, S.H. and D.R.; supervision, D.R. All authors have read and agreed to the published version of the manuscript.

Funding: The authors gratefully acknowledge the financial support of the Maddox Foundation and the Donovan Maddox Distinguished Engineering Chair Endowment.

Institutional Review Board Statement: Not applicable.

Informed Consent Statement: Not applicable.

Data Availability Statement: Not applicable.

Conflicts of Interest: The authors declare no conflict of interest.

\section{References}

1. Liu, L.; Hejazi, M.; Patel, P.; Kyle, P.; Davies, E.; Zhou, Y.; Clarke, L.; Edmonds, J. Water demands for electricity generation in the US: Modeling different scenarios for the water-energy nexus. Technol. Forecast. Soc. Chang. 2015, 94, 318-334. [CrossRef]

2. Feeley, T.J., III; Skone, T.J.; Stiegel, G.J., Jr.; McNemar, A.; Nemeth, M.; Schimmoller, B.; Murphy, J.T.; Manfredo, L. Water: A critical resource in the thermoelectric power industry. Energy 2008, 33, 1-11. [CrossRef]

3. Kondash, A.J.; Lauer, N.E.; Vengosh, A. The intensification of the water footprint of hydraulic fracturing. Sci. Adv. 2018, 4, eaar5982. [CrossRef] [PubMed]

4. Stanton, J.S.; Anning, D.W.; Brown, C.J.; Moore, R.B.; McGuire, V.L.; Qi, S.L.; Harris, A.C.; Dennehy, K.F.; McMahon, P.B.; Degnan, J.R. Brackish Groundwater in the United States; 2330-7102; US Geological Survey: Reston, VA, USA, 2017.

5. Honarparvar, S.; Saravi, S.H.; Reible, D.; Chen, C.-C. Comprehensive thermodynamic modeling of saline water with electrolyte NRTL model: A study of aqueous $\mathrm{Sr}^{2+}-\mathrm{Na}^{+}-\mathrm{Cl}^{-}-\mathrm{SO}_{4}{ }^{2-}$ quaternary system. Fluid Phase Equilibria 2018, 470, 221-231. [CrossRef]

6. Honarparvar, S.; Saravi, S.H.; Reible, D.; Chen, C.-C. Comprehensive thermodynamic modeling of saline water with electrolyte NRTL model: A study on aqueous $\mathrm{Ba}^{2+}-\mathrm{Na}^{+}-\mathrm{Cl}^{-}-\mathrm{SO}_{4}{ }^{2-}$ quaternary system. Fluid Phase Equilibria 2017, 447, 29-38. [CrossRef]

7. Jones, E.; Qadir, M.; van Vliet, M.T.H.; Smakhtin, V.; Kang, S.M. The state of desalination and brine production: A global outlook. Sci. Total Environ. 2019, 657, 1343-1356. [CrossRef] [PubMed]

8. Greenlee, L.F.; Lawler, D.F.; Freeman, B.D.; Marrot, B.; Moulin, P. Reverse osmosis desalination: Water sources, technology, and today's challenges. Water Res. 2009, 43, 2317-2348. [CrossRef]

9. Patel, S.K.; Qin, M.; Walker, W.S.; Elimelech, M. Energy efficiency of electro-driven brackish water desalination: Electrodialysis significantly outperforms membrane capacitive deionization. Environ. Sci. Technol. 2020, 54, 3663-3677. [CrossRef]

10. Nagy, E. Basic Equations of Mass Transport Through a Membrane Layer; Elsevier: Amsterdam, The Netherlands, 2018.

11. Qiu, T.; Davies, P.A. Comparison of configurations for high-recovery inland desalination systems. Water 2012, 4, 690-706. [CrossRef]

12. Drak, A.; Adato, M. Energy recovery consideration in brackish water desalination. Desalination 2014, 339, 34-39. [CrossRef]

13. Yacubowicz, H.; Yacubowicz, J. Nanofiltration: Properties and uses. Filtr. Sep. 2005, 42, 16-21. [CrossRef]

14. Dach, H. Comparison of Nanofiltration and Reverse Osmosis Processes for a Selective Desalination of Brackish Water Feeds. Ph.D. Thesis, Université d'Angers, Angers, France, 2008. 
15. Sim, L.N.; Chong, T.H.; Taheri, A.H.; Sim, S.T.V.; Lai, L.; Krantz, W.B.; Fane, A.G. A review of fouling indices and monitoring techniques for reverse osmosis. Desalination 2018, 434, 169-188. [CrossRef]

16. Rommerskirchen, A.; Ohs, B.; Hepp, K.A.; Femmer, R.; Wessling, M. Modeling continuous flow-electrode capacitive deionization processes with ion-exchange membranes. J. Membr. Sci. 2018, 546, 188-196. [CrossRef]

17. Yang, Z.; Zhou, Y.; Feng, Z.; Rui, X.; Zhang, T.; Zhang, Z. A Review on Reverse Osmosis and Nanofiltration Membranes for Water Purification. Polymers 2019, 11, 1252. [CrossRef]

18. Lee, K.P.; Arnot, T.C.; Mattia, D. A review of reverse osmosis membrane materials for desalination-Development to date and future potential. J. Membr. Sci. 2011, 370,1-22. [CrossRef]

19. Macedonio, F.; Drioli, E. 4.09-Membrane Systems for Seawater and Brackish Water Desalination. In Comprehensive Membrane Science and Engineering; Drioli, E., Giorno, L., Eds.; Elsevier: Oxford, UK, 2010; pp. 241-257.

20. Jeong, B.-H.; Hoek, E.M.V.; Yan, Y.; Subramani, A.; Huang, X.; Hurwitz, G.; Ghosh, A.K.; Jawor, A. Interfacial polymerization of thin film nanocomposites: A new concept for reverse osmosis membranes. J. Membr. Sci. 2007, 294, 1-7. [CrossRef]

21. Lau, W.J.; Gray, S.; Matsuura, T.; Emadzadeh, D.; Chen, J.P.; Ismail, A.F. A review on polyamide thin film nanocomposite (TFN) membranes: History, applications, challenges and approaches. Water Res. 2015, 80, 306-324. [CrossRef]

22. Popper, K.; Merson, R.L.; Camirand, W.M. Desalination by Osmosis-Reverse Osmosis Couple. Science 1968, 159, 1364-1365. [CrossRef]

23. Loeb, S.; Norman, R.S. Osmotic power plants. Science 1975, 189, 654-655. [CrossRef]

24. Lee, K.L.; Baker, R.W.; Lonsdale, H.K. Membranes for power generation by pressure-retarded osmosis. J. Membr. Sci. 1981, 8, 141-171. [CrossRef]

25. Klaysom, C.; Cath, T.Y.; Depuydt, T.; Vankelecom, I.F. Forward and pressure retarded osmosis: Potential solutions for global challenges in energy and water supply. Chem. Soc. Rev. 2013, 42, 6959-6989. [CrossRef]

26. Thompson, N.A.; Nicoll, P.G. Forward osmosis desalination: A commercial reality. In Proceedings of the IDA World CongressPerth Convention and Exhibition Centre (PCEC), Perth, Australia, 4-9 September 2011.

27. Achilli, A.; Childress, A.E. Pressure retarded osmosis: From the vision of Sidney Loeb to the first prototype installation-Review. Desalination 2010, 261, 205-211. [CrossRef]

28. Bear, J. Dynamics of Fluids in Porous Media; Courier Corporation: Chelmsford, MA, USA, 2013.

29. Chun, Y.; Zaviska, F.; Kim, S.-J.; Mulcahy, D.; Yang, E.; Kim, I.S.; Zou, L. Fouling characteristics and their implications on cleaning of a FO-RO pilot process for treating brackish surface water. Desalination 2016, 394, 91-100. [CrossRef]

30. Kim, J.E.; Phuntsho, S.; Lotfi, F.; Shon, H.K. Investigation of pilot-scale 8040 FO membrane module under different operating conditions for brackish water desalination. Desalination Water Treat. 2014, 53, 2782-2791. [CrossRef]

31. Yang, Z.; Ma, X.-H.; Tang, C.Y. Recent development of novel membranes for desalination. Desalination 2018, 434, 37-59. [CrossRef]

32. Liaw, D.-J.; Wang, K.-L.; Huang, Y.-C.; Lee, K.-R.; Lai, J.-Y.; Ha, C.-S. Advanced polyimide materials: Syntheses, physical properties and applications. Prog. Polym. Sci. 2012, 37, 907-974. [CrossRef]

33. Fujioka, T.; Khan, S.J.; McDonald, J.A.; Nghiem, L.D. Rejection of trace organic chemicals by a hollow fibre cellulose triacetate reverse osmosis membrane. Desalination 2015, 368, 69-75. [CrossRef]

34. Khan, M.T.; Hong, P.Y.; Nada, N.; Croue, J.P. Does chlorination of seawater reverse osmosis membranes control biofouling? Water Res. 2015, 78, 84-97. [CrossRef] [PubMed]

35. Baker, R.W. Membrane Technology and Applications; John Wiley \& Sons: Hoboken, NJ, USA, 2012.

36. Gohil, J.M.; Ray, P. A review on semi-aromatic polyamide TFC membranes prepared by interfacial polymerization: Potential for water treatment and desalination. Sep. Purif. Technol. 2017, 181, 159-182. [CrossRef]

37. Davies, P.A.; Wayman, J.; Alatta, C.; Nguyen, K.; Orfi, J. A desalination system with efficiency approaching the theoretical limits. Desalination Water Treat. 2016, 57, 23206-23216. [CrossRef]

38. Cohen, Y.; Semiat, R.; Rahardianto, A. A perspective on reverse osmosis water desalination: Quest for sustainability. AIChE J. 2017, 63, 1771-1784. [CrossRef]

39. Efraty, A. Closed circuit desalination series no-3: High recovery low energy desalination of brackish water by a new two-mode consecutive sequential method. Desalination Water Treat. 2012, 42, 256-261. [CrossRef]

40. Warsinger, D.M.; Tow, E.W.; Nayar, K.G.; Maswadeh, L.A.; Lienhard, V.J. Energy efficiency of batch and semi-batch (CCRO) reverse osmosis desalination. Water Res. 2016, 106, 272-282. [CrossRef] [PubMed]

41. Werber, J.R.; Deshmukh, A.; Elimelech, M. Can batch or semi-batch processes save energy in reverse-osmosis desalination? Desalination 2017, 402, 109-122. [CrossRef]

42. Swaminathan, J.; Tow, E.W.; Stover, R.L.; Lienhard, J.H. Practical aspects of batch RO design for energy-efficient seawater desalination. Desalination 2019, 470. [CrossRef]

43. Lin, S.; Elimelech, M. Kinetics and energetics trade-off in reverse osmosis desalination with different configurations. Desalination 2017, 401, 42-52. [CrossRef]

44. Lee, T.; Rahardianto, A.; Cohen, Y. Multi-cycle operation of semi-batch reverse osmosis (SBRO) desalination. J. Membr. Sci. 2019, 588. [CrossRef]

45. Cohen, Y.; Rahardianto, A.; Lee, T.K. Autonomous Low Energy Consumption Cyclic Desalination Systems; Bureau of Reclamation: Denver, CO, USA, 2017. 
46. Parra, A.; Noriega, M.; Yokohama, L.; Bagajewicz, M. Reverse osmosis network rigorous design optimization. Ind. Eng. Chem. Res. 2019, 58, 3060-3071. [CrossRef]

47. Fritzmann, C.; Löwenberg, J.; Wintgens, T.; Melin, T. State-of-the-art of reverse osmosis desalination. Desalination 2007, 216, 1-76. [CrossRef]

48. Park, H.B.; Kamcev, J.; Robeson, L.M.; Elimelech, M.; Freeman, B.D. Maximizing the right stuff: The trade-off between membrane permeability and selectivity. Science 2017, 356. [CrossRef] [PubMed]

49. Yang, Z.; Guo, H.; Tang, C.Y. The upper bound of thin-film composite (TFC) polyamide membranes for desalination. J. Membr. Sci. 2019, 590. [CrossRef]

50. Zhang, R.; Liu, Y.; He, M.; Su, Y.; Zhao, X.; Elimelech, M.; Jiang, Z. Antifouling membranes for sustainable water purification: Strategies and mechanisms. Chem. Soc. Rev. 2016, 45, 5888-5924. [CrossRef]

51. Verbeke, R.; Gómez, V.; Vankelecom, I.F.J. Chlorine-resistance of reverse osmosis (RO) polyamide membranes. Prog. Polym. Sci. 2017, 72, 1-15. [CrossRef]

52. Gohil, J.M.; Suresh, A.K. Chlorine attack on reverse osmosis membranes: Mechanisms and mitigation strategies. J. Membr. Sci. 2017, 541, 108-126. [CrossRef]

53. Miller, D.J.; Dreyer, D.R.; Bielawski, C.W.; Paul, D.R.; Freeman, B.D. Surface Modification of Water Purification Membranes. Angew. Chem. Int. Ed. Engl. 2017, 56, 4662-4711. [CrossRef] [PubMed]

54. Asempour, F.; Emadzadeh, D.; Matsuura, T.; Kruczek, B. Synthesis and characterization of novel Cellulose Nanocrystals-based Thin Film Nanocomposite membranes for reverse osmosis applications. Desalination 2018, 439, 179-187. [CrossRef]

55. Zhao, Y.; Qiu, C.; Li, X.; Vararattanavech, A.; Shen, W.; Torres, J.; Hélix-Nielsen, C.; Wang, R.; Hu, X.; Fane, A.G.; et al. Synthesis of robust and high-performance aquaporin-based biomimetic membranes by interfacial polymerization-membrane preparation and RO performance characterization. J. Membr. Sci. 2012, 423-424, 422-428. [CrossRef]

56. Kadhom, M.; Deng, B. Thin film nanocomposite membranes filled with bentonite nanoparticles for brackish water desalination: A novel water uptake concept. Microporous Mesoporous Mater. 2019, 279, 82-91. [CrossRef]

57. Huang, X.; Marsh, K.L.; McVerry, B.T.; Hoek, E.M.; Kaner, R.B. Low-Fouling Antibacterial Reverse Osmosis Membranes via Surface Grafting of Graphene Oxide. ACS Appl. Mater. Interfaces 2016, 8, 14334-14338. [CrossRef]

58. Choi, W.; Choi, J.; Bang, J.; Lee, J.H. Layer-by-layer assembly of graphene oxide nanosheets on polyamide membranes for durable reverse-osmosis applications. ACS Appl. Mater. Interfaces 2013, 5, 12510-12519. [CrossRef]

59. Takizawa, Y.; Inukai, S.; Araki, T.; Cruz-Silva, R.; Uemura, N.; Morelos-Gomez, A.; Ortiz-Medina, J.; Tejima, S.; Takeuchi, K.; Kawaguchi, T.; et al. Antiorganic Fouling and Low-Protein Adhesion on Reverse-Osmosis Membranes Made of Carbon Nanotubes and Polyamide Nanocomposite. ACS Appl. Mater. Interfaces 2017, 9, 32192-32201. [CrossRef]

60. Fathizadeh, M.; Tien, H.N.; Khivantsev, K.; Song, Z.; Zhou, F.; Yu, M. Polyamide/nitrogen-doped graphene oxide quantum dots (N-GOQD) thin film nanocomposite reverse osmosis membranes for high flux desalination. Desalination 2019, 451, 125-132. [CrossRef]

61. Lind, M.L.; Eumine Suk, D.; Nguyen, T.V.; Hoek, E.M. Tailoring the structure of thin film nanocomposite membranes to achieve seawater RO membrane performance. Envioron. Sci. Technol. 2010, 44, 8230-8235. [CrossRef]

62. Mansor, E.S.; Jamil, T.S.; Abdallah, H.; Shaban, A.M. Highly thin film nanocomposite membrane based metal organic complexes for brackish water desalination. J. Environ. Chem. Eng. 2018, 6, 5459-5469. [CrossRef]

63. Ben-Sasson, M.; Zodrow, K.R.; Genggeng, Q.; Kang, Y.; Giannelis, E.P.; Elimelech, M. Surface functionalization of thin-film composite membranes with copper nanoparticles for antimicrobial surface properties. Envioron. Sci. Technol. 2014, 48, 384-393. [CrossRef] [PubMed]

64. Yin, J.; Yang, Y.; Hu, Z.; Deng, B. Attachment of silver nanoparticles (AgNPs) onto thin-film composite (TFC) membranes through covalent bonding to reduce membrane biofouling. J. Membr. Sci. 2013, 441, 73-82. [CrossRef]

65. Jadav, G.L.; Singh, P.S. Synthesis of novel silica-polyamide nanocomposite membrane with enhanced properties. J. Membr. Sci. 2009, 328, 257-267. [CrossRef]

66. Kong, C.; koushima, A.; Kamada, T.; Shintani, T.; Kanezashi, M.; Yoshioka, T.; Tsuru, T. Enhanced performance of inorganicpolyamide nanocomposite membranes prepared by metal-alkoxide-assisted interfacial polymerization. J. Membr. Sci. 2011, 366, 382-388. [CrossRef]

67. Baek, Y.; Freeman, B.D.; Zydney, A.L.; Yoon, J. A facile surface modification for antifouling reverse osmosis membranes using polydopamine under UV irradiation. Ind. Eng. Chem. Res. 2017, 56, 5756-5760. [CrossRef]

68. Ray, J.R.; Wong, W.; Jun, Y.S. Antiscaling efficacy of $\mathrm{CaCO}_{3}$ and $\mathrm{CaSO}_{4}$ on polyethylene glycol (PEG)-modified reverse osmosis membranes in the presence of humic acid: Interplay of membrane surface properties and water chemistry. Phys. Chem. Chem. Phys. 2017, 19, 5647-5657. [CrossRef]

69. Gholami, S.; Rezvani, A.; Vatanpour, V.; Cortina, J.L. Improving the chlorine resistance property of polyamide TFC RO membrane by polyethylene glycol diacrylate (PEGDA) coating. Desalination 2018, 443, 245-255. [CrossRef]

70. Chen, D.; Liu, T.; Kang, J.; Xu, R.; Cao, Y.; Xiang, M. Enhancing the permeability and antifouling properties of polyamide composite reverse osmosis membrane by surface modification with zwitterionic amino acid l-arginine. Adv. Mater. Interfaces 2019, 6. [CrossRef] 
71. Saffarimiandoab, F.; Yavuzturk Gul, B.; Erkoc-Ilter, S.; Guclu, S.; Unal, S.; Tunaboylu, B.; Menceloglu, Y.Z.; Koyuncu, I. Evaluation of biofouling behavior of zwitterionic silane coated reverse osmosis membranes fouled by marine bacteria. Prog. Org. Coat. 2019, 134, 303-311. [CrossRef]

72. Shen, L.; Yi, M.; Tian, L.; Wang, F.; Ding, C.; Sun, S.; Lu, A.; Su, L.; Wang, Y. Efficient surface ionization and metallization of TFC membranes with superior separation performance, antifouling and anti-bacterial properties. J. Membr. Sci. 2019, 586, 84-97. [CrossRef]

73. Manawi, Y.; Kochkodan, V.; Ismail, A.F.; Mohammad, A.W.; Ali Atieh, M. Performance of acacia gum as a novel additive in thin film composite polyamide RO membranes. Membranes 2019, 9, 30. [CrossRef]

74. Abbaszadeh, M.; Krizak, D.; Kundu, S. Layer-by-layer assembly of graphene oxide nanoplatelets embedded desalination membranes with improved chlorine resistance. Desalination 2019, 470. [CrossRef]

75. He, M.; Li, T.; Hu, M.; Chen, C.; Liu, B.; Crittenden, J.; Chu, L.-Y.; Ng, H.Y. Performance improvement for thin-film composite nanofiltration membranes prepared on PSf/PSf-g-PEG blended substrates. Sep. Purif. Technol. 2020, 230. [CrossRef]

76. Lee, J.; Jang, J.H.; Chae, H.-R.; Lee, S.H.; Lee, C.-H.; Park, P.-K.; Won, Y.-J.; Kim, I.-C. A facile route to enhance the water flux of a thin-film composite reverse osmosis membrane: Incorporating thickness-controlled graphene oxide into a highly porous support layer. J. Mater. Chem. A 2015, 3, 22053-22060. [CrossRef]

77. Kim, E.-S.; Hwang, G.; Gamal El-Din, M.; Liu, Y. Development of nanosilver and multi-walled carbon nanotubes thin-film nanocomposite membrane for enhanced water treatment. J. Membr. Sci. 2012, 394-395, 37-48. [CrossRef]

78. Jarusutthirak, C.; Mattaraj, S.; Jiraratananon, R. Influence of inorganic scalants and natural organic matter on nanofiltration membrane fouling. J. Membr. Sci. 2007, 287, 138-145. [CrossRef]

79. Hou, D.; Lin, D.; Zhao, C.; Wang, J.; Fu, C. Control of protein (BSA) fouling by ultrasonic irradiation during membrane distillation process. Sep. Purif. Technol. 2017, 175, 287-297. [CrossRef]

80. Quay, A.N.; Tong, T.; Hashmi, S.M.; Zhou, Y.; Zhao, S.; Elimelech, M. Combined organic fouling and inorganic scaling in reverse osmosis: Role of protein-silica interactions. Envioron. Sci. Technol. 2018, 52, 9145-9153. [CrossRef]

81. Trachta, M.; Bludský, O.; Rubeš, M. The interaction of proteins with silica surfaces. Part II: Free energies of capped amino acids. Comput. Theor. Chem. 2019, 1148, 38-43. [CrossRef]

82. Kavitha, J.; Rajalakshmi, M.; Phani, A.R.; Padaki, M. Pretreatment processes for seawater reverse osmosis desalination systems-A review. J. Water Process Eng. 2019, 32. [CrossRef]

83. Badruzzaman, M.; Voutchkov, N.; Weinrich, L.; Jacangelo, J.G. Selection of pretreatment technologies for seawater reverse osmosis plants: A review. Desalination 2019, 449, 78-91. [CrossRef]

84. Anis, S.F.; Hashaikeh, R.; Hilal, N. Reverse osmosis pretreatment technologies and future trends: A comprehensive review. Desalination 2019, 452, 159-195. [CrossRef]

85. Jiang, S.; Li, Y.; Ladewig, B.P. A review of reverse osmosis membrane fouling and control strategies. Sci. Total Environ. 2017, 595, 567-583. [CrossRef] [PubMed]

86. Verma, M.; Kumar, R.N. Coagulation and electrocoagulation for co-treatment of stabilized landfill leachate and municipal wastewater. J. Water Reuse Desalination 2018, 8, 234-243. [CrossRef]

87. Moosavirad, S.M. Treatment and operation cost analysis of greywater by electrocoagulation and comparison with coagulation process in mining areas. Sep. Sci. Technol. 2017, 52, 1742-1750. [CrossRef]

88. Zhang, X.; Lu, M.; Idrus, M.A.M.; Crombie, C.; Jegatheesan, V. Performance of precipitation and electrocoagulation as pretreatment of silica removal in brackish water and seawater. Process Saf. Environ. Prot. 2019, 126, 18-24. [CrossRef]

89. Zhu, J.; Qin, L.; Uliana, A.; Hou, J.; Wang, J.; Zhang, Y.; Li, X.; Yuan, S.; Li, J.; Tian, M. Elevated performance of thin film nanocomposite membranes enabled by modified hydrophilic MOFs for nanofiltration. ACS Appl. Mater. Interfaces 2017, 9, 1975-1986. [CrossRef]

90. De la Fuente, A.; Muro-Pastor, A.M.; Merchán, F.; Madrid, F.; Pérez-Martínez, J.I.; Undabeytia, T. Electrocoagulation/flocculation of cyanobacteria from surface waters. J. Clean. Prod. 2019, 238. [CrossRef]

91. Hakizimana, J.N.; Gourich, B.; Vial, C.; Drogui, P.; Oumani, A.; Naja, J.; Hilali, L. Assessment of hardness, microorganism and organic matter removal from seawater by electrocoagulation as a pretreatment of desalination by reverse osmosis. Desalination 2016, 393, 90-101. [CrossRef]

92. Shruthi, M.; Mahesh, S.; Sahana, M.; Srikantha, H. Arsenite removal mechanism from groundwater in a two-dimensional batch electrochemical treatment process. Desalination Water Treat. 2019, 146, 266-277. [CrossRef]

93. Zaviska, F.; Chun, Y.; Heran, M.; Zou, L. Using FO as pre-treatment of RO for high scaling potential brackish water: Energy and performance optimisation. J. Membr. Sci. 2015, 492, 430-438. [CrossRef]

94. Chun, Y.; Mulcahy, D.; Zou, L.; Kim, I.S. A Short Review of Membrane Fouling in Forward Osmosis Processes. Membranes 2017, 7, 30. [CrossRef] [PubMed]

95. Hasson, D.; Shemer, H.; Sher, A. State of the Art of Friendly “Green” Scale Control Inhibitors: A Review Article. Ind. Eng. Chem. Res. 2011, 50, 7601-7607. [CrossRef]

96. Zimmer, K.; Hater, W.; Icart, A.; Jaworski, J.; Kruse, N.; Braun, G. The performance of polycarboxylates as inhibitors for CaCO3scaling in reverse osmosis plants. Desalination Water Treat. 2016, 57, 23162-23175. [CrossRef]

97. Kim, D.; Wu, T.; Cohen, M.; Jeon, I.; Jun, Y.-S. Designing the crystalline structure of calcium phosphate seed minerals in organic templates for sustainable phosphorus management. Green Chem. 2018, 20, 534-543. [CrossRef] 
98. Kadhom, M.; Albayati, N.; Salih, S.; Al-Furaiji, M.; Bayati, M.; Deng, B. Role of Cellulose Micro and Nano Crystals in Thin Film and Support Layer of Nanocomposite Membranes for Brackish Water Desalination. Membranes 2019, 9, 101. [CrossRef] [PubMed]

99. Sweity, A.; Zere, T.R.; David, I.; Bason, S.; Oren, Y.; Ronen, Z.; Herzberg, M. Side effects of antiscalants on biofouling of reverse osmosis membranes in brackish water desalination. J. Membr. Sci. 2015, 481, 172-187. [CrossRef]

100. Rabizadeh, T.; Morgan, D.J.; Peacock, C.L.; Benning, L.G. Effectiveness of green ddditives vs poly(acrylic acid) in inhibiting calcium sulfate dihydrate crystallization. Ind. Eng. Chem. Res. 2019, 58, 1561-1569. [CrossRef]

101. Yu, W.; Song, D.; Li, A.; Yang, H. Control of gypsum-dominated scaling in reverse osmosis system using carboxymethyl cellulose. J. Membr. Sci. 2019, 577, 20-30. [CrossRef]

102. Al-Roomi, Y.M.; Hussain, K.F. Application and evaluation of novel acrylic based CaSO4 inhibitors for pipes. Desalination 2015, 355, 33-44. [CrossRef]

103. Hao, J.; Li, L.; Zhao, W.; Wu, X.; Xiao, Y.; Zhang, H.; Tang, N.; Wang, X. Synthesis and Application of CCQDs as a Novel Type of Environmentally Friendly Scale Inhibitor. ACS Appl. Mater. Interfaces 2019, 11, 9277-9282. [CrossRef]

104. Pramanik, B.K.; Gao, Y.; Fan, L.; Roddick, F.A.; Liu, Z. Antiscaling effect of polyaspartic acid and its derivative for RO membranes used for saline wastewater and brackish water desalination. Desalination 2017, 404, 224-229. [CrossRef]

105. Marian, I.; Adroer, N.; Cortada, E.; Vidal, D.; Aumatell, J. Environmentally friendly antiscalant effective in inhibition of scale formation and dispersing organic and colloidal matter in seawater desalination plants. Desalination Water Treat. 2014, 55, 3485-3497. [CrossRef]

106. Dayarathne, H.N.P.; Jeong, S.; Jang, A. Chemical-free scale inhibition method for seawater reverse osmosis membrane process: Air micro-nano bubbles. Desalination 2019, 461, 1-9. [CrossRef]

107. Dayarathne, H.N.P.; Choi, J.; Jang, A. Enhancement of cleaning-in-place (CIP) of a reverse osmosis desalination process with air micro-nano bubbles. Desalination 2017, 422, 1-4. [CrossRef]

108. Rey, C.; Hengl, N.; Baup, S.; Karrouch, M.; Dufresne, A.; Djeridi, H.; Dattani, R.; Pignon, F. Velocity, stress and concentration fields revealed by micro-PIV and SAXS within concentration polarization layers during cross-flow ultrafiltration of colloidal Laponite clay suspensions. J. Membr. Sci. 2019, 578, 69-84. [CrossRef]

109. Meng, B.Y.; Li, X.Y. In Situ Visualization of Concentration Polarization during Membrane Ultrafiltration Using Microscopic Laser-Induced Fluorescence. Envioron. Sci. Technol. 2019, 53, 2660-2669. [CrossRef]

110. Ho, J.S.; Sim, L.N.; Webster, R.D.; Viswanath, B.; Coster, H.G.L.; Fane, A.G. Monitoring fouling behavior of reverse osmosis membranes using electrical impedance spectroscopy: A field trial study. Desalination 2017, 407, 75-84. [CrossRef]

111. Li, X.; Zhang, H.; Hou, Y.; Gao, Y.; Li, J.; Guo, W.; Ngo, H.H. In situ investigation of combined organic and colloidal fouling for nanofiltration membrane using ultrasonic time domain reflectometry. Desalination 2015, 362, 43-51. [CrossRef]

112. Gamal Khedr, M. Processing of Desalination Reject Brine for Optimization of Process Efficiency, Cost Effectiveness and Environmental Safety. In Advancing Desalination; INTECH: Wheeling, IL, USA, 2012.

113. Li, X.; Hasson, D.; Semiat, R.; Shemer, H. Intermediate concentrate demineralization techniques for enhanced brackish water reverse osmosis water recovery-A review. Desalination 2019, 466, 24-35. [CrossRef]

114. Subramani, A.; Jacangelo, J.G. Treatment technologies for reverse osmosis concentrate volume minimization: A review. Sep. Purif. Technol. 2014, 122, 472-489. [CrossRef]

115. Giwa, A.; Dufour, V.; Al Marzooqi, F.; Al Kaabi, M.; Hasan, S.W. Brine management methods: Recent innovations and current status. Desalination 2017, 407, 1-23. [CrossRef]

116. Ge, L.; Wu, B.; Li, Q.; Wang, Y.; Yu, D.; Wu, L.; Pan, J.; Miao, J.; Xu, T. Electrodialysis with nanofiltration membrane (EDNF) for high-efficiency cations fractionation. J. Membr. Sci. 2016, 498, 192-200. [CrossRef]

117. Muhammad, Y.; Lee, W. Zero-liquid discharge (ZLD) technology for resource recovery from wastewater: A review. Sci. Total Environ. 2019, 681, 551-563. [CrossRef] [PubMed]

118. Tsai, J.-H.; Macedonio, F.; Drioli, E.; Giorno, L.; Chou, C.-Y.; Hu, F.-C.; Li, C.-L.; Chuang, C.-J.; Tung, K.-L. Membrane-based zero liquid discharge: Myth or reality? J. Taiwan Inst. Chem. Eng. 2017, 80, 192-202. [CrossRef]

119. McGovern, R.K.; Zubair, S.M.; Lienhard V, J.H. The benefits of hybridising electrodialysis with reverse osmosis. J. Membr. Sci. 2014, 469, 326-335. [CrossRef]

120. Loganathan, K.; Chelme-Ayala, P.; Gamal El-Din, M. Treatment of basal water using a hybrid electrodialysis reversal-reverse osmosis system combined with a low-temperature crystallizer for near-zero liquid discharge. Desalination 2015, 363, 92-98. [CrossRef]

121. Bond, R.; Batchelor, B.; Davis, T.; Klayman, B. Zero liquid discharge desalination of brackish water with an innovative form of electrodialysis: Electrodialysis metathesis. Fla. Water Resour. J. 2011, 63, 36-44.

122. Han, G.; Zhang, S.; Li, X.; Chung, T.-S. Progress in pressure retarded osmosis (PRO) membranes for osmotic power generation. Prog. Polym. Sci. 2015, 51, 1-27. [CrossRef]

123. Wang, Q.; Zhou, Z.; Li, J.; Tang, Q.; Hu, Y. Investigation of the reduced specific energy consumption of the RO-PRO hybrid system based on temperature-enhanced pressure retarded osmosis. J. Membr. Sci. 2019, 581, 439-452. [CrossRef]

124. Altaee, A.; Hilal, N. High recovery rate NF-FO-RO hybrid system for inland brackish water treatment. Desalination 2015, 363, 19-25. [CrossRef]

125. Jamil, S.; Loganathan, P.; Kazner, C.; Vigneswaran, S. Forward osmosis treatment for volume minimisation of reverse osmosis concentrate from a water reclamation plant and removal of organic micropollutants. Desalination 2015, 372, 32-38. [CrossRef] 
126. Lu, J.; Wang, X. Volume reduction and water reclamation of reverse osmosis concentrate from coal chemical industry by forward osmosis with an osmotic backwash strategy. Water Sci. Technol. 2020, 81, 2674-2684. [CrossRef] [PubMed]

127. Lu, J.; You, S.; Wang, X. Forward osmosis coupled with lime-soda ash softening for volume minimization of reverse osmosis concentrate and $\mathrm{CaCO} 3$ recovery: A case study on the coal chemical industry. Front. Environ. Sci. Eng. 2021, 15, 1-10. [CrossRef]

128. Straub, A.P.; Deshmukh, A.; Elimelech, M. Pressure-retarded osmosis for power generation from salinity gradients: Is it viable? Energy Environ. Sci. 2016, 9, 31-48. [CrossRef]

129. Shaffer, D.L.; Werber, J.R.; Jaramillo, H.; Lin, S.; Elimelech, M. Forward osmosis: Where are we now? Desalination 2015, 356, 271-284. [CrossRef]

130. Li, M.; Karanikola, V.; Zhang, X.; Wang, L.; Elimelech, M. A self-standing, support-free membrane for forward osmosis with no internal concentration polarization. Environ. Sci. Technol. Lett. 2018, 5, 266-271. [CrossRef]

131. Johnson, D.J.; Suwaileh, W.A.; Mohammed, A.W.; Hilal, N. Osmotic's potential: An overview of draw solutes for forward osmosis. Desalination 2018, 434, 100-120. [CrossRef]

132. Duong, H.C.; Chivas, A.R.; Nelemans, B.; Duke, M.; Gray, S.; Cath, T.Y.; Nghiem, L.D. Treatment of RO brine from CSG produced water by spiral-wound air gap membrane distillation-A pilot study. Desalination 2015, 366, 121-129. [CrossRef]

133. Salvador Cob, S.; Yeme, C.; Hofs, B.; Cornelissen, E.R.; Vries, D.; Genceli Güner, F.E.; Witkamp, G.J. Towards zero liquid discharge in the presence of silica: STable 98\% recovery in nanofiltration and reverse osmosis. Sep. Purif. Technol. 2015, 140, 23-31. [CrossRef]

134. Naidu, G.; Jeong, S.; Choi, Y.; Vigneswaran, S. Membrane distillation for wastewater reverse osmosis concentrate treatment with water reuse potential. J. Membr. Sci. 2017, 524, 565-575. [CrossRef]

135. Martinetti, C.R.; Childress, A.E.; Cath, T.Y. High recovery of concentrated RO brines using forward osmosis and membrane distillation. J. Membr. Sci. 2009, 331, 31-39. [CrossRef]

136. Li, J.; Ren, L.-F.; Shao, J.; Tu, Y.; Ma, Z.; Lin, Y.; He, Y. Fabrication of triple layer composite membrane and its application in membrane distillation (MD): Effect of hydrophobic-hydrophilic membrane structure on MD performance. Sep. Purif. Technol. 2020, 234. [CrossRef]

137. Wang, J.; He, H.; Wang, M.; Xiao, Z.; Chen, Y.; Wang, Y.; Song, J.; Li, X.-M.; Zhang, Y.; He, T. 3-[[3-(Triethoxysilyl)-propyl] amino] propane-1-sulfonic acid zwitterion grafted polyvinylidene fluoride antifouling membranes for concentrating greywater in direct contact membrane distillation. Desalination 2019, 455, 71-78. [CrossRef]

138. Dudchenko, A.V.; Chen, C.; Cardenas, A.; Rolf, J.; Jassby, D. Frequency-dependent stability of CNT Joule heaters in ionizable media and desalination processes. Nat. Nanotechnol. 2017, 12, 557. [CrossRef] [PubMed]

139. Pal, P. Introduction to the arsenic contamination problem. In Groundwater Arsenic Remediation; Elsevier: Oxford, UK, 2015.

140. Van der Bruggen, B.; Vandecasteele, C.; Van Gestel, T.; Doyen, W.; Leysen, R. A review of pressure-driven membrane processes in wastewater treatment and drinking water production. Environ. Prog. 2003, 22, 46-56. [CrossRef]

141. Abdel-Fatah, M.A. Nanofiltration systems and applications in wastewater treatment. Ain Shams Eng. J. 2018, 9, 3077-3092. [CrossRef]

142. Sengupta, A.K.; Sarkar, S. Brackish and Sea Water Desalination Using a Hybrid Ion Exchange-Nanofiltration Process. U.S. Patent No. 7,901,577, 8 March 2011.

143. Uhlinger, R.A. Desalination Method and Apparatus Utilizing Nanofiltration and Reverse Osmosis Membranes. U.S. Patent No. 6,190,556, 20 February 2001.

144. Hassan, A. Fully Integrated NF-Thermal Seawater Desalination Process and Equipment. U.S. Patent No. 2006/0157410, 20 July 2006.

145. Vrijenhoek, E.M.; Waypa, J.J. Arsenic removal from drinking water by a "loose" nanofiltration membrane. Desalination 2000, 130, 265-277. [CrossRef]

146. Livingston, A.G.; Bhole, Y.S.; Solomon, M.F.J. Solvent Resistant Polyamide Nanofiltration Membranes. U.S. Patent 2013/0112619, 9 May 2013.

147. Lalia, B.S.; Kochkodan, V.; Hashaikeh, R.; Hilal, N. A review on membrane fabrication: Structure, properties and performance relationship. Desalination 2013, 326, 77-95. [CrossRef]

148. Lee, A.; Elam, J.W.; Darling, S.B. Membrane materials for water purification: Design, development, and application. Environ. Sci. Water Res. Technol. 2016, 2, 17-42. [CrossRef]

149. Goh, P.; Ismail, A. A review on inorganic membranes for desalination and wastewater treatment. Desalination 2018, 434, 60-80. [CrossRef]

150. Timmer, J.M.K. Properties of Nanofiltration Membranes: Model Development and Industrial Application; Technische Universiteit Eindhoven: Eindhoven, The Netherlands, 2001.

151. Van der Bruggen, B. Microfiltration, ultrafiltration, nanofiltration, reverse osmosis, and forward osmosis. In Fundamental Modelling of Membrane Systems; Elsevier: Amsterdam, The Netherlands, 2018; pp. 25-70.

152. Bacchin, P.; Aimar, P.; Field, R.W. Critical and sustainable fluxes: Theory, experiments and applications. J. Membr. Sci. 2006, 281, 42-69. [CrossRef]

153. Vrijenhoek, E.M.; Hong, S.; Elimelech, M. Influence of membrane surface properties on initial rate of colloidal fouling of reverse osmosis and nanofiltration membranes. J. Membr. Sci. 2001, 188, 115-128. [CrossRef]

154. Lee, S.; Cho, J.; Elimelech, M. Combined influence of natural organic matter (NOM) and colloidal particles on nanofiltration membrane fouling. J. Membr. Sci. 2005, 262, 27-41. [CrossRef] 
155. Al-Amoudi, A.; Lovitt, R.W. Fouling strategies and the cleaning system of NF membranes and factors affecting cleaning efficiency. J. Membr. Sci. 2007, 303, 4-28. [CrossRef]

156. Tin, M.M.M.; Anioke, G.; Nakagoe, O.; Tanabe, S.; Kodamatani, H.; Nghiem, L.D.; Fujioka, T. Membrane fouling, chemical cleaning and separation performance assessment of a chlorine-resistant nanofiltration membrane for water recycling applications. Sep. Purif. Technol. 2017, 189, 170-175. [CrossRef]

157. Chen, J.P.; Kim, S.; Ting, Y. Optimization of membrane physical and chemical cleaning by a statistically designed approach. J. Membr. Sci. 2003, 219, 27-45. [CrossRef]

158. Ducom, G.; Matamoros, H.; Cabassud, C. Air sparging for flux enhancement in nanofiltration membranes: Application to O/W stabilised and non-stabilised emulsions. J. Membr. Sci. 2002, 204, 221-236. [CrossRef]

159. Lin, J.C.-T.; Lee, D.-J.; Huang, C. Membrane fouling mitigation: Membrane cleaning. Sep. Sci. Technol. 2010, 45, 858-872. [CrossRef]

160. Ahmed, A.-A. Effect of chemical cleaning agents on virgin nanofiltration membrane as characterized by positron annihilation spectroscopy. Sep. Purif. Technol. 2013, 110, 51-56.

161. Bogati, R.; Goodwin, C.; Marshall, K.; Leung, K.; Liao, B. Optimization of chemical cleaning for improvement of membrane performance and fouling control in drinking water treatment. Sep. Sci. Technol. 2015, 50, 1835-1845. [CrossRef]

162. Wang, J.; Gao, X.; Xu, Y.; Wang, Q.; Zhang, Y.; Wang, X.; Gao, C. Ultrasonic-assisted acid cleaning of nanofiltration membranes fouled by inorganic scales in arsenic-rich brackish water. Desalination 2016, 377, 172-177. [CrossRef]

163. Ohno, K.; Matsui, Y.; Itoh, M.; Oguchi, Y.; Kondo, T.; Konno, Y.; Matsushita, T.; Magara, Y. NF membrane fouling by aluminum and iron coagulant residuals after coagulation-MF pretreatment. Desalination 2010, 254, 17-22. [CrossRef]

164. Shanmuganathan, S.; Johir, M.A.; Nguyen, T.V.; Kandasamy, J.; Vigneswaran, S. Experimental evaluation of microfiltrationgranular activated carbon (MF-GAC)/nano filter hybrid system in high quality water reuse. J. Membr. Sci. 2015, 476, 1-9. [CrossRef]

165. Park, M.; Anumol, T.; Simon, J.; Zraick, F.; Snyder, S.A. Pre-ozonation for high recovery of nanofiltration (NF) membrane system: Membrane fouling reduction and trace organic compound attenuation. J. Membr. Sci. 2017, 523, 255-263. [CrossRef]

166. Chellam, S.; Jacangelo, J.G.; Bonacquisti, T.P.; Schauer, B.A. Effect of pretreatment on surface water nanofiltration. J. Am. Water Work. Assoc. 1997, 89, 77-89. [CrossRef]

167. Shi, Y.; Huang, J.; Zeng, G.; Cheng, W.; Hu, J. Photocatalytic membrane in water purification: Is it stepping closer to be driven by visible light? J. Membr. Sci. 2019, 584, 364-392. [CrossRef]

168. Lv, Y.; Zhang, C.; He, A.; Yang, S.J.; Wu, G.P.; Darling, S.B.; Xu, Z.K. Photocatalytic nanofiltration membranes with self-cleaning property for wastewater treatment. Adv. Funct. Mater. 2017, 27, 1700251. [CrossRef]

169. Liu, F.; Ma, B.-R.; Zhou, D.; Zhu, L.-J.; Fu, Y.-Y.; Xue, L.-X. Positively charged loose nanofiltration membrane grafted by diallyl dimethyl ammonium chloride (DADMAC) via UV for salt and dye removal. React. Funct. Polym. 2015, 86, 191-198. [CrossRef]

170. Lin, J.; Ye, W.; Zeng, H.; Yang, H.; Shen, J.; Darvishmanesh, S.; Luis, P.; Sotto, A.; Van der Bruggen, B. Fractionation of direct dyes and salts in aqueous solution using loose nanofiltration membranes. J. Membr. Sci. 2015, 477, 183-193. [CrossRef]

171. Owusu-Agyeman, I.; Reinwald, M.; Jeihanipour, A.; Schäfer, A.I. Removal of fluoride and natural organic matter from natural tropical brackish waters by nanofiltration/reverse osmosis with varying water chemistry. Chemosphere 2019, 217, 47-58. [CrossRef]

172. Van der Bruggen, B. Chemical modification of polyethersulfone nanofiltration membranes: A review. J. Appl. Polym. Sci. 2009, 114, 630-642. [CrossRef]

173. Blanco, J.; Nguyen, Q.; Schaetzel, P. Novel hydrophilic membrane materials: Sulfonated polyethersulfone Cardo. J. Membr. Sci. 2001, 186, 267-279. [CrossRef]

174. Hegemann, D.; Brunner, H.; Oehr, C. Plasma treatment of polymers for surface and adhesion improvement. Nucl. Instrum. Methods Phys. Res. Sect. B Beam Interact. Mater. At. 2003, 208, 281-286. [CrossRef]

175. Kochkodan, V.; Hilal, N. A comprehensive review on surface modified polymer membranes for biofouling mitigation. Desalination 2015, 356, 187-207. [CrossRef]

176. Qu, X.; Alvarez, P.J.; Li, Q. Applications of nanotechnology in water and wastewater treatment. Water Res. 2013, 47, 3931-3946. [CrossRef]

177. Anand, A.; Unnikrishnan, B.; Mao, J.-Y.; Lin, H.-J.; Huang, C.-C. Graphene-based nanofiltration membranes for improving salt rejection, water flux and antifouling-A review. Desalination 2018, 429, 119-133. [CrossRef]

178. Jhaveri, J.H.; Murthy, Z. A comprehensive review on anti-fouling nanocomposite membranes for pressure driven membrane separation processes. Desalination 2016, 379, 137-154. [CrossRef]

179. Lee, H.S.; Im, S.J.; Kim, J.H.; Kim, H.J.; Kim, J.P.; Min, B.R. Polyamide thin-film nanofiltration membranes containing TiO 2 nanoparticles. Desalination 2008, 219, 48-56. [CrossRef]

180. Hu, Y.; Lü, Z.; Wei, C.; Yu, S.; Liu, M.; Gao, C. Separation and antifouling properties of hydrolyzed PAN hybrid membranes prepared via in-situ sol-gel $\mathrm{SiO}_{2}$ nanoparticles growth. J. Membr. Sci. 2018, 545, 250-258. [CrossRef]

181. Habib, Z.; Khan, S.J.; Ahmad, N.M.; Shahzad, H.M.A.; Jamal, Y.; Hashmi, I. Antibacterial behaviour of surface modified composite polyamide nanofiltration (NF) membrane by immobilizing Ag-doped $\mathrm{TiO}_{2}$ nanoparticles. Environ. Technol. 2020, 41, 3657-3669. [CrossRef]

182. Das, R.; Ali, M.E.; Hamid, S.B.A.; Ramakrishna, S.; Chowdhury, Z.Z. Carbon nanotube membranes for water purification: A bright future in water desalination. Desalination 2014, 336, 97-109. [CrossRef] 
183. Bano, S.; Mahmood, A.; Kim, S.-J.; Lee, K.-H. Graphene oxide modified polyamide nanofiltration membrane with improved flux and antifouling properties. J. Mater. Chem. A 2015, 3, 2065-2071. [CrossRef]

184. Kang, Y.; Obaid, M.; Jang, J.; Kim, I.S. Sulfonated graphene oxide incorporated thin film nanocomposite nanofiltration membrane to enhance permeation and antifouling properties. Desalination 2019, 470, 114125. [CrossRef]

185. Ba, C.; Ladner, D.A.; Economy, J. Using polyelectrolyte coatings to improve fouling resistance of a positively charged nanofiltration membrane. J. Membr. Sci. 2010, 347, 250-259. [CrossRef]

186. Rana, D.; Matsuura, T. Surface modifications for antifouling membranes. Chem. Rev. 2010, 110, 2448-2471. [CrossRef]

187. Mbuli, B.S.; Mhlanga, S.D.; Mamba, B.B.; Nxumalo, E.N. Fouling resistance and physicochemical properties of polyamide thin-film composite membranes modified with functionalized cyclodextrins. Adv. Polym. Technol. 2017, 36, 249-260. [CrossRef]

188. Guo, Y.-S.; Weng, X.-D.; Wu, B.; Mi, Y.-F.; Zhu, B.-K.; Ji, Y.-L.; An, Q.-F.; Gao, C.-J. Construction of nonfouling nanofiltration membrane via introducing uniformly tunable zwitterionic layer. J. Membr. Sci. 2019, 583, 152-162. [CrossRef]

189. Wu, H.; Tang, B.; Wu, P. Optimizing polyamide thin film composite membrane covalently bonded with modified mesoporous silica nanoparticles. J. Membr. Sci. 2013, 428, 341-348. [CrossRef]

190. Tansel, B.; Sager, J.; Rector, T.; Garland, J.; Strayer, R.F.; Levine, L.; Roberts, M.; Hummerick, M.; Bauer, J. Significance of hydrated radius and hydration shells on ionic permeability during nanofiltration in dead end and cross flow modes. Sep. Purif. Technol. 2006, 51, 40-47. [CrossRef]

191. Mohammad, A.W.; Teow, Y.; Ang, W.; Chung, Y.; Oatley-Radcliffe, D.; Hilal, N. Nanofiltration membranes review: Recent advances and future prospects. Desalination 2015, 356, 226-254. [CrossRef]

192. Zareei, F.; Hosseini, S.M. A new type of polyethersulfone based composite nanofiltration membrane decorated by cobalt ferrite-copper oxide nanoparticles with enhanced performance and antifouling property. Sep. Purif. Technol. 2019, 226, 48-58. [CrossRef]

193. Zarrabi, H.; Yekavalangi, M.E.; Vatanpour, V.; Shockravi, A.; Safarpour, M. Improvement in desalination performance of thin film nanocomposite nanofiltration membrane using amine-functionalized multiwalled carbon nanotube. Desalination 2016, 394, 83-90. [CrossRef]

194. Gong, G.; Wang, P.; Zhou, Z.; Hu, Y. New Insights into the Role of an Interlayer for the Fabrication of Highly Selective and Permeable Thin-Film Composite Nanofiltration Membrane. ACS Appl. Mater. Interfaces 2019, 11, 7349-7356. [CrossRef] [PubMed]

195. Tang, Y.-J.; Shen, B.-J.; Huang, B.-Q.; Zhan, Z.-M.; Xu, Z.-L. High permselectivity thin-film composite nanofiltration membranes with 3D microstructure fabricated by incorporation of beta cyclodextrin. Sep. Purif. Technol. 2019, 227, 115718. [CrossRef]

196. Bandehali, S.; Parvizian, F.; Moghadassi, A.; Hosseini, S. Copper and lead ions removal from water by new PEI based NF membrane modified by functionalized POSS nanoparticles. J. Polym. Res. 2019, 26, 211. [CrossRef]

197. Su, N.C.; Sun, D.T.; Beavers, C.M.; Britt, D.K.; Queen, W.L.; Urban, J.J. Enhanced permeation arising from dual transport pathways in hybrid polymer-MOF membranes. Energy Environ. Sci. 2016, 9, 922-931. [CrossRef]

198. Misdan, N.; Ramlee, N.; Hairom, N.H.H.; Ikhsan, S.N.W.; Yusof, N.; Lau, W.J.; Ismail, A.F.; Nordin, N.A.H.M. CuBTC metal organic framework incorporation for enhancing separation and antifouling properties of nanofiltration membrane. Chem. Eng. Res. Des. 2019, 148, 227-239. [CrossRef]

199. Saqib, J.; Aljundi, I.H. Membrane fouling and modification using surface treatment and layer-by-layer assembly of polyelectrolytes: State-of-the-art review. J. Water Process Eng. 2016, 11, 68-87. [CrossRef]

200. Ye, C.-C.; An, Q.-F.; Wu, J.-K.; Zhao, F.-Y.; Zheng, P.-Y.; Wang, N.-X. Nanofiltration membranes consisting of quaternized polyelectrolyte complex nanoparticles for heavy metal removal. Chem. Eng. J. 2019, 359, 994-1005. [CrossRef]

201. Ng, L.Y.; Mohammad, A.W.; Ng, C.Y. A review on nanofiltration membrane fabrication and modification using polyelectrolytes: Effective ways to develop membrane selective barriers and rejection capability. Adv. Colloid Interface Sci. 2013, 197, 85-107. [CrossRef]

202. Cheng, W.; Liu, C.; Tong, T.; Epsztein, R.; Sun, M.; Verduzco, R.; Ma, J.; Elimelech, M. Selective removal of divalent cations by polyelectrolyte multilayer nanofiltration membrane: Role of polyelectrolyte charge, ion size, and ionic strength. J. Membr. Sci. 2018, 559, 98-106. [CrossRef]

203. Peng, H.; Tang, Q.; Tang, S.; Gong, J.; Zhao, Q. Surface modified polyamide nanofiltration membranes with high permeability and stability. J. Membr. Sci. 2019, 592, 117386. [CrossRef]

204. Abuhabib, A.; Mohammad, A.W.; Hilal, N.; Rahman, R.A.; Shafie, A.H. Nanofiltration membrane modification by UV grafting for salt rejection and fouling resistance improvement for brackish water desalination. Desalination 2012, 295, 16-25. [CrossRef]

205. Song, Y.; Xu, J.; Xu, Y.; Gao, X.; Gao, C. Performance of UF-NF integrated membrane process for seawater softening. Desalination 2011, 276, 109-116. [CrossRef]

206. Fersi, C.; Dhahbi, M. Treatment of textile plant effluent by ultrafiltration and/or nanofiltration for water reuse. Desalination 2008, 222, 263-271. [CrossRef]

207. Yuan, C. Experimental Study on UF-NF Filtration Purification of Pipe Drinking Water. J. Phys. Conf. Ser. 2019, $1176,062021$. [CrossRef]

208. Liu, J.; Yuan, J.; Ji, Z.; Wang, B.; Hao, Y.; Guo, X. Concentrating brine from seawater desalination process by nanofiltrationelectrodialysis integrated membrane technology. Desalination 2016, 390, 53-61. [CrossRef]

209. Zhang, Y.-F.; Liu, L.; Du, J.; Fu, R.; Van der Bruggen, B.; Zhang, Y. Fracsis: Ion fractionation and metathesis by a NF-ED integrated system to improve water recovery. J. Membr. Sci. 2017, 523, 385-393. [CrossRef] 
210. Sohrabi, M.; Madaeni, S.; Khosravi, M.; Ghaedi, A. Chemical cleaning of reverse osmosis and nanofiltration membranes fouled by licorice aqueous solutions. Desalination 2011, 267, 93-100. [CrossRef]

211. Wadekar, S.S.; Wang, Y.; Lokare, O.R.; Vidic, R.D. Influence of Chemical Cleaning on Physicochemical Characteristics and Ion Rejection by Thin Film Composite Nanofiltration Membranes. Environ. Sci. Technol. 2019, 53, 10166-10176. [CrossRef]

212. Zhu, J.; Cao, W.; Yue, M.; Hou, Y.; Han, J.; Yang, M. Strong and stiff aramid nanofiber/carbon nanotube nanocomposites. ACS Nano 2015, 9, 2489-2501. [CrossRef]

213. Mustafa, G.; Wyns, K.; Vandezande, P.; Buekenhoudt, A.; Meynen, V. Novel grafting method efficiently decreases irreversible fouling of ceramic nanofiltration membranes. J. Membr. Sci. 2014, 470, 369-377. [CrossRef]

214. He, Z.; Lyu, Z.; Gu, Q.; Zhang, L.; Wang, J. Ceramic-based membranes for water and wastewater treatment. Colloids Surf. A Physicochem. Eng. Asp. 2019, 578, 123513. [CrossRef]

215. Warsinger, D.M.; Chakraborty, S.; Tow, E.W.; Plumlee, M.H.; Bellona, C.; Loutatidou, S.; Karimi, L.; Mikelonis, A.M.; Achilli, A.; Ghassemi, A. A review of polymeric membranes and processes for potable water reuse. Prog. Polym. Sci. 2018, 81, 209-237. [CrossRef]

216. Sata, T.; Yamaguchi, T.; Matsusaki, K. Anion exchange membranes for nitrate ion removal from groundwater by electrodialysis. J. Chem. Soc. Chem. Commun. 1995, 1153-1154. [CrossRef]

217. Hell, F.; Lahnsteiner, J.; Frischherz, H.; Baumgartner, G. Experience with full-scale electrodialysis for nitrate and hardness removal. Desalination 1998, 117, 173-180. [CrossRef]

218. Campione, A.; Gurreri, L.; Ciofalo, M.; Micale, G.; Tamburini, A.; Cipollina, A. Electrodialysis for water desalination: A critical assessment of recent developments on process fundamentals, models and applications. Desalination 2018, 434, 121-160. [CrossRef]

219. Wang, L.K.; Chen, J.P.; Hung, Y.-T.; Shammas, N.K. Membrane and Desalination Technologies; Springer: Berlin/Heidelberg, Germany, 2008; Volume 13.

220. Drioli, E.; Curcio, E.; Fontananova, E. Mass Transfer Operation-Membrane Separations; Eolss Publishers: Oxford, UK, 2006.

221. Wen, T.; Solt, G.; Sun, Y. Spirally wound electrodialysis (SpED) modules. Desalination 1995, 101, 79-91. [CrossRef]

222. Wright, N.C. Design of spiral-wound electrodialysis modules. Desalination 2019, 458, 54-65. [CrossRef]

223. Mohanty, K.; Purkait, M.K. Membrane Technologies and Applications; CRC Press: Boca Raton, FL, USA, 2011.

224. Grebenyuk, V.; Grebenyuk, O. Electrodialysis: From an idea to realization. Russ. J. Electrochem. 2002, 38, 806-809. [CrossRef]

225. Huang, C.; Xu, T. Electrodialysis with bipolar membranes for sustainable development. Environ. Sci. Technol. 2006, 40, 5233-5243. [CrossRef]

226. Katz, W.E. The electrodialysis reversal (EDR) process. Desalination 1979, 28, 31-40. [CrossRef]

227. Donnan, F.G. The theory of membrane equilibria. Chem. Rev. 1924, 1, 73-90. [CrossRef]

228. Frilette, V.J. Preparation and characterization of bipolar ion exchange membranes. J. Phys. Chem. 1956, 60, 435-439. [CrossRef]

229. Zhang, Y.; Paepen, S.; Pinoy, L.; Meesschaert, B.; Van der Bruggen, B. Selectrodialysis: Fractionation of divalent ions from monovalent ions in a novel electrodialysis stack. Sep. Purif. Technol. 2012, 88, 191-201. [CrossRef]

230. Deng, D.; Dydek, E.V.; Han, J.-H.; Schlumpberger, S.; Mani, A.; Zaltzman, B.; Bazant, M.Z. Overlimiting current and shock electrodialysis in porous media. Langmuir 2013, 29, 16167-16177. [CrossRef]

231. Pattle, R. Production of electric power by mixing fresh and salt water in the hydroelectric pile. Nature 1954, 174, 660-660. [CrossRef]

232. Jagur-Grodzinski, J.; Kramer, R. Novel process for direct conversion of free energy of mixing into electric power. Ind. Eng. Chem. Process Des. Dev. 1986, 25, 443-449. [CrossRef]

233. Weinstein, J.N.; Leitz, F.B. Electric power from differences in salinity: The dialytic battery. Science 1976, 191, 557-559. [CrossRef]

234. Scialdone, O.; Albanese, A.; D’Angelo, A.; Galia, A.; Guarisco, C. Investigation of electrode material-redox couple systems for reverse electrodialysis processes. Part II: Experiments in a stack with 10-50 cell pairs. J. Electroanal. Chem. 2013, 704, 1-9. [CrossRef]

235. Guler, E.; Zhang, Y.; Saakes, M.; Nijmeijer, K. Tailor-made anion-exchange membranes for salinity gradient power generation using reverse electrodialysis. ChemSusChem 2012, 5, 2262-2270. [CrossRef]

236. Vermaas, D.A.; Bajracharya, S.; Sales, B.B.; Saakes, M.; Hamelers, B.; Nijmeijer, K. Clean energy generation using capacitive electrodes in reverse electrodialysis. Energy Environ. Sci. 2013, 6, 643-651. [CrossRef]

237. Mei, Y.; Tang, C.Y. Recent developments and future perspectives of reverse electrodialysis technology: A review. Desalination 2018, 425, 156-174. [CrossRef]

238. Strathmann, H. Electrodialysis, a mature technology with a multitude of new applications. Desalination 2010, 264, 268-288. [CrossRef]

239. Strathmann, H.; Grabowski, A.; Eigenberger, G. Ion-exchange membranes in the chemical process industry. Ind. Eng. Chem. Res. 2013, 52, 10364-10379. [CrossRef]

240. Ran, J.; Wu, L.; He, Y.; Yang, Z.; Wang, Y.; Jiang, C.; Ge, L.; Bakangura, E.; Xu, T. Ion exchange membranes: New developments and applications. J. Membr. Sci. 2017, 522, 267-291. [CrossRef]

241. Xu, T. Ion exchange membranes: State of their development and perspective. J. Membr. Sci. 2005, 263, 1-29. [CrossRef]

242. Nagarale, R.; Gohil, G.; Shahi, V.K. Recent developments on ion-exchange membranes and electro-membrane processes. Adv. Colloid Interface Sci. 2006, 119, 97-130. [CrossRef] 
243. Hagesteijn, K.F.; Jiang, S.; Ladewig, B.P. A review of the synthesis and characterization of anion exchange membranes. J. Mater. Sci. 2018, 53, 11131-11150. [CrossRef]

244. Merle, G.; Chairuna, A.; Vam de Ven, E.; Nijmeijer, K. An easy method for the preparation of anion exchange membranes: Graft-polymerization of ionic liquids in porous supports. J. Appl. Polym. Sci. 2013, 129, 1143-1150. [CrossRef]

245. Kononenko, N.; Nikonenko, V.; Grande, D.; Larchet, C.; Dammak, L.; Fomenko, M.; Volfkovich, Y. Porous structure of ion exchange membranes investigated by various techniques. Adv. Colloid Interface Sci. 2017, 246, 196-216. [CrossRef]

246. Jiang, C.; Hossain, M.M.; Li, Y.; Wang, Y.; Xu, T. Ion Exchange Membranes for Electrodialysis: A Comprehensive Review of Recent Advances. J. Membr. Sep. Technol. 2014, 3, 185.

247. Hong, J.G.; Zhang, B.; Glabman, S.; Uzal, N.; Dou, X.; Zhang, H.; Wei, X.; Chen, Y. Potential ion exchange membranes and system performance in reverse electrodialysis for power generation: A review. J. Membr. Sci. 2015, 486, 71-88. [CrossRef]

248. Alabi, A.; AlHajaj, A.; Cseri, L.; Szekely, G.; Budd, P.; Zou, L. Review of nanomaterials-assisted ion exchange membranes for electromembrane desalination. NPJ Clean Water 2018, 1, 10. [CrossRef]

249. Ghalloussi, R.; Garcia-Vasquez, W.; Chaabane, L.; Dammak, L.; Larchet, C.; Deabate, S.; Nevakshenova, E.; Nikonenko, V.; Grande, D. Ageing of ion-exchange membranes in electrodialysis: A structural and physicochemical investigation. J. Membr. Sci. 2013, 436, 68-78. [CrossRef]

250. Veerman, J.; Saakes, M.; Metz, S.J.; Harmsen, G. Reverse electrodialysis: Evaluation of suitable electrode systems. J. Appl. Electrochem. 2010, 40, 1461-1474. [CrossRef]

251. Burheim, O.S.; Seland, F.; Pharoah, J.G.; Kjelstrup, S. Improved electrode systems for reverse electro-dialysis and electro-dialysis. Desalination 2012, 285, 147-152. [CrossRef]

252. Scialdone, O.; Guarisco, C.; Grispo, S.; D’Angelo, A.; Galia, A. Investigation of electrode material-Redox couple systems for reverse electrodialysis processes. Part I: Iron redox couples. J. Electroanal. Chem. 2012, 681, 66-75. [CrossRef]

253. Naderi Behdani, F.; Jaberi, M.; Karimi, L.; Ghassemi, A. Effects of electrode design on electrodialysis reversal performance. Desalination Water Treat. 2016, 57, 26539-26547. [CrossRef]

254. Turek, M.; Bandura, B. Renewable energy by reverse electrodialysis. Desalination 2007, 205, 67-74. [CrossRef]

255. Liu, F.; Coronell, O.; Call, D.F. Electricity generation using continuously recirculated flow electrodes in reverse electrodialysis. J. Power Sources 2017, 355, 206-210. [CrossRef]

256. Tanaka, Y. Ion Exchange Membranes: Fundamentals and Applications; Series 12; Elsevier: Amsterdam, The Netherlands, 2007.

257. Tanaka, Y. A computer simulation of continuous ion exchange membrane electrodialysis for desalination of saline water. Desalination 2009, 249, 809-821. [CrossRef]

258. Tanaka, Y. A computer simulation of feed and bleed ion exchange membrane electrodialysis for desalination of saline water. Desalination 2010, 254, 99-107. [CrossRef]

259. Chehayeb, K.M.; Lienhard, J.H. On the electrical operation of batch electrodialysis for reduced energy consumption. Environ. Sci. Water Res. Technol. 2019, 5, 1172-1182. [CrossRef]

260. Rubinstein, I.; Zaltzman, B. Electro-osmotically induced convection at a permselective membrane. Phys. Rev. E 2000, 62, 2238. [CrossRef]

261. Nikonenko, V.V.; Pismenskaya, N.D.; Belova, E.I.; Sistat, P.; Huguet, P.; Pourcelly, G.; Larchet, C. Intensive current transfer in membrane systems: Modelling, mechanisms and application in electrodialysis. Adv. Colloid Interface Sci. 2010, 160, 101-123. [CrossRef]

262. Nikonenko, V.V.; Kovalenko, A.V.; Urtenov, M.K.; Pismenskaya, N.D.; Han, J.; Sistat, P.; Pourcelly, G. Desalination at overlimiting currents: State-of-the-art and perspectives. Desalination 2014, 342, 85-106. [CrossRef]

263. Turek, M. Optimization of electrodialytic desalination in diluted solutions. Desalination 2003, 153, 383-387. [CrossRef]

264. Strathmann, H. Assessment of electrodialysis water desalination process costs. In Proceedings of the International Conference on Desalination Costing, Limassol, Cyprus, December 2004; pp. 32-54.

265. Roghmans, F.; Evdochenko, E.; Stockmeier, F.; Schneider, S.; Smailji, A.; Tiwari, R.; Mikosch, A.; Karatay, E.; Kühne, A.; Walther, A. 2D patterned ion-exchange membranes induce electroconvection. Adv. Mater. Interfaces 2019, 6, 1801309. [CrossRef]

266. Nebavskaya, K.; Sarapulova, V.; Sabbatovskiy, K.; Sobolev, V.; Pismenskaya, N.; Sistat, P.; Cretin, M.; Nikonenko, V. Impact of ion exchange membrane surface charge and hydrophobicity on electroconvection at underlimiting and overlimiting currents. J. Membr. Sci. 2017, 523, 36-44. [CrossRef]

267. Volodina, E.; Pismenskaya, N.; Nikonenko, V.; Larchet, C.; Pourcelly, G. Ion transfer across ion-exchange membranes with homogeneous and heterogeneous surfaces. J. Colloid Interface Sci. 2005, 285, 247-258. [CrossRef] [PubMed]

268. Pismenskaya, N.; Belova, E.; Nikonenko, V.; Zabolotsky, V.; Lopatkova, G.Y.; Karzhavin, Y.N.; Larchet, C. Lower rate of $\mathrm{H}^{+}\left(\mathrm{OH}^{-}\right)$ ions generation at an anion-exchange membrane in electrodialysis. Desalination Water Treat. 2010, 21, 109-114. [CrossRef]

269. Zhelonkina, E.; Shishkina, S.; Mikhailova, I.Y.; Ananchenko, B. Study of electrodialysis of a copper chloride solution at overlimiting currents. Pet. Chem. 2017, 57, 947-953. [CrossRef]

270. Niftaliev, S.; Kozaderova, O.; Kim, K. Electrodialysis of Ammonium Nitrate Solution in Intensive Current Regimes. Int. J. Electrochem. Sci. 2016, 11, 9057-9066. [CrossRef]

271. Nikonenko, V.; Mareev, S.; Pis'menskaya, N.; Uzdenova, A.; Kovalenko, A.; Urtenov, M.K.; Pourcelly, G. Effect of electroconvection and its use in intensifying the mass transfer in electrodialysis. Russ. J. Electrochem. 2017, 53, 1122-1144. [CrossRef] 
272. Nam, S.; Cho, I.; Heo, J.; Lim, G.; Bazant, M.Z.; Moon, D.J.; Sung, G.Y.; Kim, S.J. Experimental verification of overlimiting current by surface conduction and electro-osmotic flow in microchannels. Phys. Rev. Lett. 2015, 114, 114501. [CrossRef] [PubMed]

273. Zabolotskiy, V.; But, A.Y.; Vasil'eva, V.; Akberova, E.; Melnikov, S. Ion transport and electrochemical stability of strongly basic anion-exchange membranes under high current electrodialysis conditions. J. Membr. Sci. 2017, 526, 60-72. [CrossRef]

274. Nebavskaya, K.; Butylskii, D.Y.; Moroz, I.; Nebavsky, A.; Pismenskaya, N.; Nikonenko, V. Enhancement of mass transfer through a homogeneous anion-exchange membrane in limiting and overlimiting current regimes by screening part of its surface with nonconductive strips. Pet. Chem. 2018, 58, 780-789. [CrossRef]

275. Hanrahan, C.; Karimi, L.; Ghassemi, A.; Sharbat, A. High-recovery electrodialysis reversal for the desalination of inland brackish waters. Desalination Water Treat. 2016, 57, 11029-11039. [CrossRef]

276. Tongwen, $X$. Electrodialysis processes with bipolar membranes (EDBM) in environmental protection-A review. Resour. Conserv. Recycl. 2002, 37, 1-22. [CrossRef]

277. Alvarado, L.; Chen, A. Electrodeionization: Principles, strategies and applications. Electrochim. Acta 2014, 132, 583-597. [CrossRef]

278. Camacho, L.M.; Fox, J.A.; Ajedegba, J.O. Optimization of electrodialysis metathesis (EDM) desalination using factorial design methodology. Desalination 2017, 403, 136-143. [CrossRef]

279. Guler, E.; Nijmeijer, K. Reverse electrodialysis for salinity gradient power generation: Challenges and future perspectives. J. Membr. Sci. Res. 2018, 4, 108-110.

280. Ariono, D.; Wenten, I.G. Surface modification of ion-exchange membranes: Methods, characteristics, and performance. J. Appl. Polym. Sci. 2017, 134, 45540 .

281. Luo, T.; Abdu, S.; Wessling, M. Selectivity of ion exchange membranes: A review. J. Membr. Sci. 2018, 555, 429-454. [CrossRef]

282. Sata, T. Studies on anion exchange membranes having permselectivity for specific anions in electrodialysis-Effect of hydrophilicity of anion exchange membranes on permselectivity of anions. J. Membr. Sci. 2000, 167, 1-31. [CrossRef]

283. Grebenyuk, V.; Chebotareva, R.; Peters, S.; Linkov, V. Surface modification of anion-exchange electrodialysis membranes to enhance anti-fouling characteristics. Desalination 1998, 115, 313-329. [CrossRef]

284. Mikhaylin, S.; Bazinet, L. Fouling on ion-exchange membranes: Classification, characterization and strategies of prevention and control. Adv. Colloid Interface Sci. 2016, 229, 34-56. [CrossRef] [PubMed]

285. Vaselbehagh, M.; Karkhanechi, H.; Mulyati, S.; Takagi, R.; Matsuyama, H. Improved antifouling of anion-exchange membrane by polydopamine coating in electrodialysis process. Desalination 2014, 332, 126-133. [CrossRef]

286. Vermaas, D.A.; Kunteng, D.; Saakes, M.; Nijmeijer, K. Fouling in reverse electrodialysis under natural conditions. Water Res. 2013, 47, 1289-1298. [CrossRef]

287. Hábová, V.; Melzoch, K.; Rychtera, M.; Sekavová, B. Electrodialysis as a useful technique for lactic acid separation from a model solution and a fermentation broth. Desalination 2004, 162, 361-372. [CrossRef]

288. Madzingaidzo, L.; Danner, H.; Braun, R. Process development and optimisation of lactic acid purification using electrodialysis. J. Biotechnol. 2002, 96, 223-239. [CrossRef]

289. Tran, A.T.; Jullok, N.; Meesschaert, B.; Pinoy, L.; Van der Bruggen, B. Pellet reactor pretreatment: A feasible method to reduce scaling in bipolar membrane electrodialysis. J. Colloid Interface Sci. 2013, 401, 107-115. [CrossRef]

290. Lakretz, A.; Ron, E.Z.; Mamane, H. Biofouling control in water by various UVC wavelengths and doses. Biofouling 2009, 26, 257-267. [CrossRef] [PubMed]

291. Ghyselbrecht, K.; Van Houtte, E.; Pinoy, L.; Verbauwhede, J.; Van der Bruggen, B.; Meesschaert, B. Treatment of RO concentrate by means of a combination of a willow field and electrodialysis. Resour. Conserv. Recycl. 2012, 65, 116-123. [CrossRef]

292. Wang, Q.; Yang, P.; Cong, W. Cation-exchange membrane fouling and cleaning in bipolar membrane electrodialysis of industrial glutamate production wastewater. Sep. Purif. Technol. 2011, 79, 103-113. [CrossRef]

293. Oztekin, E.; Altin, S. Wastewater treatment by electrodialysis system and fouling problems. Turk. Online J. Sci. Technol. 2016, 6, 91-99.

294. Bdiri, M.; Dammak, L.; Chaabane, L.; Larchet, C.; Hellal, F.; Nikonenko, V.; Pismenskaya, N. Cleaning of cation-exchange membranes used in electrodialysis for food industry by chemical solutions. Sep. Purif. Technol. 2018, 199, 114-123. [CrossRef]

295. Guo, H.; You, F.; Yu, S.; Li, L.; Zhao, D. Mechanisms of chemical cleaning of ion exchange membranes: A case study of plant-scale electrodialysis for oily wastewater treatment. J. Membr. Sci. 2015, 496, 310-317. [CrossRef]

296. Garcia-Vasquez, W.; Ghalloussi, R.; Dammak, L.; Larchet, C.; Nikonenko, V.; Grande, D. Structure and properties of heterogeneous and homogeneous ion-exchange membranes subjected to ageing in sodium hypochlorite. J. Membr. Sci. 2014, 452, 104-116. [CrossRef]

297. Bauer, B.; Strathmann, H.; Effenberger, F. Anion-exchange membranes with improved alkaline stability. Desalination 1990, 79, 125-144. [CrossRef]

298. Vaselbehagh, M.; Karkhanechi, H.; Takagi, R.; Matsuyama, H. Effect of polydopamine coating and direct electric current application on anti-biofouling properties of anion exchange membranes in electrodialysis. J. Membr. Sci. 2016, 515, 98-108. [CrossRef]

299. Mulyati, S.; Takagi, R.; Fujii, A.; Ohmukai, Y.; Matsuyama, H. Simultaneous improvement of the monovalent anion selectivity and antifouling properties of an anion exchange membrane in an electrodialysis process, using polyelectrolyte multilayer deposition. J. Membr. Sci. 2013, 431, 113-120. [CrossRef] 
300. Li, Y.; Shi, S.; Cao, H.; Zhao, Z.; Wen, H. Modification and properties characterization of heterogeneous anion-exchange membranes by electrodeposition of graphene oxide (GO). Appl. Surf. Sci. 2018, 442, 700-710. [CrossRef]

301. Pontié, M.; Rejeb, S.B.; Legrand, J. Anti-microbial approach onto cationic-exchange membranes. Sep. Purif. Technol. 2012, 101, 91-97. [CrossRef]

302. Liu, C.; Zhang, D.; He, Y.; Zhao, X.; Bai, R. Modification of membrane surface for anti-biofouling performance: Effect of anti-adhesion and anti-bacteria approaches. J. Membr. Sci. 2010, 346, 121-130. [CrossRef]

303. Yang, H.-L.; Chun-Te Lin, J.; Huang, C. Application of nanosilver surface modification to RO membrane and spacer for mitigating biofouling in seawater desalination. Water Res. 2009, 43, 3777-3786. [CrossRef] [PubMed]

304. Turek, M.; Dydo, P. Electrodialysis reversal of calcium sulphate and calcium carbonate supersaturated solution. Desalination 2003, 158, 91-94. [CrossRef]

305. Turek, M.; Mitko, K.; Piotrowski, K.; Dydo, P.; Laskowska, E.; Jakóbik-Kolon, A. Prospects for high water recovery membrane desalination. Desalination 2017, 401, 180-189. [CrossRef]

306. Mishchuk, N.; Koopal, L.; Gonzalez-Caballero, F. Intensification of electrodialysis by applying a non-stationary electric field. Colloids Surf. A Physicochem. Eng. Asp. 2001, 176, 195-212. [CrossRef]

307. Lee, H.-J.; Park, J.-S.; Moon, S.-H. A study on fouling mitigation using pulsing electric fields in electrodialysis of lactate containing BSA. Korean J. Chem. Eng. 2002, 19, 880-887. [CrossRef]

308. Lee, H.-J.; Moon, S.-H.; Tsai, S.-P. Effects of pulsed electric fields on membrane fouling in electrodialysis of $\mathrm{NaCl}$ solution containing humate. Sep. Purif. Technol. 2002, 27, 89-95. [CrossRef]

309. Lee, H.-J.; Moon, S.-H. Enhancement of electrodialysis performances using pulsing electric fields during extended period operation. J. Colloid Interface Sci. 2005, 287, 597-603. [CrossRef]

310. Cifuentes-Araya, N.; Pourcelly, G.; Bazinet, L. Impact of pulsed electric field on electrodialysis process performance and membrane fouling during consecutive demineralization of a model salt solution containing a high magnesium/calcium ratio. J. Colloid Interface Sci. 2011, 361, 79-89. [CrossRef] [PubMed]

311. Sun, T.R.; Ottosen, L.M. Effects of pulse current on energy consumption and removal of heavy metals during electrodialytic soil remediation. Electrochim. Acta 2012, 86, 28-35. [CrossRef]

312. Mikhaylin, S.; Nikonenko, V.; Pourcelly, G.; Bazinet, L. Intensification of demineralization process and decrease in scaling by application of pulsed electric field with short pulse/pause conditions. J. Membr. Sci. 2014, 468, 389-399. [CrossRef]

313. Cifuentes-Araya, N.; Astudillo-Castro, C.; Bazinet, L. Mechanisms of mineral membrane fouling growth modulated by pulsed modes of current during electrodialysis: Evidences of water splitting implications in the appearance of the amorphous phases of magnesium hydroxide and calcium carbonate. J. Colloid Interface Sci. 2014, 426, 221-234. [CrossRef]

314. Sistat, P.; Huguet, P.; Ruiz, B.; Pourcelly, G.; Mareev, S.; Nikonenko, V. Effect of pulsed electric field on electrodialysis of a NaCl solution in sub-limiting current regime. Electrochim. Acta 2015, 164, 267-280. [CrossRef]

315. Uzdenova, A.M.; Kovalenko, A.V.; Urtenov, M.K.; Nikonenko, V.V. Effect of electroconvection during pulsed electric field electrodialysis. Numerical experiments. Electrochem. Commun. 2015, 51, 1-5. [CrossRef]

316. Mikhaylin, S.; Nikonenko, V.; Pismenskaya, N.; Pourcelly, G.; Choi, S.; Kwon, H.J.; Han, J.; Bazinet, L. How physico-chemical and surface properties of cation-exchange membrane affect membrane scaling and electroconvective vortices: Influence on performance of electrodialysis with pulsed electric field. Desalination 2016, 393, 102-114. [CrossRef]

317. Mikhaylin, S.; Nikonenko, V.; Pourcelly, G.; Bazinet, L. Hybrid bipolar membrane electrodialysis/ultrafiltration technology assisted by a pulsed electric field for casein production. Green Chem. 2016, 18, 307-314. [CrossRef]

318. Andreeva, M.; Gil, V.; Pismenskaya, N.; Dammak, L.; Kononenko, N.; Larchet, C.; Grande, D.; Nikonenko, V. Mitigation of membrane scaling in electrodialysis by electroconvection enhancement, $\mathrm{pH}$ adjustment and pulsed electric field application. J. Membr. Sci. 2018, 549, 129-140. [CrossRef]

319. Ruiz, B.; Sistat, P.; Pourcelly, G.; Huguet, P. Electromembrane process with pulsed electric field. Desalination 2006, $199,62-63$. [CrossRef]

320. Chen, X.; Jiang, Y.; Yang, S.; Pan, J.; Yan, R.; Van der Bruggen, B.; Sotto, A.; Gao, C.; Shen, J. Internal cross-linked anion exchange membranes with improved dimensional stability for electrodialysis. J. Membr. Sci. 2017, 542, 280-288. [CrossRef]

321. Zhou, S.; Hai, S.; Kim, D. Cross-linked Poly (arylene ether ketone) Proton Exchange Membranes with High Ion Exchange Capacity for Fuel Cells. Fuel Cells 2012, 12, 589-598. [CrossRef]

322. Yang, J.; Li, Q.; Cleemann, L.N.; Jensen, J.O.; Pan, C.; Bjerrum, N.J.; He, R. Crosslinked hexafluoropropylidene polybenzimidazole membranes with chloromethyl polysulfone for fuel cell applications. Adv. Energy Mater. 2013, 3, 622-630. [CrossRef]

323. Lee, K.H.; Cho, D.H.; Kim, Y.M.; Moon, S.J.; Seong, J.G.; Shin, D.W.; Sohn, J.-Y.; Kim, J.F.; Lee, Y.M. Highly conductive and durable poly (arylene ether sulfone) anion exchange membrane with end-group cross-linking. Energy Environ. Sci. 2017, 10, 275-285. [CrossRef]

324. Igunnu, E.T.; Chen, G.Z. Produced water treatment technologies. Int. J. Low-Carbon Technol. 2012, 9, 157-177. [CrossRef]

325. Pawlowski, S.; Crespo, J.G.; Velizarov, S. Profiled ion exchange membranes: A comprehensible review. Int. J. Mol. Sci. 2019, 20, 165. [CrossRef] [PubMed]

326. Belfort, G.; Guter, G.A. An experimental study of electrodialysis hydrodynamics. Desalination 1972, 10, 221-262. [CrossRef]

327. Jia, Y.; Yan, C.; Chen, L.; Hu, Y. Optimized Design of Spacer in Electrodialyzer Using CFD Simulation Method. J. Ocean Univ. China 2018, 17, 603-608. [CrossRef] 
328. Mehdizadeh, S.; Yasukawa, M.; Abo, T.; Kakihana, Y.; Higa, M. Effect of spacer geometry on membrane and solution compartment resistances in reverse electrodialysis. J. Membr. Sci. 2019, 572, 271-280. [CrossRef]

329. Gurreri, L.; Tamburini, A.; Cipollina, A.; Micale, G.; Ciofalo, M. CFD prediction of concentration polarization phenomena in spacer-filled channels for reverse electrodialysis. J. Membr. Sci. 2014, 468, 133-148. [CrossRef]

330. Kedem, O. Reduction of polarization in electrodialysis by ion-conducting spacers. Desalination 1975, 16, 105-118. [CrossRef]

331. Korngold, E.; Aronov, L.; Kedem, O. Novel ion-exchange spacer for improving electrodialysis I. Reacted spacer. J. Membr. Sci. 1998, 138, 165-170. [CrossRef]

332. Messalem, R.; Mirsky, Y.; Daltrophe, N.; Saveliev, G.; Kedem, O. Novel ion-exchange spacer for improving electrodialysis II. Coated spacer. J. Membr. Sci. 1998, 138, 171-180. [CrossRef]

333. Długołęcki, P.; van der Wal, A. Energy recovery in membrane capacitive deionization. Environ. Sci. Technol. 2013, 47, 4904-4910. [CrossRef]

334. Balster, J.; Stamatialis, D.; Wessling, M. Towards spacer free electrodialysis. J. Membr. Sci. 2009, 341, 131-138. [CrossRef]

335. Ahdab, Y.D.; Thiel, G.P.; Böhlke, J.K.; Stanton, J.; Lienhard, J.H. Minimum energy requirements for desalination of brackish groundwater in the United States with comparison to international datasets. Water Res. 2018, 141, 387-404. [CrossRef] [PubMed]

336. Honarparvar, S.; Zhang, X.; Chen, T.; Na, C.; Reible, D. Modeling technologies for desalination of brackish water: Toward a sustainable water supply. Curr. Opin. Chem. Eng. 2019, 26, 104-111. [CrossRef]

337. Biesheuvel, P.; Fu, Y.; Bazant, M.Z. Diffuse charge and Faradaic reactions in porous electrodes. Phys. Rev. E $2011,83,061507$. [CrossRef]

338. Hassanvand, A. Membrane Capacitive Deionisation as a Novel Approach to Wastewater Treatment. Ph.D Thesis, The University of Melbourne, Melbourne, Australia, 2018.

339. Volfkovich, Y.M.; Rychagov, A.Y.; Mikhalin, A.; Kardash, M.; Kononenko, N.; Ainetdinov, D.; Shkirskaya, S.; Sosenkin, V. Capacitive deionization of water using mosaic membrane. Desalination 2018, 426, 1-10. [CrossRef]

340. Liang, P.; Yuan, L.; Yang, X.; Zhou, S.; Huang, X. Coupling ion-exchangers with inexpensive activated carbon fiber electrodes to enhance the performance of capacitive deionization cells for domestic wastewater desalination. Water Res. 2013, 47, 2523-2530. [CrossRef]

341. Bian, Y.; Yang, X.; Liang, P.; Jiang, Y.; Zhang, C.; Huang, X. Enhanced desalination performance of membrane capacitive deionization cells by packing the flow chamber with granular activated carbon. Water Res. 2015, 85, 371-376. [CrossRef]

342. Ahmed, M.A.; Tewari, S. Capacitive deionization: Processes, materials and state of the technology. J. Electroanal. Chem. 2018, 813, 178-192. [CrossRef]

343. Huang, Z.-H.; Yang, Z.; Kang, F.; Inagaki, M. Carbon electrodes for capacitive deionization. J. Mater. Chem. A 2017, 5, 470-496. [CrossRef]

344. Zhang, X.; Reible, D. Exploring the Function of Ion-Exchange Membrane in Membrane Capacitive Deionization via a Fully Coupled Two-Dimensional Process Model. Processes 2020, 8, 1312. [CrossRef]

345. Lee, J.-B.; Park, K.-K.; Eum, H.-M.; Lee, C.-W. Desalination of a thermal power plant wastewater by membrane capacitive deionization. Desalination 2006, 196, 125-134. [CrossRef]

346. Blair, J.W.; Murphy, G.W. Electrochemical Demineralization of Water with Porous Electrodes of Large Surface Area; ACS Publication: Washington, DC, USA, 1960; pp. 206-223.

347. Johnson, A.; Venolia, A.; Newman, J.; Wilbourne, R.; Wong, C.; Gillam, W.; Johnson, S.; Horowitz, R. Electrosorb Process for Desalting Water, Office of Saline Water Research and Development; Progress Report No 516, Publication 200 056; US Department of the Interior: Washington, DC, USA, 1970.

348. Pasta, M.; Wessells, C.D.; Cui, Y.; La Mantia, F. A desalination battery. Nano Lett. 2012, 12, 839-843. [CrossRef] [PubMed]

349. Jeon, S.-I.; Park, H.-R.; Yeo, J.-G.; Yang, S.; Cho, C.H.; Han, M.H.; Kim, D.K. Desalination via a new membrane capacitive deionization process utilizing flow-electrodes. Energy Environ. Sci. 2013, 6, 1471-1475. [CrossRef]

350. Lee, J.; Kim, S.; Kim, C.; Yoon, J. Hybrid capacitive deionization to enhance the desalination performance of capacitive techniques. Energy Environ. Sci. 2014, 7, 3683-3689. [CrossRef]

351. Gao, X.; Omosebi, A.; Landon, J.; Liu, K. Surface charge enhanced carbon electrodes for stable and efficient capacitive deionization using inverted adsorption-desorption behavior. Energy Environ. Sci. 2015, 8, 897-909. [CrossRef]

352. Smith, K.C.; Dmello, R. Na-ion desalination (NID) enabled by Na-blocking membranes and symmetric Na-intercalation: Porouselectrode modeling. J. Electrochem. Soc. 2016, 163, A530-A539. [CrossRef]

353. Gao, X.; Omosebi, A.; Landon, J.; Liu, K. Enhanced salt removal in an inverted capacitive deionization cell using amine modified microporous carbon cathodes. Environ. Sci. Technol. 2015, 49, 10920-10926. [CrossRef]

354. Farmer, J.C.; Fix, D.V.; Mack, G.V.; Pekala, R.W.; Poco, J.F. Capacitive, Deionization with Carbon Aerogel Electrodes: Carbonate, Sulfate, and Phosphate; Lawrence Livermore National Lab.: Livermore, CA, USA, 1995.

355. Dai, K.; Shi, L.; Fang, J.; Zhang, D.; Yu, B. NaCl adsorption in multi-walled carbon nanotubes. Mater. Lett. 2005, 59, 1989-1992. [CrossRef]

356. Zou, L.; Li, L.; Song, H.; Morris, G. Using mesoporous carbon electrodes for brackish water desalination. Water Res. 2008, 42, 2340-2348. [CrossRef]

357. Li, H.; Lu, T.; Pan, L.; Zhang, Y.; Sun, Z. Electrosorption behavior of graphene in NaCl solutions. J. Mater. Chem. 2009, 19, 6773-6779. [CrossRef] 
358. Kwak, N.-S.; Koo, J.S.; Hwang, T.S.; Choi, E.M. Synthesis and electrical properties of NaSS-MAA-MMA cation exchange membranes for membrane capacitive deionization (MCDI). Desalination 2012, 285, 138-146. [CrossRef]

359. Kim, Y.-J.; Choi, J.-H. Improvement of desalination efficiency in capacitive deionization using a carbon electrode coated with an ion-exchange polymer. Water Res. 2010, 44, 990-996. [CrossRef]

360. Kim, J.-S.; Choi, J.-H. Fabrication and characterization of a carbon electrode coated with cation-exchange polymer for the membrane capacitive deionization applications. J. Membr. Sci. 2010, 355, 85-90. [CrossRef]

361. Hassanvand, A.; Wei, K.; Talebi, S.; Chen, G.Q.; Kentish, S.E. The role of ion exchange membranes in membrane capacitive deionisation. Membranes 2017, 7, 54. [CrossRef] [PubMed]

362. Kang, K.W.; Hwang, C.W.; Hwang, T.S. Synthesis and properties of sodium vinylbenzene sulfonate-grafted poly (vinylidene fluoride) cation exchange membranes for membrane capacitive deionization process. Macromol. Res. 2015, 23, 1126-1133. [CrossRef]

363. Jeong, K.S.; Hwang, W.C.; Hwang, T.S. Synthesis of an aminated poly (vinylidene fluride-g-4-vinyl benzyl chloride) anion exchange membrane for membrane capacitive deionization (MCDI). J. Membr. Sci. 2015, 495, 316-321. [CrossRef]

364. Jain, A.; Weathers, C.; Kim, J.; Meyer, M.D.; Walker, W.S.; Li, Q.; Verduzco, R. Self assembled, sulfonated pentablock copolymer cation exchange coatings for membrane capacitive deionization. Mol. Syst. Des. Eng. 2019, 4, 348-356. [CrossRef]

365. Qiu, Q.; Cha, J.-H.; Choi, Y.-W.; Choi, J.-H.; Shin, J.; Lee, Y.-S. Preparation of stable polyethylene membranes filled with crosslinked sulfonated polystyrene for membrane capacitive deionization by $\gamma$-irradiation. Macromol. Res. 2017, 25, 92-95. [CrossRef]

366. Qiu, Q.; Cha, J.-H.; Choi, Y.-W.; Choi, J.-H.; Shin, J.; Lee, Y.-S. Preparation of polyethylene membranes filled with crosslinked sulfonated polystyrene for cation exchange and transport in membrane capacitive deionization process. Desalination 2017, 417, 87-93. [CrossRef]

367. Kim, D.-H.; Choi, Y.-E.; Park, J.-S.; Kang, M.-S. Capacitive deionization employing pore-filled cation-exchange membranes for energy-efficient removal of multivalent cations. Electrochim. Acta 2019, 295, 164-172. [CrossRef]

368. Ul Haq, O.; Choi, J.-H.; Lee, Y.-S. Anion-exchange membrane for membrane capacitive deionization prepared via pore-filling polymerization in a porous polyethylene supporting membrane. React. Funct. Polym. 2018, 132, 36-42. [CrossRef]

369. Gaikwad, M.S.; Balomajumder, C. Polymer coated capacitive deionization electrode for desalination: A mini review. Electrochem. Energy Technol. 2016, 2, 2. [CrossRef]

370. Kim, J.S.; Jeon, Y.S.; Rhim, J.W. Application of poly (vinyl alcohol) and polysulfone based ionic exchange polymers to membrane capacitive deionization for the removal of mono-and divalent salts. Sep. Purif. Technol. 2016, 157, 45-52. [CrossRef]

371. McNair, R.; Szekely, G.; Dryfe, R.A. Ion-Exchange Materials for Membrane Capacitive Deionization. ACS ESET Water 2021, 1, 217-239. [CrossRef]

372. Choi, J.-H. Comparison of constant voltage (CV) and constant current (CC) operation in the membrane capacitive deionisation process. Desalination Water Treat. 2015, 56, 921-928. [CrossRef]

373. Kang, J.; Kim, T.; Jo, K.; Yoon, J. Comparison of salt adsorption capacity and energy consumption between constant current and constant voltage operation in capacitive deionization. Desalination 2014, 352, 52-57. [CrossRef]

374. Qu, Y.; Campbell, P.G.; Gu, L.; Knipe, J.M.; Dzenitis, E.; Santiago, J.G.; Stadermann, M. Energy consumption analysis of constant voltage and constant current operations in capacitive deionization. Desalination 2016, 400, 18-24. [CrossRef]

375. Saleem, M.W.; Jande, Y.; Asif, M.; Kim, W.-S. Hybrid CV-CC operation of capacitive deionization in comparison with constant current and constant voltage. Sep. Sci. Technol. 2016, 51, 1063-1069. [CrossRef]

376. Wang, L.; Lin, S. Membrane capacitive deionization with constant current vs constant voltage charging: Which is better? Environ. Sci. Technol. 2018, 52, 4051-4060. [CrossRef]

377. Dykstra, J.; Porada, S.; van der Wal, A.; Biesheuvel, P. Energy consumption in capacitive deionization-Constant current versus constant voltage operation. Water Res. 2018, 143, 367-375. [CrossRef] [PubMed]

378. Kim, T.; Dykstra, J.; Porada, S.; Van Der Wal, A.; Yoon, J.; Biesheuvel, P. Enhanced charge efficiency and reduced energy use in capacitive deionization by increasing the discharge voltage. J. Colloid Interface Sci. 2015, 446, 317-326. [CrossRef]

379. Tang, W.; Liang, J.; He, D.; Gong, J.; Tang, L.; Liu, Z.; Wang, D.; Zeng, G. Various cell architectures of capacitive deionization: Recent advances and future trends. Water Res. 2019, 150, 225-251. [CrossRef]

380. Guyes, E.N.; Simanovski, A.; Suss, M.E. Several orders of magnitude increase in the hydraulic permeability of flow-through capacitive deionization electrodes via laser perforations. RSC Adv. 2017, 7, 21308-21313. [CrossRef]

381. Fritz, P.A.; Boom, R.; Schroen, K. Polyelectrolyte-activated carbon composite electrodes for inverted membrane capacitive deionization (iMCDI). Sep. Purif. Technol. 2019, 220, 145-151. [CrossRef]

382. Rommerskirchen, A.; Gendel, Y.; Wessling, M. Single module flow-electrode capacitive deionization for continuous water desalination. Electrochem. Commun. 2015, 60, 34-37. [CrossRef]

383. Yang, S.; Choi, J.; Yeo, J.-G.; Jeon, S.-I.; Park, H.-R.; Kim, D.K. Flow-electrode capacitive deionization using an aqueous electrolyte with a high salt concentration. Environ. Sci. Technol. 2016, 50, 5892-5899. [CrossRef]

384. Ma, J.; He, C.; He, D.; Zhang, C.; Waite, T.D. Analysis of capacitive and electrodialytic contributions to water desalination by flow-electrode CDI. Water Res. 2018, 144, 296-303. [CrossRef]

385. Fang, K.; Gong, H.; He, W.; Peng, F.; He, C.; Wang, K. Recovering ammonia from municipal wastewater by flow-electrode capacitive deionization. Chem. Eng. J. 2018, 348, 301-309. [CrossRef] 
386. Cho, Y.; Yoo, C.-Y.; Lee, S.W.; Yoon, H.; Lee, K.S.; Yang, S.; Kim, D.K. Flow-electrode capacitive deionization with highly enhanced salt removal performance utilizing high-aspect ratio functionalized carbon nanotubes. Water Res. 2019, 151, 252-259. [CrossRef] [PubMed]

387. Yang, S.; Park, H.-R.; Yoo, J.; Kim, H.; Choi, J.; Han, M.H.; Kim, D.K. Plate-shaped graphite for improved performance of flow-electrode capacitive deionization. J. Electrochem. Soc. 2017, 164, E480-E488. [CrossRef]

388. Liu, Z.; Yue, Z.; $\mathrm{Li}, \mathrm{H}$. $\mathrm{Na}_{0.71} \mathrm{CoO}_{2}$ promoted sodium uptake via faradaic reaction for highly efficient capacitive deionization. Sep. Purif. Technol. 2019, 234, 116090. [CrossRef]

389. Li, M.; Park, H.G. Pseudocapacitive coating for effective capacitive deionization. ACS Appl. Mater. Interfaces 2018, 10, 2442-2450. [CrossRef]

390. Reale, E.R.; Shrivastava, A.; Smith, K.C. Effect of conductive additives on the transport properties of porous flow-through electrodes with insulative particles and their optimization for Faradaic deionization. Water Res. 2019, 165, 114995. [CrossRef]

391. Singh, K.; Porada, S.; De Gier, H.; Biesheuvel, P.; De Smet, L. Timeline on the application of intercalation materials in Capacitive Deionization. Desalination 2019, 455, 115-134. [CrossRef]

392. Tu, Y.-H.; Liu, C.-F.; Wang, J.-A.; Hu, C.-C. Construction of an inverted-capacitive deionization system utilizing pseudocapacitive materials. Electrochem. Commun. 2019, 104, 106486. [CrossRef]

393. Pernía, A.M.; Prieto, M.J.; Martín-Ramos, J.A.; Villegas, P.J.; Álvarez-González, F.J. Energy Recovery in Capacitive Deionization Technology. Desalination Water Treat. 2018, 37-54. [CrossRef]

394. Chen, L.; Yin, X.; Zhu, L.; Qiu, Y. Energy recovery and electrode regeneration under different charge/discharge conditions in membrane capacitive deionization. Desalination 2018, 439, 93-101. [CrossRef]

395. Kang, J.; Kim, T.; Shin, H.; Lee, J.; Ha, J.-I.; Yoon, J. Direct energy recovery system for membrane capacitive deionization. Desalination 2016, 398, 144-150. [CrossRef]

396. Chen, Y.-W.; Chen, J.-F.; Lin, C.-H.; Hou, C.-H. Integrating a supercapacitor with capacitive deionization for direct energy recovery from the desalination of brackish water. Appl. Energy 2019, 252, 113417. [CrossRef]

397. Tan, C.; He, C.; Fletcher, J.; Waite, T.D. Energy recovery in pilot scale membrane CDI treatment of brackish waters. Water Res. 2020, 168, 115146. [CrossRef] [PubMed]

398. Ma, J.; Liang, P.; Sun, X.; Zhang, H.; Bian, Y.; Yang, F.; Bai, J.; Gong, Q.; Huang, X. Energy recovery from the flow-electrode capacitive deionization. J. Power Sources 2019, 421, 50-55. [CrossRef]

399. Porada, S.; Weingarth, D.; Hamelers, H.; Bryjak, M.; Presser, V.; Biesheuvel, P. Carbon flow electrodes for continuous operation of capacitive deionization and capacitive mixing energy generation. J. Mater. Chem. A 2014, 2, 9313-9321. [CrossRef]

400. Lim, H.; Ha, Y.; Jung, H.B.; Jo, P.S.; Yoon, H.; Quyen, D.; Cho, N.; Yoo, C.-Y.; Cho, Y. Energy Storage and Generation through Desalination Using Flow-Electrodes Capacitive Deionization. J. Ind. Eng. Chem. 2020, 81, 317-322. [CrossRef]

401. Laxman, K.; Kimoto, D.; Sahakyan, A.; Dutta, J. Nanoparticulate Dielectric Overlayer for Enhanced Electric Fields in a Capacitive Deionization Device. ACS Appl. Mater. Interfaces 2018, 10, 5941-5948. [CrossRef]

402. Zhao, R.; Biesheuvel, P.; Miedema, H.; Bruning, H.; Van der Wal, A. Charge efficiency: A functional tool to probe the double-layer structure inside of porous electrodes and application in the modeling of capacitive deionization. J. Phys. Chem. Lett. 2009, 1, 205-210. [CrossRef]

403. Ma, J.; Wang, L.; Yu, F.; Dai, X. Mesoporous amorphous $\mathrm{FePO}_{4}$ nanosphere@ Graphene as a faradic electrode in capacitive deionization for high-capacity and fast removal of $\mathrm{NaCl}$ from water. Chem. Eng. J. 2019, 370, 938-943. [CrossRef]

404. Li, H.; Zaviska, F.; Liang, S.; Li, J.; He, L.; Yang, H.Y. A high charge efficiency electrode by self-assembling sulphonated reduced graphene oxide onto carbon fibre: Towards enhanced capacitive deionization. J. Mater. Chem. A 2014, 2, 3484-3491. [CrossRef]

405. Cohen, I.; Avraham, E.; Noked, M.; Soffer, A.; Aurbach, D. Enhanced charge efficiency in capacitive deionization achieved by surface-treated electrodes and by means of a third electrode. J. Phys. Chem. C 2011, 115, 19856-19863. [CrossRef]

406. Liu, X.; Liu, H.; Mi, M.; Kong, W.; Ge, Y.; Hu, J. Nitrogen-doped hierarchical porous carbon aerogel for high-performance capacitive deionization. Sep. Purif. Technol. 2019, 224, 44-50. [CrossRef]

407. Al Suwaidi, F.; Younes, H.; Sreepal, V.; Nair, R.R.; Aubry, C.; Zou, L. Strategies for tuning hierarchical porosity of 3D rGO to optimize ion electrosorption. 2D Mater. 2019, 6, 045010. [CrossRef]

408. Biesheuvel, P.; Porada, S.; Levi, M.; Bazant, M.Z. Attractive forces in microporous carbon electrodes for capacitive deionization. J. Solid State Electrochem. 2014, 18, 1365-1376. [CrossRef]

409. Kim, C.; Srimuk, P.; Lee, J.; Fleischmann, S.; Aslan, M.; Presser, V. Influence of pore structure and cell voltage of activated carbon cloth as a versatile electrode material for capacitive deionization. Carbon 2017, 122, 329-335. [CrossRef]

410. Chmiola, J.; Yushin, G.; Gogotsi, Y.; Portet, C.; Simon, P.; Taberna, P.-L. Anomalous increase in carbon capacitance at pore sizes less than 1 nanometer. Science 2006, 313, 1760-1763. [CrossRef]

411. Lin, C.; Ritter, J.A.; Popov, B.N. Correlation of double-layer capacitance with the pore structure of sol-gel derived carbon xerogels. J. Electrochem. Soc. 1999, 146, 3639-3643. [CrossRef]

412. Yang, K.-L.; Ying, T.-Y.; Yiacoumi, S.; Tsouris, C.; Vittoratos, E.S. Electrosorption of ions from aqueous solutions by carbon aerogel: An electrical double-layer model. Langmuir 2001, 17, 1961-1969. [CrossRef]

413. Brown, M.A.; Goel, A.; Abbas, Z. Effect of electrolyte concentration on the stern layer thickness at a charged interface. Angew. Chem. Int. Ed. 2016, 55, 3790-3794. [CrossRef] 
414. Han, L.; Karthikeyan, K.; Anderson, M.A.; Gregory, K.B. Exploring the impact of pore size distribution on the performance of carbon electrodes for capacitive deionization. J. Colloid Interface Sci. 2014, 430, 93-99. [CrossRef]

415. Zhang, Y.; Wang, G.; Wang, S.; Wang, J.; Qiu, J. Boron-nitride-carbon Nanosheets with Different Pore Structure and Surface Properties for Capacitive Deionization. J. Colloid Interface Sci. 2019, 552, 604-612. [CrossRef]

416. Elisadiki, J.; Kibona, T.E.; Machunda, R.L.; Saleem, M.W.; Kim, W.-S.; Jande, Y.A. Biomass-based carbon electrode materials for capacitive deionization: A review. Biomass Convers. Biorefinery 2020, 10, 1327-1356. [CrossRef]

417. Quan, G.; Wang, H.; Zhu, F.; Yan, J. Porous biomass carbon coated with $\mathrm{SiO}_{2}$ as high performance electrodes for capacitive deionization. BioResources 2018, 13, 437-449. [CrossRef]

418. Hai, A.; Bharath, G.; Babu, K.R.; Taher, H.; Naushad, M.; Banat, F. Date seeds biomass-derived activated carbon for efficient removal of $\mathrm{NaCl}$ from saline solution. Process Saf. Environ. Prot. 2019, 129, 103-111. [CrossRef]

419. Zhang, Y.; Ji, L.; Zheng, Y.; Liu, H.; Xu, X. Nanopatterned metal-organic framework electrodes with improved capacitive deionization properties for highly efficient water desalination. Sep. Purif. Technol. 2020, 234, 116124. [CrossRef]

420. Ding, M.; Shi, W.; Guo, L.; Leong, Z.Y.; Baji, A.; Yang, H.Y. Bimetallic metal-organic framework derived porous carbon nanostructures for high performance membrane capacitive desalination. J. Mater. Chem. A 2017, 5, 6113-6121. [CrossRef]

421. Wu, Q.; Liang, D.; Ma, X.; Lu, S.; Xiang, Y. Chitosan-based activated carbon as economic and efficient sustainable material for capacitive deionization of low salinity water. RSC Adv. 2019, 9, 26676-26684. [CrossRef]

422. Sriramulu, D.; Vafakhah, S.; Yang, H.Y. Activated Luffa derived biowaste carbon for enhanced desalination performance in brackish water. RSC Adv. 2019, 9, 14884-14892. [CrossRef]

423. Zhao, Y.; Zhang, Y.; Tian, P.; Wang, L.; Li, K.; Lv, C.; Liang, B. Nitrogen-rich mesoporous carbons derived from zeolitic imidazolate framework-8 for efficient capacitive deionization. Electrochim. Acta 2019, 321, 134665. [CrossRef]

424. Li, Y.; Qi, J.; Li, J.; Shen, J.; Liu, Y.; Sun, X.; Shen, J.; Han, W.; Wang, L. Nitrogen-doped hollow mesoporous carbon spheres for efficient water desalination by capacitive deionization. ACS Sustain. Chem. Eng. 2017, 5, 6635-6644. [CrossRef]

425. Xu, D.; Tong, Y.; Yan, T.; Shi, L.; Zhang, D. N, P-codoped meso-/microporous carbon derived from biomass materials via a dual-activation strategy as high-performance electrodes for deionization capacitors. ACS Sustain. Chem. Eng. 2017, 5, 5810-5819. [CrossRef]

426. Zhang, J.; Fang, J.; Han, J.; Yan, T.; Shi, L.; Zhang, D. N, P, S co-doped hollow carbon polyhedra derived from MOF-based core-shell nanocomposites for capacitive deionization. J. Mater. Chem. A 2018, 6, 15245-15252. [CrossRef]

427. Yasin, A.S.; Mohamed, A.Y.; Mohamed, I.M.; Cho, D.-Y.; Park, C.H.; Kim, C.S. Theoretical insight into the structure-property relationship of mixed transition metal oxides nanofibers doped in activated carbon and 3D graphene for capacitive deionization. Chem. Eng. J. 2019, 371, 166-181. [CrossRef]

428. Min, X.; Hu, X.; Li, X.; Wang, H.; Yang, W. Synergistic effect of nitrogen, sulfur-codoping on porous carbon nanosheets as highly efficient electrodes for capacitive deionization. J. Colloid Interface Sci. 2019, 550, 147-158. [CrossRef] [PubMed]

429. Jia, B.; Zou, L. Wettability and its influence on graphene nansoheets as electrode material for capacitive deionization. Chem. Phys. Lett. 2012, 548, 23-28. [CrossRef]

430. Cheng, Y.; Hao, Z.; Hao, C.; Deng, Y.; Li, X.; Li, K.; Zhao, Y. A review of modification of carbon electrode material in capacitive deionization. RSC Adv. 2019, 9, 24401-24419. [CrossRef]

431. Alencherry, T.; Naveen, A.; Ghosh, S.; Daniel, J.; Venkataraghavan, R. Effect of increasing electrical conductivity and hydrophilicity on the electrosorption capacity of activated carbon electrodes for capacitive deionization. Desalination 2017, 415, 14-19. [CrossRef]

432. Li, D.; Wang, S.; Wang, G.; Li, C.; Che, X.; Wang, S.; Zhang, Y.; Qiu, J. Facile Fabrication of NiCoAl-Layered Metal Oxide/Graphene Nanosheets for Efficient Capacitive Deionization Defluorination. ACS Appl. Mater. Interfaces 2019, 11, 31200-31209. [CrossRef] [PubMed]

433. Leong, Z.Y.; Lu, G.; Yang, H.Y. Three-dimensional graphene oxide and polyvinyl alcohol composites as structured activated carbons for capacitive desalination. Desalination 2019, 451, 172-181. [CrossRef]

434. Li, D.; Ning, X.-A.; Huang, Y.; Li, S. Nitrogen-rich microporous carbon materials for high-performance membrane capacitive deionization. Electrochim. Acta 2019, 312, 251-262. [CrossRef]

435. Hojati-Talemi, P.; Zou, L.; Fabretto, M.; Short, R.D. Using oxygen plasma treatment to improve the performance of electrodes for capacitive water deionization. Electrochim. Acta 2013, 106, 494-499. [CrossRef]

436. Liu, P.; Wang, H.; Yan, T.; Zhang, J.; Shi, L.; Zhang, D. Grafting sulfonic and amine functional groups on 3D graphene for improved capacitive deionization. J. Mater. Chem. A 2016, 4, 5303-5313. [CrossRef]

437. Ma, D.; Cai, Y.; Wang, Y.; Xu, S.; Wang, J.; Ullah Khan, M. Grafting the charged functional groups on carbon nanotubes for improving the efficiency and stability of capacitive deionization process. ACS Appl. Mater. Interfaces 2019, 11, 17617-17628. [CrossRef]

438. Singh, K.; Bouwmeester, H.; de Smet, L.; Bazant, M.; Biesheuvel, P. Theory of water desalination with intercalation materials. Phys. Rev. Appl. 2018, 9, 064036. [CrossRef]

439. Yu, F.; Wang, L.; Wang, Y.; Shen, X.; Cheng, Y.; Ma, J. Faradaic Reactions in Capacitive Deionization for Desalination and Ion Separation. J. Mater. Chem. A 2019, 7, 15999-16027. [CrossRef]

440. Omosebi, A.; Gao, X.; Landon, J.; Liu, K. Asymmetric electrode configuration for enhanced membrane capacitive deionization. ACS Appl. Mater. Interfaces 2014, 6, 12640-12649. [CrossRef] [PubMed] 
441. Wang, S.; Wang, G.; Che, X.; Wang, S.; Li, C.; Li, D.; Zhang, Y.; Dong, Q.; Qiu, J. Enhancing the capacitive deionization performance of $\mathrm{NaMnO}_{2}$ by interface engineering and redox-reaction. Environ. Sci. Nano 2019, 6, 2379-2388. [CrossRef]

442. Kong, H.; Yang, M.; Miao, Y.; Zhao, X. Polypyrrole as a Novel Chloride-Storage Electrode for Seawater Desalination. Energy Technol. 2019, 7, 1900835. [CrossRef]

443. Yue, Z.; Gao, T.; Li, H. Robust synthesis of carbon@ $\mathrm{Na}_{4} \mathrm{Ti}_{9} \mathrm{O}_{20}$ core-shell nanotubes for hybrid capacitive deionization with enhanced performance. Desalination 2019, 449, 69-77. [CrossRef]

444. Cao, J.; Wang, Y.; Wang, L.; Yu, F.; Ma, J. $\mathrm{Na}_{3} \mathrm{~V}_{2}\left(\mathrm{PO}_{4}\right) 3 @ \mathrm{C}$ as faradaic electrodes in capacitive deionization for high-performance desalination. Nano Lett. 2019, 19, 823-828. [CrossRef] [PubMed]

445. Wang, Z.; Wang, Y.; Ma, D.; Xu, S.; Wang, J. Investigations on the fouling characteristics of ion-doped polypyrrole/carbon nanotube composite electrodes in capacitive deionization by using half cycle running mode. Sep. Purif. Technol. 2018, 192, 15-20. [CrossRef]

446. Hassanvand, A.; Chen, G.; Webley, P.; Kentish, S. An investigation of the impact of fouling agents in capacitive and membrane capacitive deionisation. Desalination 2019, 457, 96-102. [CrossRef]

447. Zhang, W.; Mossad, M.; Zou, L. A study of the long-term operation of capacitive deionisation in inland brackish water desalination. Desalination 2013, 320, 80-85. [CrossRef]

448. Mossad, M.; Zou, L. Study of fouling and scaling in capacitive deionisation by using dissolved organic and inorganic salts. J. Hazard. Mater. 2013, 244, 387-393. [CrossRef]

449. Zhang, W.; Jia, B. Toward anti-fouling capacitive deionization by using visible-light reduced $\mathrm{TiO}_{2} /$ graphene nanocomposites. MRS Commun. 2015, 5, 613-617. [CrossRef]

450. Zhang, P.; Fritz, P.A.; Schroën, K.; Duan, H.; Boom, R.M.; Chan-Park, M.B. Zwitterionic polymer modified porous carbon for high-performance and antifouling capacitive desalination. ACS Appl. Mater. Interfaces 2018, 10, 33564-33573. [CrossRef]

451. Liang, S.; Li, M.; Cao, J.; Zuo, K.; Bian, Y.; Xiao, K.; Huang, X. Integrated ultrafiltration capacitive-deionization (UCDI) for enhanced antifouling performance and synchronous removal of organic matter and salts. Sep. Purif. Technol. 2019, 226, 146-153. [CrossRef]

452. Chen, L.; Wang, C.; Liu, S.; Hu, Q.; Zhu, L.; Cao, C. Investigation of the long-term desalination performance of membrane capacitive deionization at the presence of organic foulants. Chemosphere 2018, 193, 989-997. [CrossRef] [PubMed]

453. Wang, C.; Chen, L.; Zhu, L. Effect of combined fouling on desalination performance of membrane capacitive deionization (MCDI) during long-term operation. J. Dispers. Sci. Technol. 2019, 41, 383-392. [CrossRef]

454. Zhang, C.; He, D.; Ma, J.; Tang, W.; Waite, T.D. Faradaic reactions in capacitive deionization (CDI)-problems and possibilities: A review. Water Res. 2018, 128, 314-330. [CrossRef] [PubMed]

455. Han, L.; Karthikeyan, K.; Gregory, K.B. Energy consumption and recovery in capacitive deionization using nanoporous activated carbon electrodes. J. Electrochem. Soc. 2015, 162, E282-E288. [CrossRef]

456. Choi, J.-Y.; Choi, J.-H. A carbon electrode fabricated using a poly (vinylidene fluoride) binder controlled the Faradaic reaction of carbon powder. J. Ind. Eng. Chem. 2010, 16, 401-405. [CrossRef]

457. Gao, X.; Omosebi, A.; Holubowitch, N.; Liu, A.; Ruh, K.; Landon, J.; Liu, K. Polymer-coated composite anodes for efficient and stable capacitive deionization. Desalination 2016, 399, 16-20. [CrossRef]

458. Evans, S.F.; Ivancevic, M.R.; Wilson, D.J.; Hood, Z.D.; Adhikari, S.P.; Naskar, A.K.; Tsouris, C.; Paranthaman, M.P. Carbon polyaniline capacitive deionization electrodes with stable cycle life. Desalination 2019, 464, 25-32. [CrossRef]

459. Min, B.H.; Choi, J.-H.; Jung, K.Y. Improvement of capacitive deionization performance via using a Tiron-grafted TiO 2 nanoparticle layer on porous carbon electrode. Korean J. Chem. Eng. 2018, 35, 272-282. [CrossRef]

460. Srimuk, P.; Zeiger, M.; Jäckel, N.; Tolosa, A.; Krüner, B.; Fleischmann, S.; Grobelsek, I.; Aslan, M.; Shvartsev, B.; Suss, M.E. Enhanced performance stability of carbon/titania hybrid electrodes during capacitive deionization of oxygen saturated saline water. Electrochim. Acta 2017, 224, 314-328. [CrossRef]

461. Choi, J.-H.; Yoon, D.-J. The maximum allowable charge for operating membrane capacitive deionization without electrode reactions. Sep. Purif. Technol. 2019, 215, 125-133. [CrossRef]

462. Hemmatifar, A. Energy Consumption and Salt Adsorption in Capacitive Deionization. Ph.D. Thesis, Stanford University, Stanford, CA, USA, 2018.

463. Tang, W.; He, D.; Zhang, C.; Kovalsky, P.; Waite, T.D. Comparison of Faradaic reactions in capacitive deionization (CDI) and membrane capacitive deionization (MCDI) water treatment processes. Water Res. 2017, 120, 229-237. [CrossRef]

464. Palakkal, V.M.; Rubio, J.E.; Lin, Y.J.; Arges, C.G. Low-resistant ion-exchange membranes for energy efficient membrane capacitive deionization. ACS Sustain. Chem. Eng. 2018, 6, 13778-13786. [CrossRef]

465. Zhang, C.; He, D.; Ma, J.; Tang, W.; Waite, T.D. Comparison of faradaic reactions in flow-through and flow-by capacitive deionization (CDI) systems. Electrochim. Acta 2019, 299, 727-735. [CrossRef]

466. Volfkovich, Y.M. Capacitive deionization of water (a review). Russ. J. Electrochem. 2020, 56, 18-51. [CrossRef]

467. Suss, M.; Porada, S.; Sun, X.; Biesheuvel, P.; Yoon, J.; Presser, V. Water desalination via capacitive deionization: What is it and what can we expect from it? Energy Environ. Sci. 2015, 8, 2296-2319. [CrossRef]

468. Zhao, Y.; Wang, Y.; Wang, R.; Wu, Y.; Xu, S.; Wang, J. Performance comparison and energy consumption analysis of capacitive deionization and membrane capacitive deionization processes. Desalination 2013, 324, 127-133. [CrossRef] 
469. Qin, M.; Deshmukh, A.; Epsztein, R.; Patel, S.K.; Owoseni, O.M.; Walker, W.S.; Elimelech, M. Comparison of energy consumption in desalination by capacitive deionization and reverse osmosis. Desalination 2019, 455, 100-114. [CrossRef]

470. Qin, M.; Deshmukh, A.; Epsztein, R.; Patel, S.K.; Owoseni, O.M.; Walker, W.S.; Elimelech, M. Response to comments on "comparison of energy consumption in desalination by capacitive deionization and reverse osmosis". Desalination 2019, 462, 48-55. [CrossRef]

471. Porada, S.; Zhang, L.; Dykstra, J. Energy consumption in membrane capacitive deionization and comparison with reverse osmosis. Desalination 2020, 488, 114383. [CrossRef]

472. Beltrán, J.M. Irrigation with saline water: Benefits and environmental impact. Agric. Water Manag. 1999, 40, 183-194. [CrossRef]

473. Feizi, M.; Hajabbasi, M.A.; Mostafazadeh-Fard, B. Saline Irrigation Water Management Strategies for Better Yield of Safflower ('Carthamus tinctorius' L.) in an Arid Region. Aust. J. Crop Sci. 2010, 4, 408.

474. Zhou, D.; Zhu, L.; Fu, Y.; Zhu, M.; Xue, L. Development of lower cost seawater desalination processes using nanofiltration technologies-A review. Desalination 2015, 376, 109-116. [CrossRef]

475. White, N.; Misovich, M.; Alemayehu, E.; Yaroshchuk, A.; Bruening, M.L. Highly selective separations of multivalent and monovalent cations in electrodialysis through Nafion membranes coated with polyelectrolyte multilayers. Polymer 2016, 103, 478-485. [CrossRef]

476. Ortiz, J.M.; Sotoca, J.A.; Exposito, E.; Gallud, F.; Garcia-Garcia, V.; Montiel, V.; Aldaz, A. Brackish water desalination by electrodialysis: Batch recirculation operation modeling. J. Membr. Sci. 2005, 252, 65-75. [CrossRef]

477. Tsiakis, P.; Papageorgiou, L.G. Optimal design of an electrodialysis brackish water desalination plant. Desalination 2005, 173, 173-186. [CrossRef]

478. Valero, F.; Arbós, R. Desalination of brackish river water using Electrodialysis Reversal (EDR): Control of the THMs formation in the Barcelona (NE Spain) area. Desalination 2010, 253, 170-174. [CrossRef]

479. Ali, M.B.S.; Mnif, A.; Hamrouni, B.; Dhahbi, M. Electrodialytic desalination of brackish water: Effect of process parameters and water characteristics. Ionics 2010, 16, 621-629.

480. Wenten, I.G.; Arfianto, F. Bench scale electrodeionization for high pressure boiler feed water. Desalination 2013, 314, 109-114. [CrossRef]

481. Ji, Z.-Y.; Chen, Q.-B.; Yuan, J.-S.; Liu, J.; Zhao, Y.-Y.; Feng, W.-X. Preliminary study on recovering lithium from high $\mathrm{Mg}^{2+} / \mathrm{Li}^{+}$ ratio brines by electrodialysis. Sep. Purif. Technol. 2017, 172, 168-177. [CrossRef]

482. Hoshino, T. Lithium recovery from seawater by electrodialysis using ionic liquid-based membrane technology. ECS Trans. 2014, 58, 173-177. [CrossRef]

483. Montaña, M.; Camacho, A.; Serrano, I.; Devesa, R.; Matia, L.; Vallés, I. Removal of radionuclides in drinking water by membrane treatment using ultrafiltration, reverse osmosis and electrodialysis reversal. J. Environ. Radioact. 2013, 125, 86-92. [CrossRef]

484. Gabarrón, S.; Gernjak, W.; Valero, F.; Barceló, A.; Petrovic, M.; Rodríguez-Roda, I. Evaluation of emerging contaminants in a drinking water treatment plant using electrodialysis reversal technology. J. Hazard. Mater. 2016, 309, 192-201. [CrossRef]

485. Fu, F.; Wang, Q. Removal of heavy metal ions from wastewaters: A review. J. Environ. Manag. 2011, 92, 407-418. [CrossRef]

486. Zhang, Y.; Ghyselbrecht, K.; Vanherpe, R.; Meesschaert, B.; Pinoy, L.; Van der Bruggen, B. RO concentrate minimization by electrodialysis: Techno-economic analysis and environmental concerns. J. Environ. Manag. 2012, 107, 28-36. [CrossRef]

487. Bernardes, A.; Rodrigues, M.; Ferreira, J.Z. Electrodialysis and Water Reuse; Springer: Berlin/Heidelberg, Germany, 2016.

488. Sosa-Fernandez, P.; Post, J.; Bruning, H.; Leermakers, F.; Rijnaarts, H. Electrodialysis-based desalination and reuse of sea and brackish polymer-flooding produced water. Desalination 2018, 447, 120-132. [CrossRef]

489. Burn, S.; Hoang, M.; Zarzo, D.; Olewniak, F.; Campos, E.; Bolto, B.; Barron, O. Desalination techniques-A review of the opportunities for desalination in agriculture. Desalination 2015, 364, 2-16. [CrossRef]

490. Kim, D.H. A review of desalting process techniques and economic analysis of the recovery of salts from retentates. Desalination 2011, 270, 1-8. [CrossRef]

491. Nayar, K.G.; Sundararaman, P.; O'Connor, C.L.; Schacherl, J.D.; Heath, M.L.; Gabriel, M.O.; Shah, S.R.; Wright, N.C.; Winter, A.G. Feasibility study of an electrodialysis system for in-home water desalination in urban India. Dev. Eng. 2017, 2, 38-46. [CrossRef]

492. Cherif, A.T.; Molenat, J.; Elmidaoui, A. Nitric acid and sodium hydroxide generation by electrodialysis using bipolar membranes. J. Appl. Electrochem. 1997, 27, 1069-1074. [CrossRef]

493. Zhang, Y.; Desmidt, E.; Van Looveren, A.; Pinoy, L.; Meesschaert, B.; Van der Bruggen, B. Phosphate separation and recovery from wastewater by novel electrodialysis. Environ. Sci. Technol. 2013, 47, 5888-5895. [CrossRef]

494. Ward, A.J.; Arola, K.; Brewster, E.T.; Mehta, C.M.; Batstone, D.J. Nutrient recovery from wastewater through pilot scale electrodialysis. Water Res. 2018, 135, 57-65. [CrossRef]

495. Huang, C.; Xu, T.; Zhang, Y.; Xue, Y.; Chen, G. Application of electrodialysis to the production of organic acids: State-of-the-art and recent developments. J. Membr. Sci. 2007, 288, 1-12. [CrossRef]

496. Choi, J.; Dorji, P.; Shon, H.K.; Hong, S. Applications of capacitive deionization: Desalination, softening, selective removal, and energy efficiency. Desalination 2019, 449, 118-130. [CrossRef]

497. Kalfa, A.; Shapira, B.; Shopin, A.; Cohen, I.; Avraham, E.; Aurbach, D. Capacitive deionization for wastewater treatment: Opportunities and challenges. Chemosphere 2020, 241, 125003. [CrossRef]

498. Liu, X.; Shanbhag, S.; Bartholomew, T.V.; Whitacre, J.F.; Mauter, M.S. Cost Comparison of Capacitive Deionization and Reverse Osmosis for Brackish Water Desalination. ACS ESET Eng. 2021, 1, 261-273. [CrossRef] 
499. Dorji, P.; Kim, D.I.; Hong, S.; Phuntsho, S.; Shon, H.K. Pilot-scale membrane capacitive deionisation for effective bromide removal and high water recovery in seawater desalination. Desalination 2020, 479, 114309. [CrossRef]

500. Wang, L.; Dykstra, J.; Lin, S. Energy efficiency of capacitive deionization. Environ. Sci. Technol. 2019, 53, 3366-3378. [CrossRef] [PubMed]

501. Gendel, Y.; Rommerskirchen, A.K.E.; David, O.; Wessling, M. Batch mode and continuous desalination of water using flowing carbon deionization (FCDI) technology. Electrochem. Commun. 2014, 46, 152-156. [CrossRef]

502. Ma, J.; Ma, J.; Zhang, C.; Song, J.; Dong, W.; Waite, T.D. Flow-electrode capacitive deionization (FCDI) scale-up using a membrane stack configuration. Water Res. 2020, 168, 115186. [CrossRef]

503. Zhang, X.; Reible, D. Theoretical Analysis of Constant Voltage Mode Membrane Capacitive Deionization for Water Softening Membranes 2021, 11, 231. [CrossRef]

504. Bales, C.; Kovalsky, P.; Fletcher, J.; Waite, T.D. Low cost desalination of brackish groundwaters by Capacitive Deionization (CDI)-Implications for irrigated agriculture. Desalination 2019, 453, 37-53. [CrossRef]

505. Ye, G.; Yu, Z.; Li, Y.; Li, L.; Song, L.; Gu, L.; Cao, X. Efficient treatment of brine wastewater through a flow-through technology integrating desalination and photocatalysis. Water Res. 2019, 157, 134-144. [CrossRef] [PubMed]

506. He, C.; Ma, J.; Zhang, C.; Song, J.; Waite, T.D. Short-circuited closed-cycle operation of flow-electrode CDI for brackish water softening. Environ. Sci. Technol. 2018, 52, 9350-9360. [CrossRef] [PubMed]

507. Zhang, C.; Ma, J.; Waite, T.D. Ammonia-rich solution production from wastewaters using chemical-free flow-electrode capacitive deionization. ACS Sustain. Chem. Eng. 2019, 7, 6480-6485. [CrossRef]

508. Bian, Y.; Chen, X.; Lu, L.; Liang, P.; Ren, Z.J. Concurrent nitrogen and phosphorus recovery using flow-electrode capacitive deionization. ACS Sustain. Chem. Eng. 2019, 7, 7844-7850. [CrossRef]

509. Song, J.; Ma, J.; Zhang, C.; He, C.; Waite, D. Implication of non-electrostatic contribution to deionization in flow-electrode CDI: Case study of nitrate removal from contaminated source waters. Front. Chem. 2019, 7, 146. [CrossRef] [PubMed]

510. Zhang, X.; Yang, F.; Ma, J.; Liang, P. Effective removal and selective capture of copper from salty solution in flow electrode capacitive deionization. Environ. Sci. Water Res. Technol. 2019, 6, 341-350. [CrossRef]

511. Ha, Y.; Jung, H.B.; Lim, H.; Jo, P.S.; Yoon, H.; Yoo, C.-Y.; Pham, T.K.; Ahn, W.; Cho, Y. Continuous Lithium Extraction from Aqueous Solution Using Flow-Electrode Capacitive Deionization. Energies 2019, 12, 2913. [CrossRef]

512. Nativ, P.; Lahav, O.; Gendel, Y. Separation of divalent and monovalent ions using flow-electrode capacitive deionization with nanofiltration membranes. Desalination 2018, 425, 123-129. [CrossRef]

513. Ma, J.; Zhang, Y.; Collins, R.N.; Tsarev, S.; Aoyagi, N.; Kinsela, A.S.; Jones, A.M.; Waite, T.D. Flow-electrode CDI removes the uncharged $\mathrm{Ca}-\mathrm{UO}_{2}-\mathrm{CO}_{3}$ ternary complex from brackish potable groundwater: Complex dissociation, transport, and sorption. Environ. Sci. Technol. 2019, 53, 2739-2747. [CrossRef] [PubMed] 